\title{
One-Pot Synthesis of $\alpha$-Alkyl Styrene Derivatives
}

\author{
Olatunji S. Ojo ${ }^{1}$ and Alejandro Bugarin ${ }^{2, *}$ \\ ${ }^{1}$ Department of Chemistry and Biochemistry, University of Texas-Arlington, \\ Box 19065, Arlington, TX 76019 \\ ${ }^{2}$ Department of Chemistry and Physics, Florida Gulf Coast University, \\ 10501 FGCU Boulevard South, Fort Myers, FL 33965
}

abugarin@fgcu.edu

\section{Table of Contents}

Mechanism Investigations.

Proposed Mechanism.

DBU Scope with Isolated Yields.

${ }^{1} \mathrm{H}$ and ${ }^{13} \mathrm{C}$ NMR Spectra

S-6 


\section{Scheme S1: Mechanistic Investigation}

The following reactions were performed to support a potential mechanism of reaction:

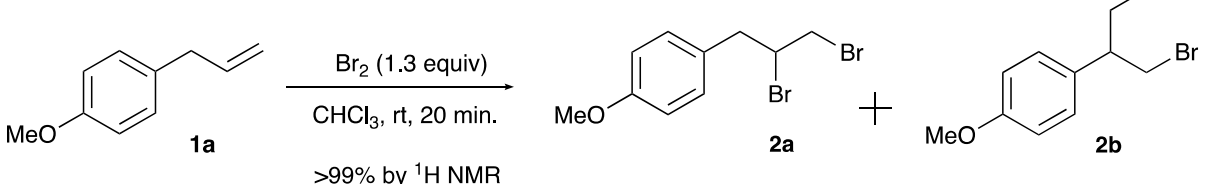

$2 \mathbf{a}: 2 \mathbf{b}$ ratio $=0.7: 1$

(2)<smiles>C=CCc1ccc(OC)cc1</smiles>

(3)

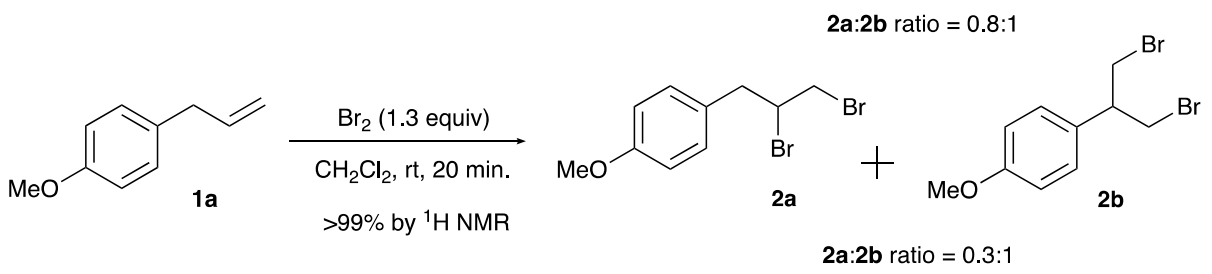

(4)<smiles>C=CCc1ccc(OC)cc1</smiles>

(5)<smiles>C=CCc1ccc(OC)cc1</smiles>

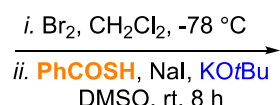<smiles>O=C(SC/C=C/[Al])c1ccccc1</smiles><smiles>C=C([Al])CSC(=O)P</smiles>
$4 n^{\prime}$ $4 n$<smiles>O=C(SCC(Cl)CSC(=O)c1ccccc1)c1ccccc1</smiles>

1a $10 \%$ $13 \%$

(6)<smiles>C=CCc1ccc(OC)cc1</smiles>

1a

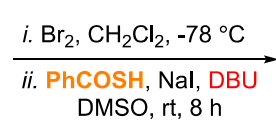
DMSO, rt, $8 \mathrm{~h}$<smiles></smiles>

$4 n^{\prime}$<smiles>C=C(Br)CSC(=O)c1ccccc1</smiles>

$4 n$
$4 n^{\prime \prime}$

traces<smiles>O=C(SCC([Al])CSC(=O)c1ccccc1)c1ccccc1</smiles>

$4 n^{\prime \prime}$

We have reported a regio- and stereoselective method that enables the production of liner $(E)$-allylic compounds using C, N, O, \& S nucleophiles (Org. Biomol. Chem., 2018, 16, 9354 or Org. Lett., 2015, 17, 2594). To obtain those liner $(E)$-allylic compounds, intermediates such as $\mathbf{2 a}$ were primarily observed. For this work, using electron rich substrates [i.e., estragole (1a) \& safrole(1) $)$, intermediates such as $\mathbf{2 b}$ were favored, which can give access to $\alpha$-allyl styrene derivatives. Clearly, using colder temperatures and dichloromethane as solvent favored the formation of intermediate $\mathbf{2 b}$ (equations 1-4). Interestingly, during our studies, we observed that thiobenzoic acid (pKa is 3.61) gave the expected product $\mathbf{4 n}$ in $13 \%$ and two additional adducts, the liner adduct $\mathbf{4 n}$ ' in $10 \%$, and a disubstituted adduct $\mathbf{4 n}$ "' in $41 \%$, when using $\mathrm{KO} t \mathrm{Bu}$ as base. However, when using DBU as base, the major product was the expected $\alpha$-allyl styrene derivatives $4 \mathbf{n}$ in $61 \%{ }^{1} \mathrm{H}$ NMR yield (50\% isolated yield). Note: we only observed these 3 adducts for thiobenzoic acid (pKa is 3.61). It is proposed that the high yield $(41 \%)$ of the disubstituted adduct $\mathbf{4 n}$ "' is due to its lower pKa. At least $14 \mathrm{x}$ lower when compared to the other nucleophiles (e.g., $\mathrm{pKa}=5$, for $\mathrm{RCO}_{2} \mathrm{H}$ ). So, $\mathrm{KO} t \mathrm{Bu}$ (2 equiv.) will be almost used up to deprotonate $\mathrm{PhCOSH}$ (1.5 equiv), leaving only a small amount to perform the E2 reaction (see below). Thus, favoring the $\mathrm{S}_{\mathrm{N}} 2$ reactions. On the other hand, DBU (a weaker base) won't fully deprotonate the nucleophile, giving time to the E2 rection to occur. Thus, affording the expected $\alpha$-allyl styrene derivatives $4 \mathbf{n}$ in higher yield (61\%). 


\section{Scheme S2: Proposed Mechanism}

Based on the reactions shown above, a very plausible mechanism will be as follows: Estragole 1a undergoes an alkene bromination to form bromonium ion (I), which in turn undergoes an intramolecular attack by the electron-rich benzene to form a spiro[2.5] intermediate (II). This intermediate, can be ring-opened by bromide ion to produce either a 2,3-dibromo (2a) or a 1,3-dibromo intermediate (2b). The 1,3-dibromo adduct is the product of a rearrangement step driven by the formation of the spiro[2.5] intermediate and it is the favored adduct. Therefore, it is present in higher ratio. After this dibromination step, an E2 elimination, enabled by $\mathrm{KO} t \mathrm{Bu}$ produces allyl bromide (III), which in turn reacts via a $\mathrm{S}_{\mathrm{N}} 2$ displacement to afford the expected $\alpha$-allyl styrene (IV). It is important to note that intermediates $\mathbf{I}, \mathbf{I I}, \mathbf{2} \mathbf{a}$, and $\mathbf{2} \mathbf{b}$ are in equilibrium and therefore under the correct conditions, we can favor the formation of intermediate $\mathbf{2} \mathbf{b}$ to enhance the rearrangement yields. Mechanistic details for the formation of adducts like (V) can either be found in Org. Biomol. Chem., 2018, 16, 9354 or Org. Lett., 2015, 17, 2594.
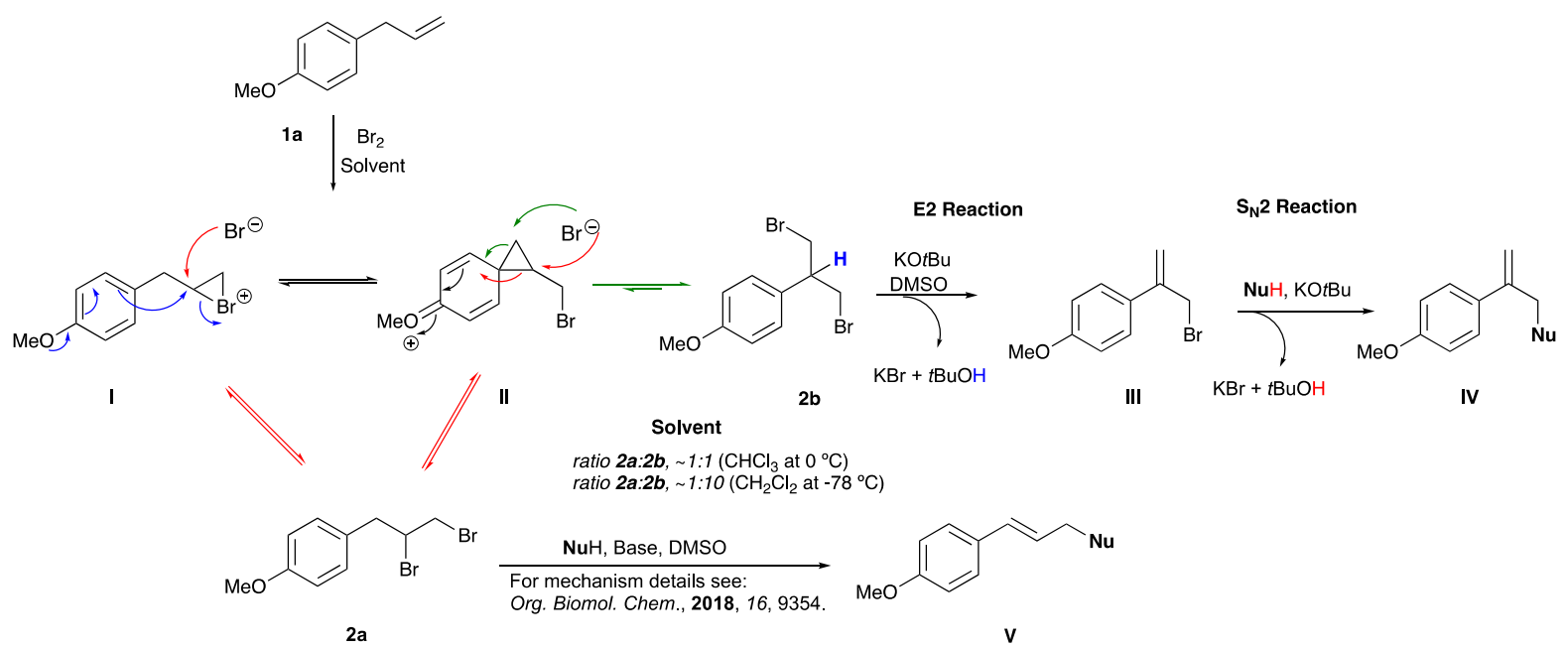
Table S1. Scope of nitrogen-containing nucleophiles using $\mathrm{DBU}$ as base ${ }^{\mathrm{a}}$

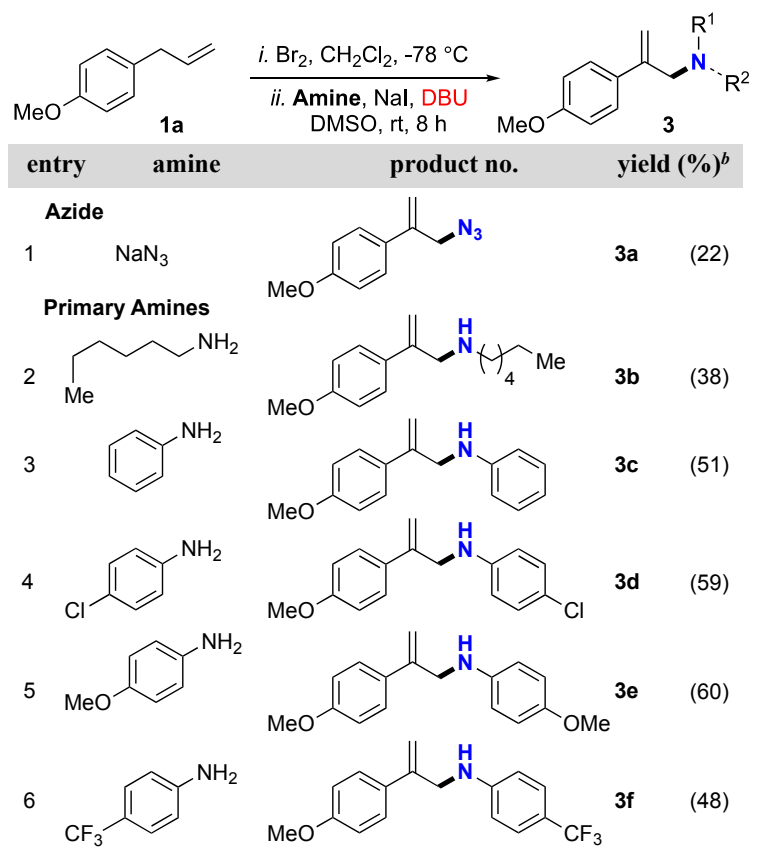

\section{Secondary Amines}<smiles>C=CCNCC=C</smiles><smiles>C=CCCC(=O)c1ccc(OC)cc1</smiles>

9<smiles>CNCc1ccccc1</smiles>
Me<smiles>C=C(CN(C)Cc1ccccc1)c1ccc(OC)cc1</smiles><smiles>C1COCCN1</smiles>

11<smiles>C1CCNCC1</smiles>

12<smiles>O=C1NC(=O)c2ccccc21</smiles>

13<smiles>c1ccc(C(c2ccccc2)N2CCNCC2)cc1</smiles>

14<smiles>CC(=O)c1c[nH]c2ccccc12</smiles><smiles>C=C(CN1CCCCC1)c1ccc(OC)cc1</smiles><smiles>C=CCOC</smiles><smiles>C=C(CN1CCCCC1)c1ccc(OC)cc1</smiles>

Table S2. Scope of other nucleophiles using DBU as base $^{\text {aa }}$
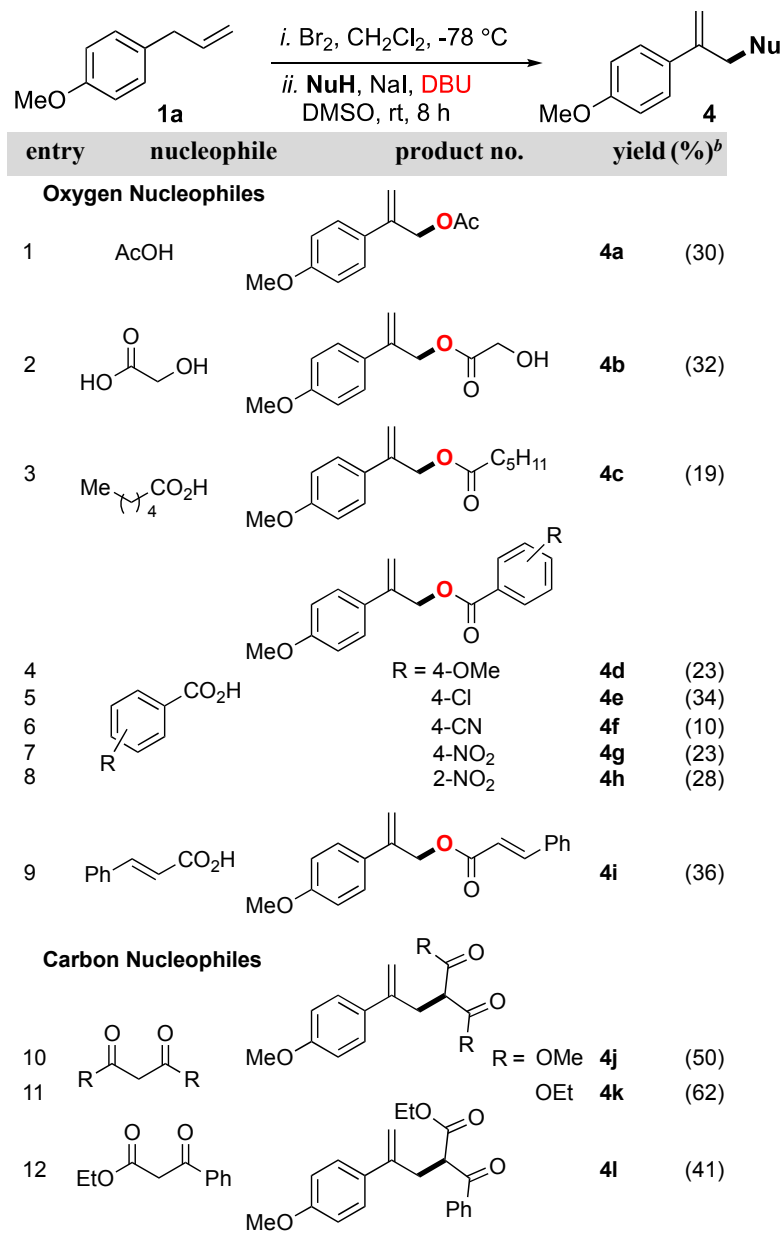

Sulfur Nucleophiles

13
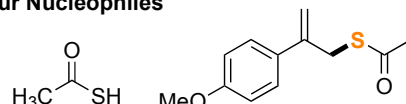

$4 m$

$14 \quad \mathrm{Ph}_{\mathrm{SH}}^{\mathrm{O}}$<smiles>C=C(CSC(=O)c1ccccc1)c1ccc(OC)cc1</smiles>

a Reactions conditions: estragole 1a $(0.5 \mathrm{mmol}, 1.0$ equiv. $)$ Bromine ( $0.65 \mathrm{mmol}, 104 \mathrm{mg}, 34 \mu \mathrm{L}, 1.3$ equiv.), in $2.0 \mathrm{~mL}$ of $\mathrm{CH}_{2} \mathrm{Cl}_{2}$ at $-78^{\circ} \mathrm{C}$ for $30 \mathrm{~min}$. Then, the volatiles were removed. To the crude reaction mixture was added $2.0 \mathrm{~mL}$ of DMSO, NaI ( $0.50 \mathrm{mmol}, 1.0$ equiv. $)$, nucleophile $(0.75 \mathrm{mmol}, 1.5$ equiv. $)$, and DBU (1.15 mmol, 2.3 equiv.), at $22{ }^{\circ} \mathrm{C}$ and stirred for $8 \mathrm{~h} .{ }^{\mathrm{b}}$ Isolated yields based on 1a, using silica gel flash column chromatography.

a Reactions conditions: estragole 1a ( $0.5 \mathrm{mmol}, 1.0$ equiv.), Bromine ( $0.65 \mathrm{mmol}, 104 \mathrm{mg}, 34 \mu \mathrm{L}, 1.3$ equiv.), in $2.0 \mathrm{~mL}$ of $\mathrm{CH}_{2} \mathrm{Cl}_{2}$ at $-78^{\circ} \mathrm{C}$ for $30 \mathrm{~min}$. Then, the volatiles were removed. To the crude reaction mixture was added $2 \mathrm{~mL}$ of DMSO, NaI ( $0.50 \mathrm{mmol}, 1.0$ equiv.), amine ( $0.75 \mathrm{mmol}, 1.5$ equiv.), and DBU (1.15 mmol, 2.3 equiv.), at $22{ }^{\circ} \mathrm{C}$ and stirred for $8 \mathrm{~h}$. b Isolated yields based on 1a, using silica gel flash column chromatography. 
Table S3. Scope of representative nucleophiles with Safrole and using DBU as base $\mathrm{b}^{\mathrm{a}}$

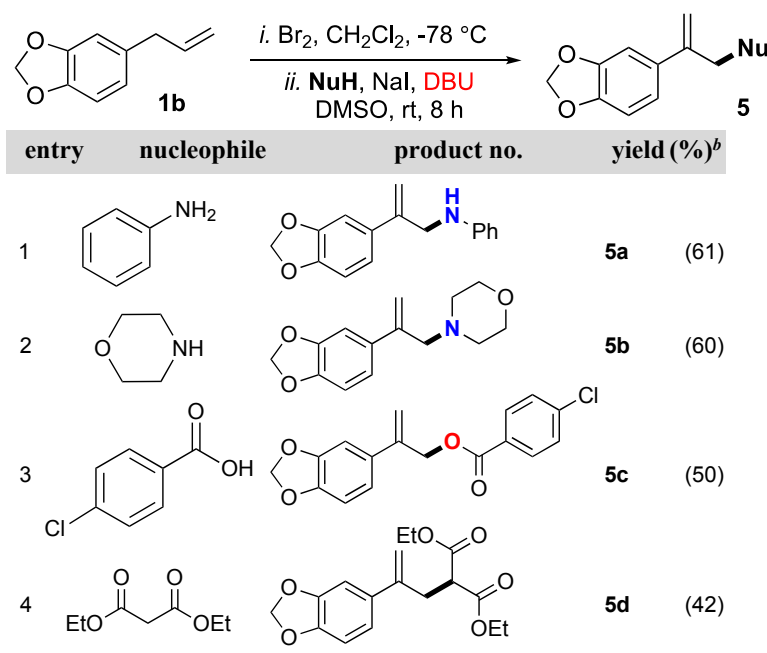

a Reactions conditions: safrole 1a $(0.5 \mathrm{mmol}, 1.0$ equiv. $)$, Bromine ( $0.65 \mathrm{mmol}, 104 \mathrm{mg}, 34 \mu \mathrm{L}, 1.3$ equiv.), in $2.0 \mathrm{~mL}$ of $\mathrm{CH}_{2} \mathrm{Cl}_{2}$ at $-78{ }^{\circ} \mathrm{C}$ for $30 \mathrm{~min}$. Then, the volatiles were removed. To the crude reaction mixture was added $2.0 \mathrm{~mL}$ of DMSO, $\mathrm{NaI}$ ( $0.50 \mathrm{mmol}, 1.0$ equiv. $)$, nucleophile $(0.75 \mathrm{mmol}, 1.5$ equiv. $)$, and DBU ( 1.15 mmol, 2.3 equiv.), at $22{ }^{\circ} \mathrm{C}$ and stirred for $8 \mathrm{~h} .{ }^{\mathrm{b}}$ Isolated yields based on $\mathbf{1 b}$, using silica gel flash column chromatography. 
Figure S1: ${ }^{1} \mathrm{H}$ NMR $\left(500 \mathrm{MHz}, \mathrm{CDCl}_{3}\right)$

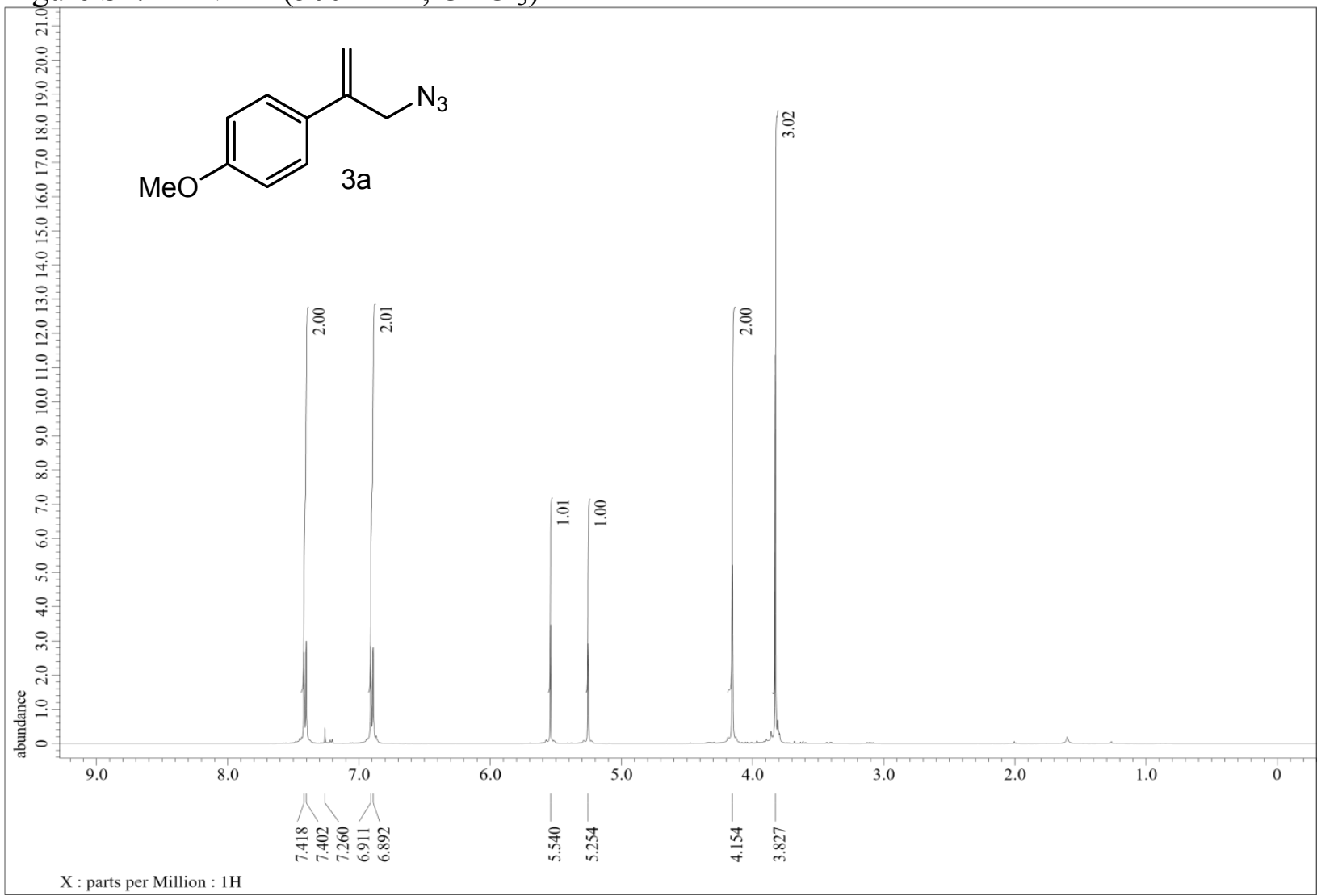

Figure $\mathrm{S} 2:{ }^{13} \mathrm{C}$ NMR $\left(125 \mathrm{MHz}, \mathrm{CDCl}_{3}\right)$

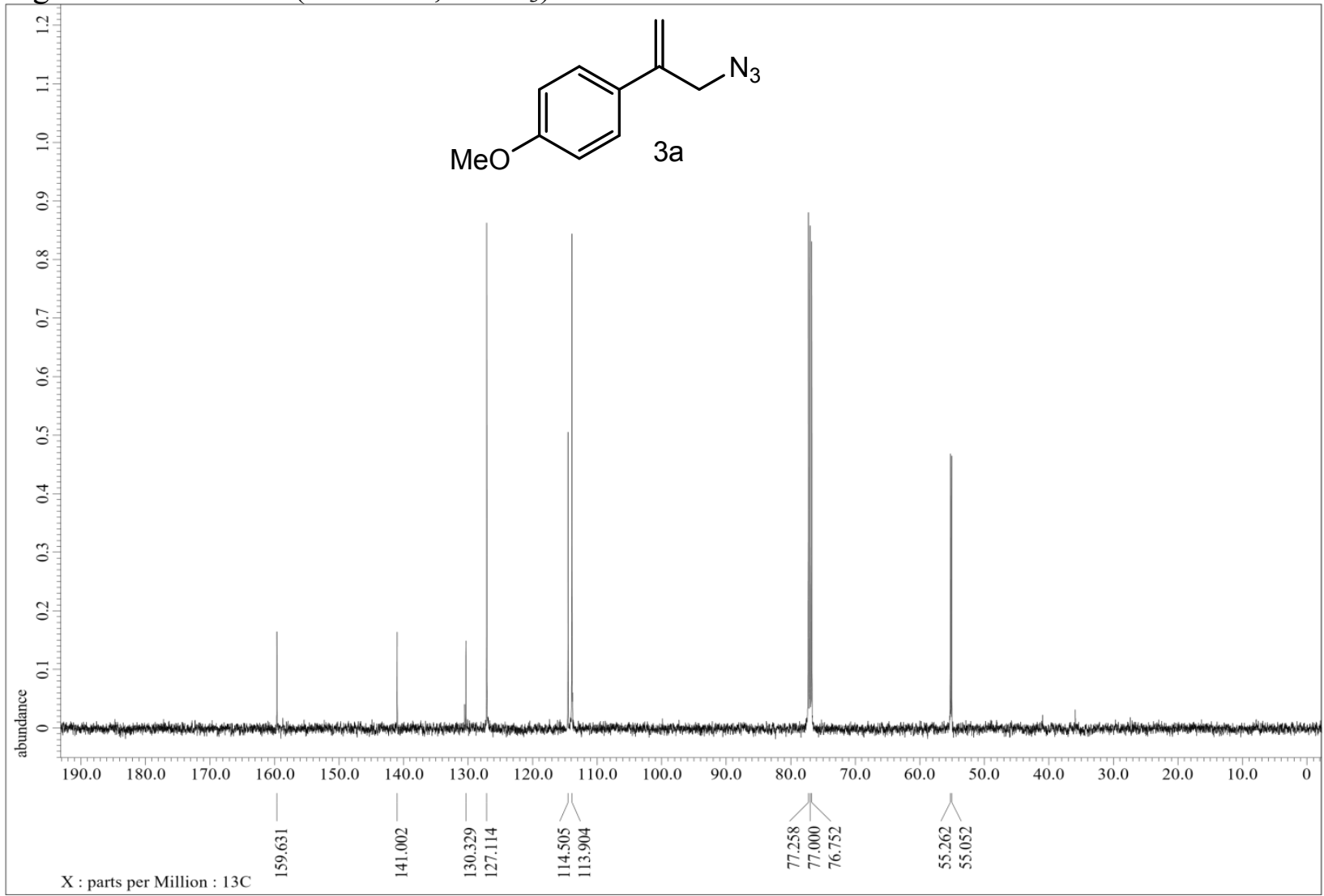


Figure S3: ${ }^{1} \mathrm{H}$ NMR $\left(500 \mathrm{MHz}, \mathrm{CDCl}_{3}\right)$

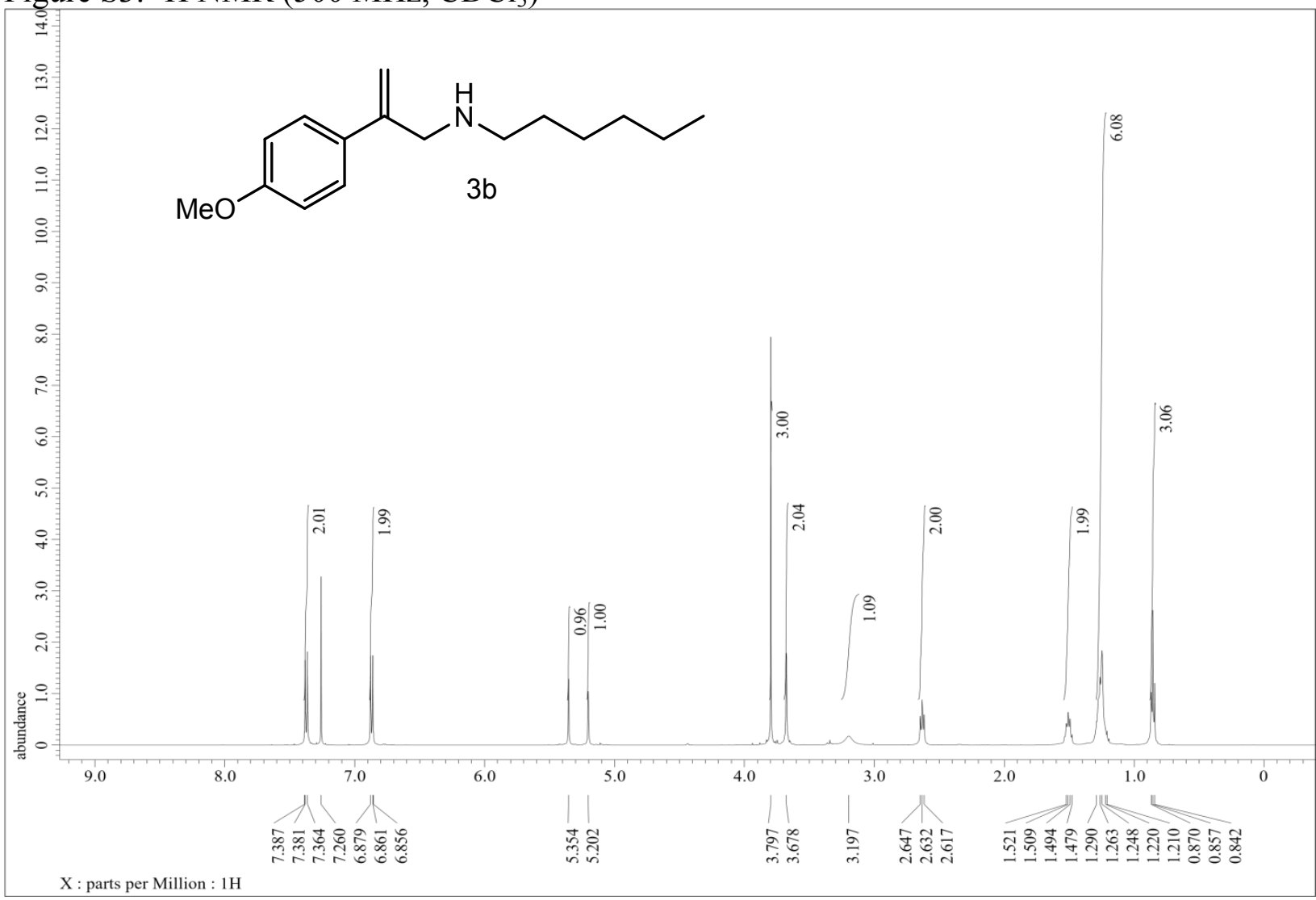

Figure S4: ${ }^{13} \mathrm{C}$ NMR (125 MHz, $\mathrm{CDCl}_{3}$ )

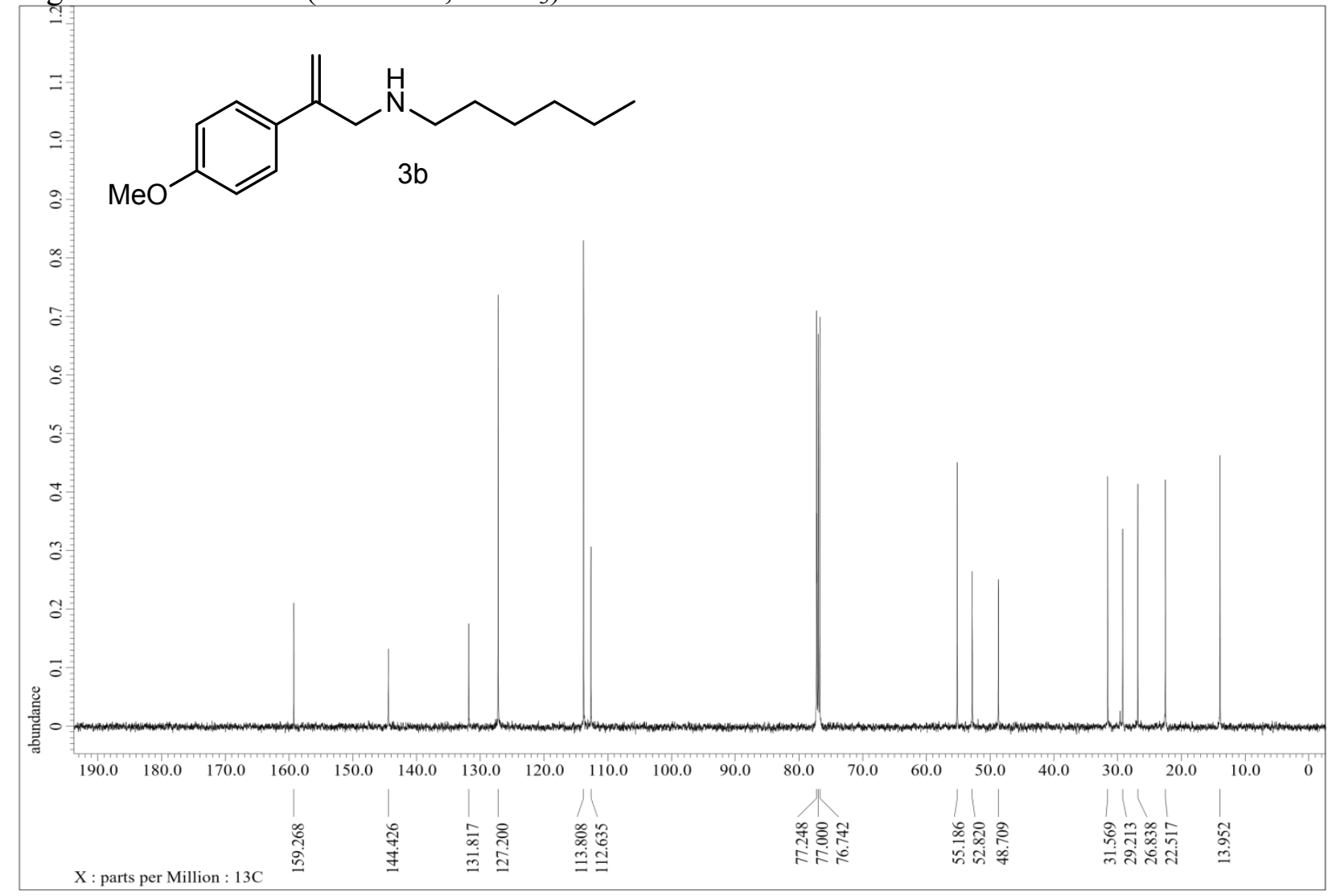


Figure S5: ${ }^{1} \mathrm{H}$ NMR $\left(500 \mathrm{MHz}, \mathrm{CDCl}_{3}\right)$

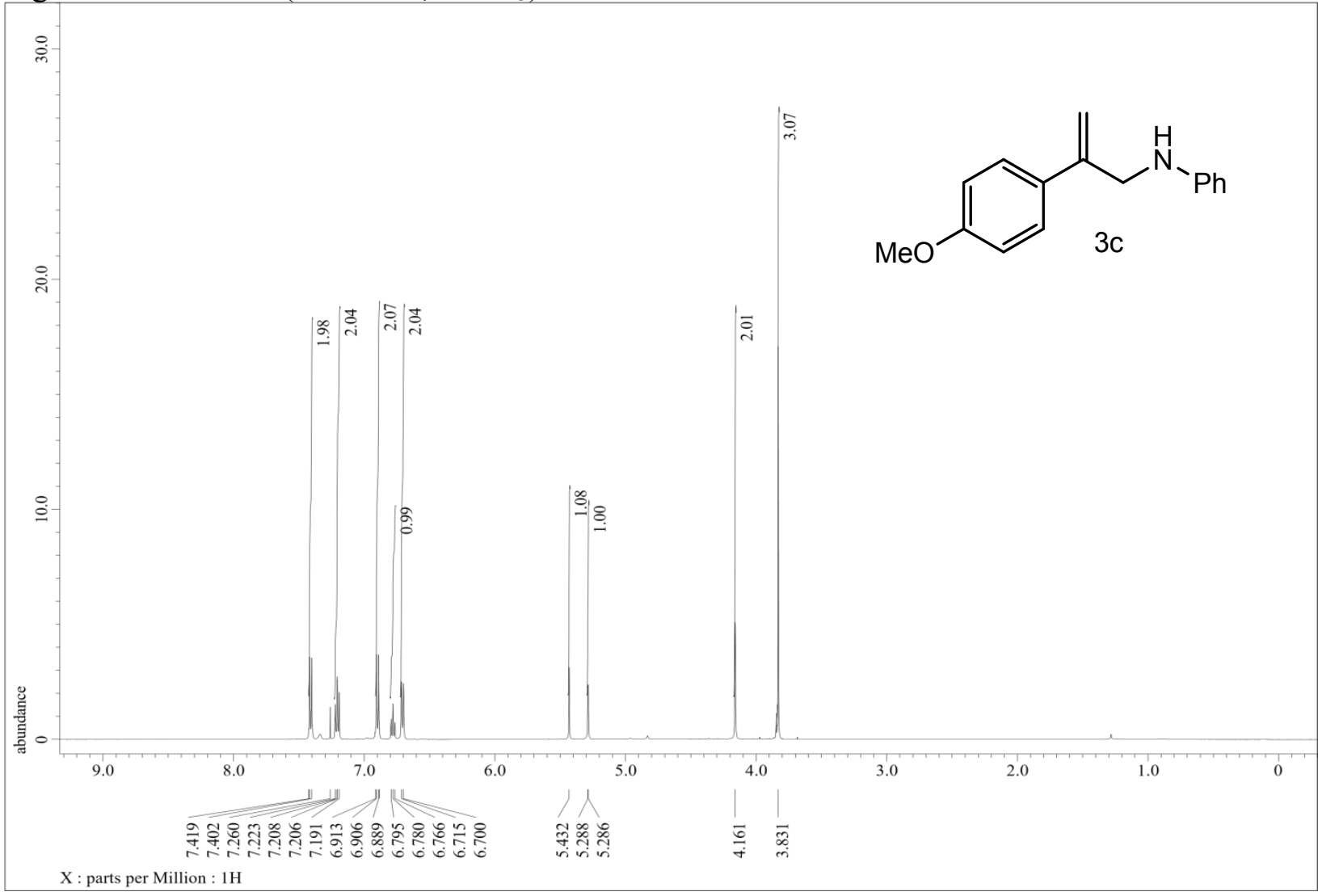

Figure S6: ${ }^{13} \mathrm{C}$ NMR $\left(125 \mathrm{MHz}, \mathrm{CDCl}_{3}\right)$

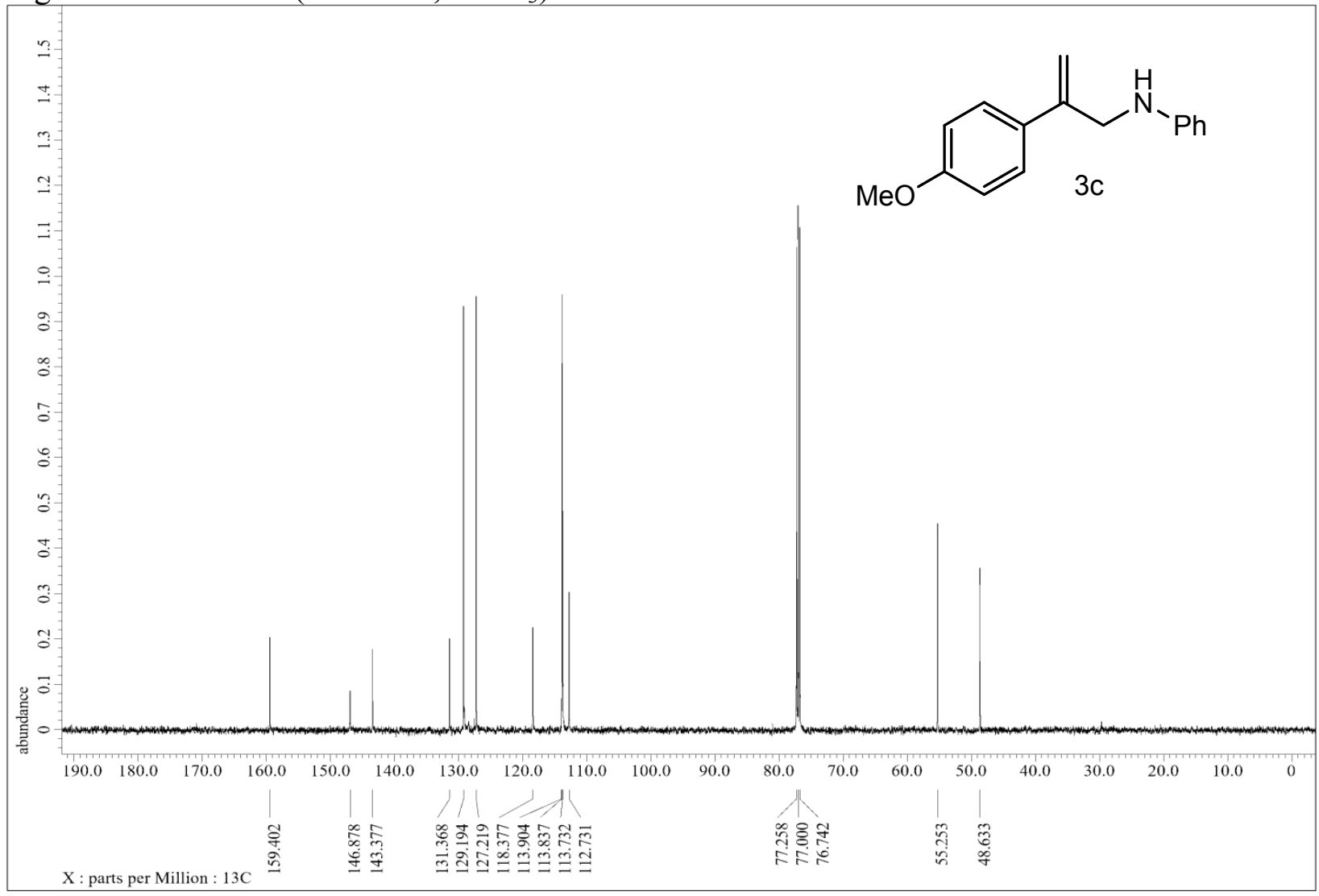


Figure S7: ${ }^{1} \mathrm{H}$ NMR $\left(500 \mathrm{MHz}, \mathrm{CDCl}_{3}\right)$

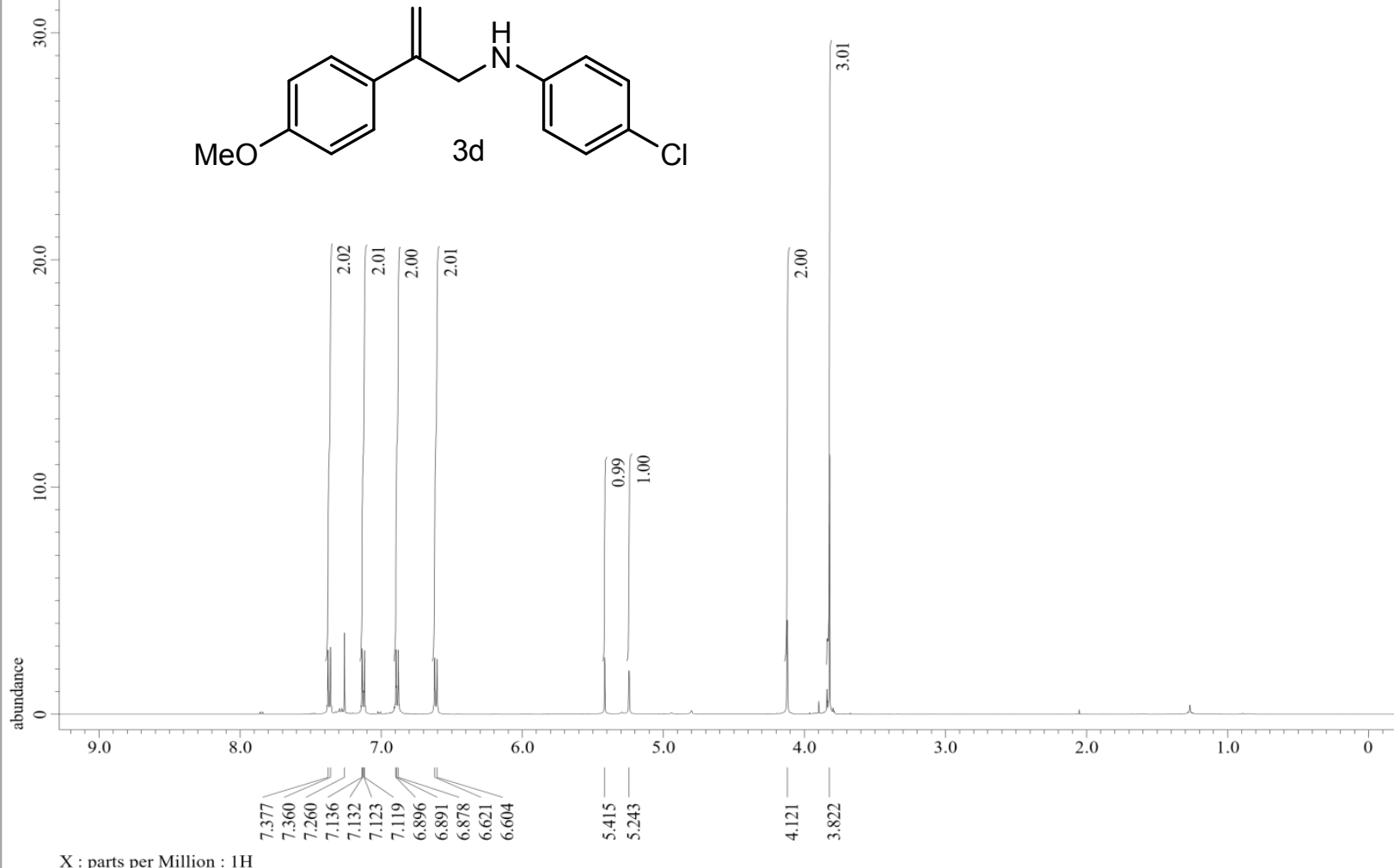

Figure S8: ${ }^{13} \mathrm{C}$ NMR $\left(125 \mathrm{MHz}, \mathrm{CDCl}_{3}\right)$

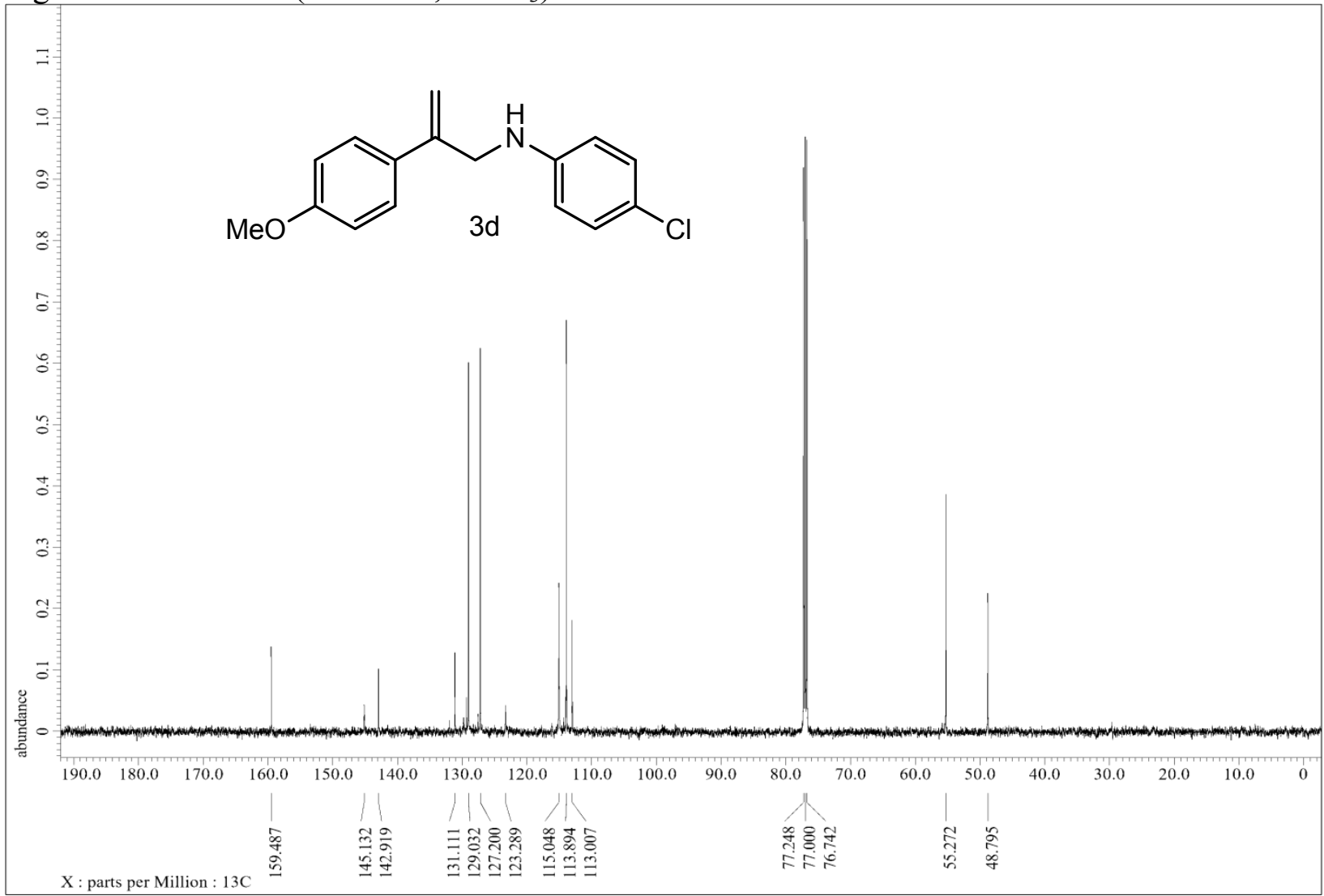


Supporting Information

$S-10$

Figure S9: ${ }^{1} \mathrm{H} \mathrm{NMR}\left(500 \mathrm{MHz}, \mathrm{CDCl}_{3}\right)$

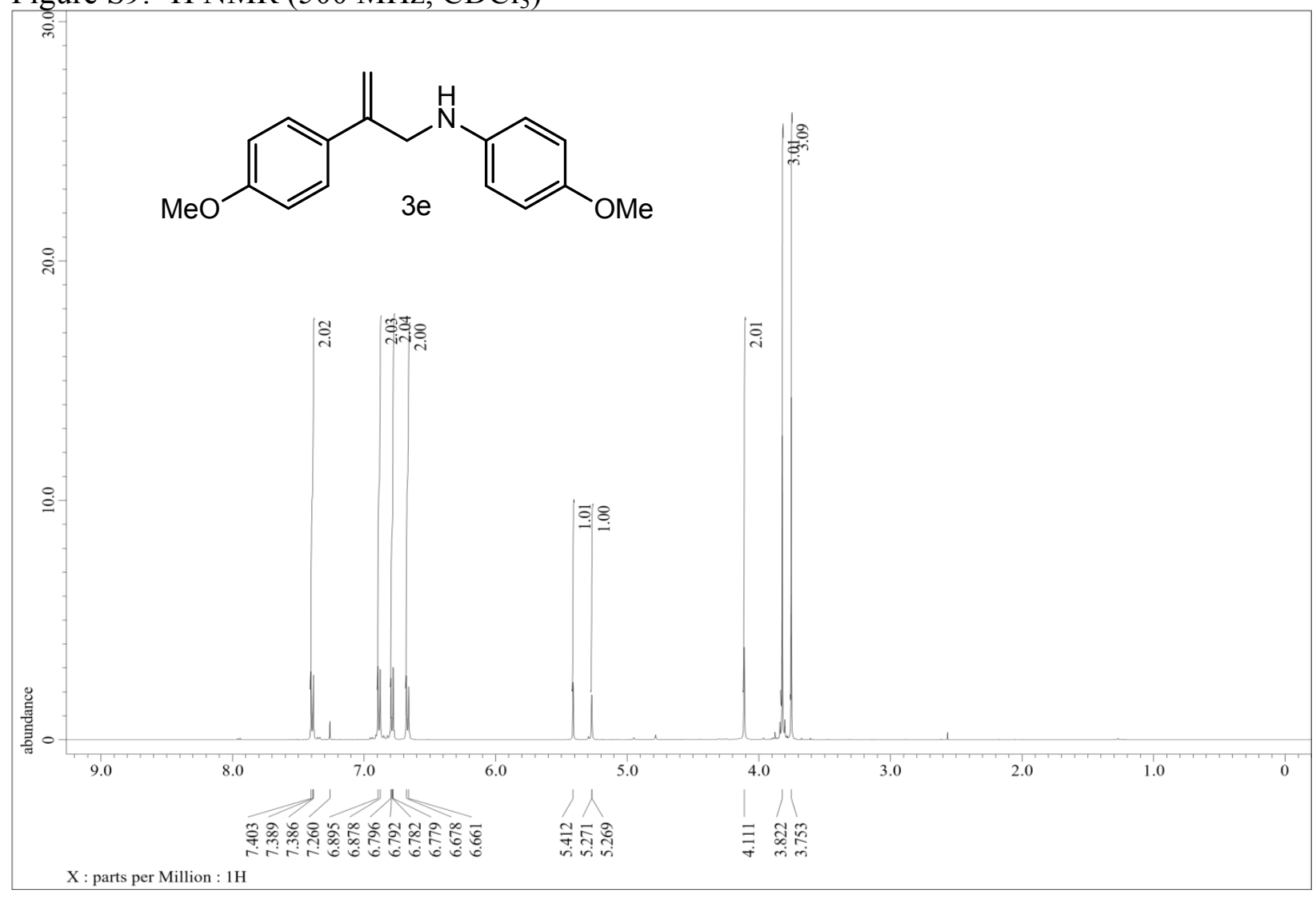

Figure $\mathrm{S} 10:{ }^{13} \mathrm{C} \mathrm{NMR}\left(125 \mathrm{MHz}, \mathrm{CDCl}_{3}\right)$

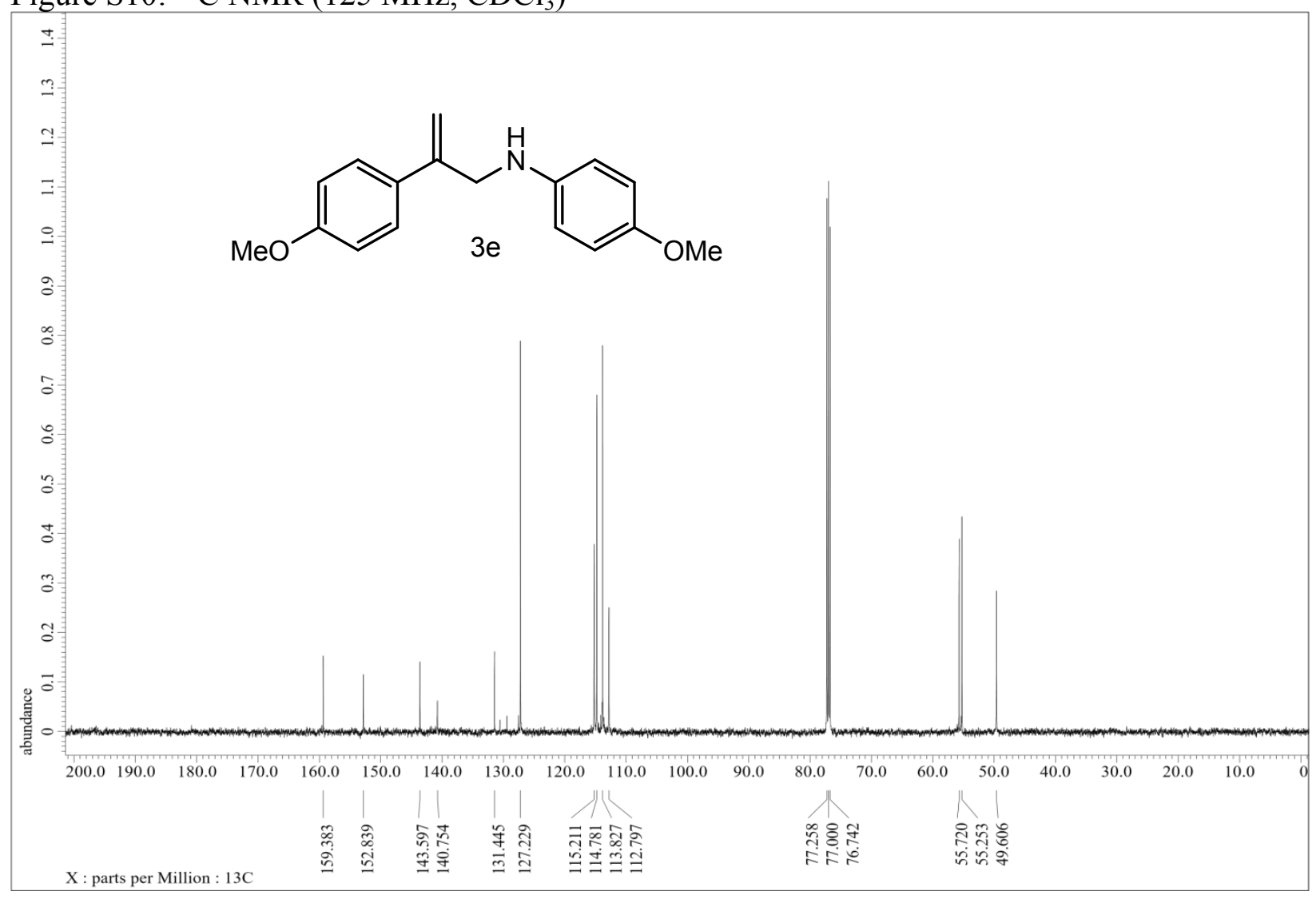


Figure S11: ${ }^{1} \mathrm{H} \mathrm{NMR}\left(500 \mathrm{MHz}, \mathrm{CDCl}_{3}\right)$

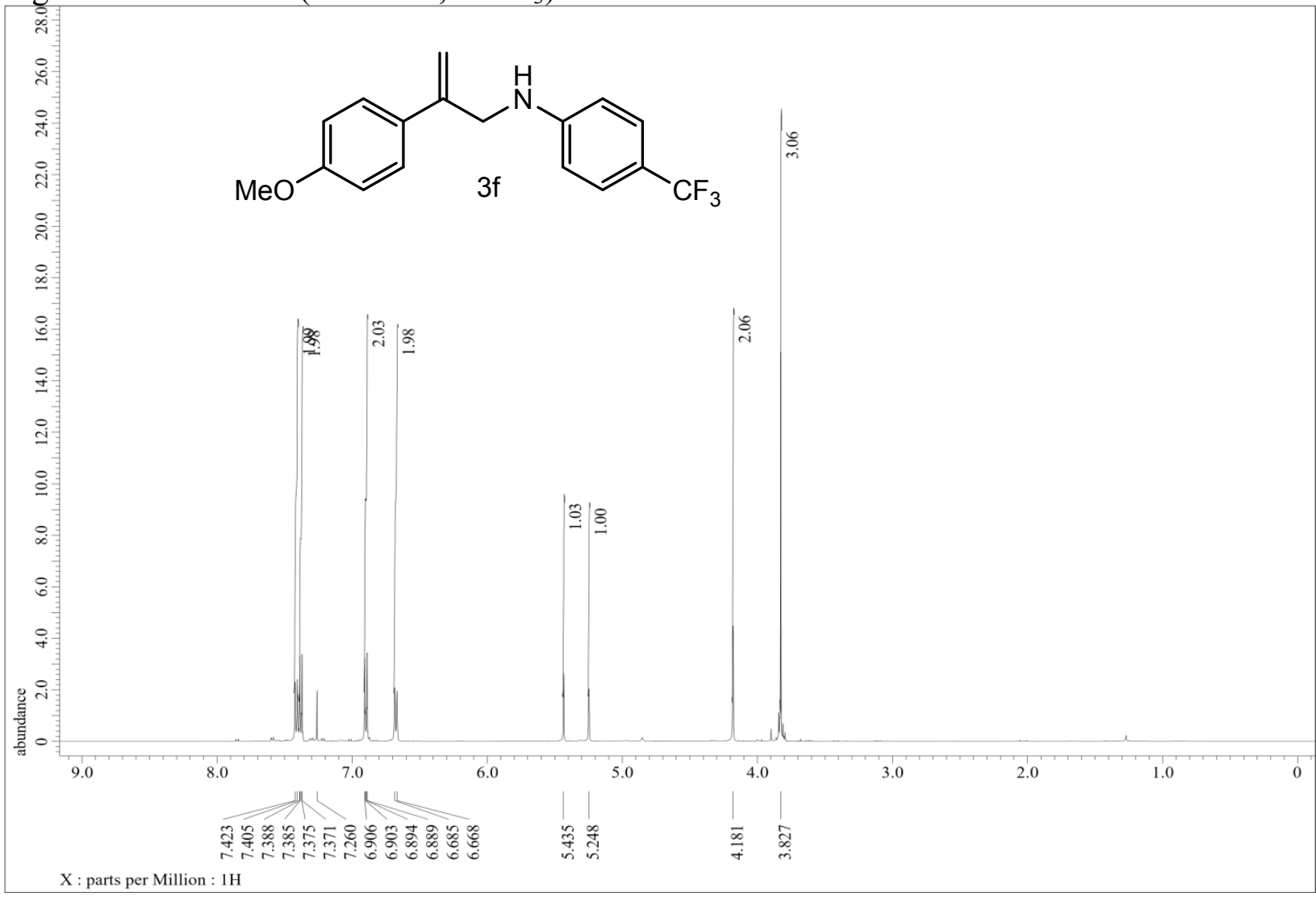

Figure S12: ${ }^{13} \mathrm{C}$ NMR $\left(125 \mathrm{MHz}, \mathrm{CDCl}_{3}\right)$

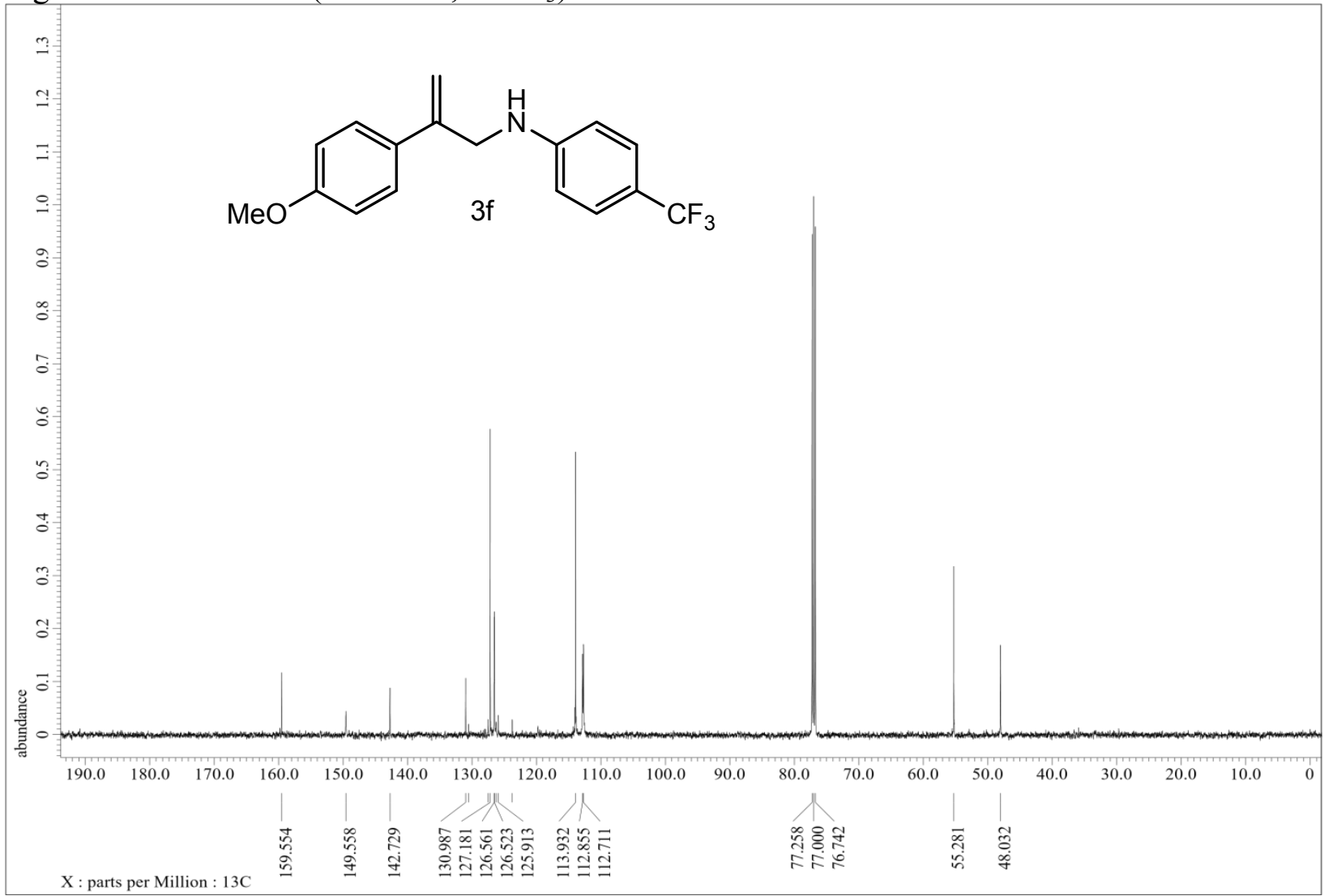


Figure S13: ${ }^{1} \mathrm{H} \mathrm{NMR}\left(500 \mathrm{MHz}, \mathrm{CDCl}_{3}\right)$

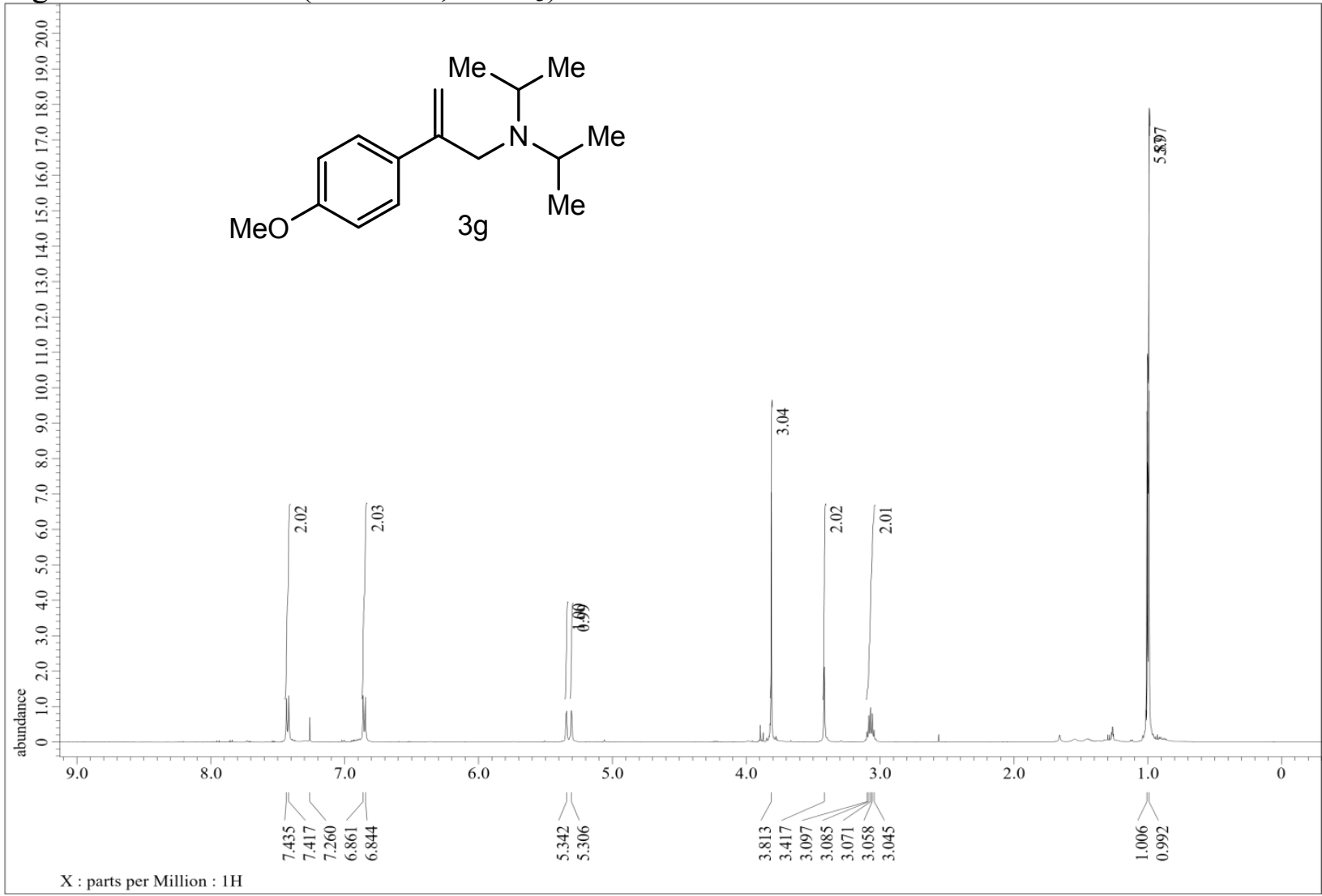

Figure S14: ${ }^{13} \mathrm{C}$ NMR (125 MHz, $\mathrm{CDCl}_{3}$ )

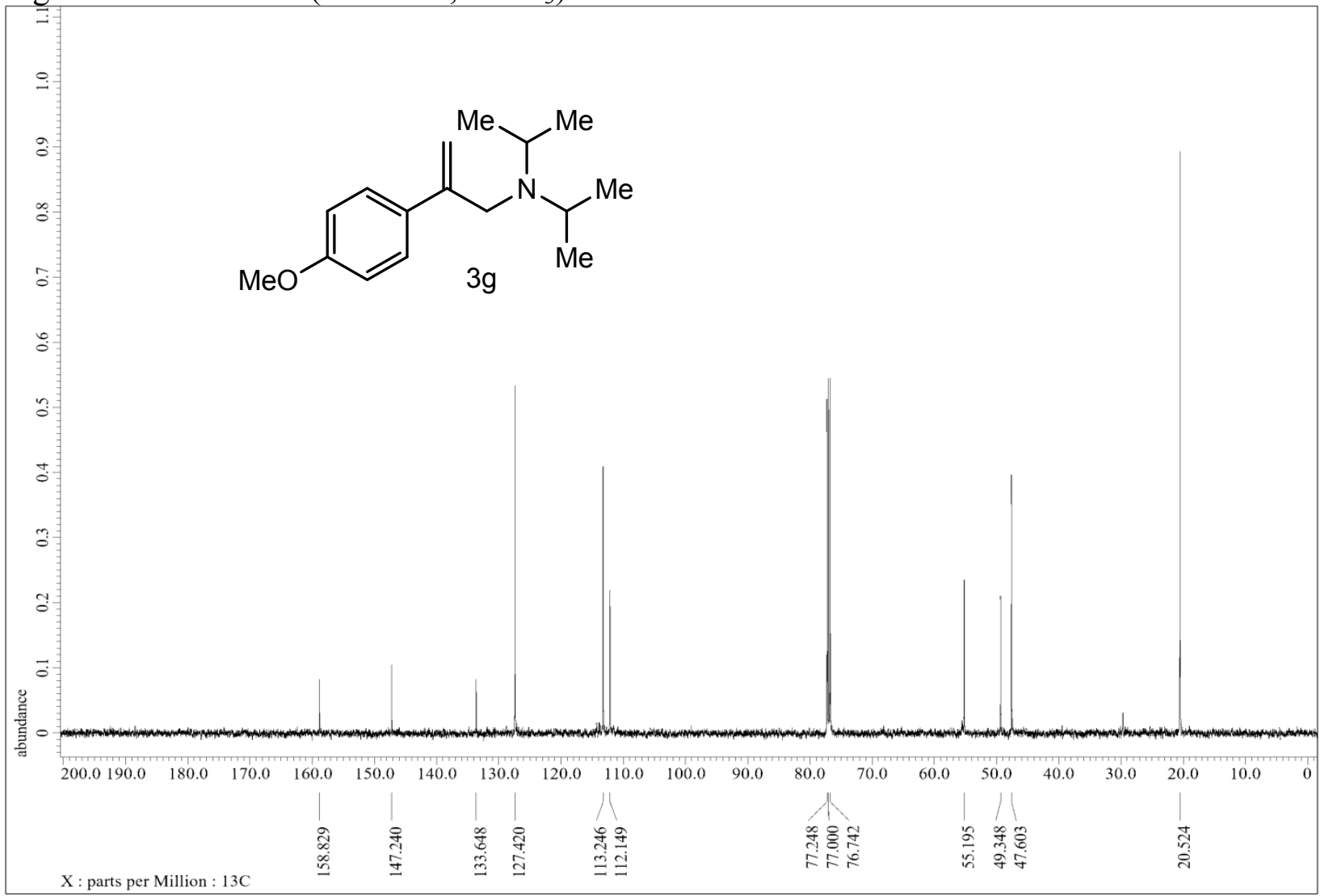


Figure S15: ${ }^{1} \mathrm{H}$ NMR $\left(500 \mathrm{~Hz}, \mathrm{CDCl}_{3}\right)$

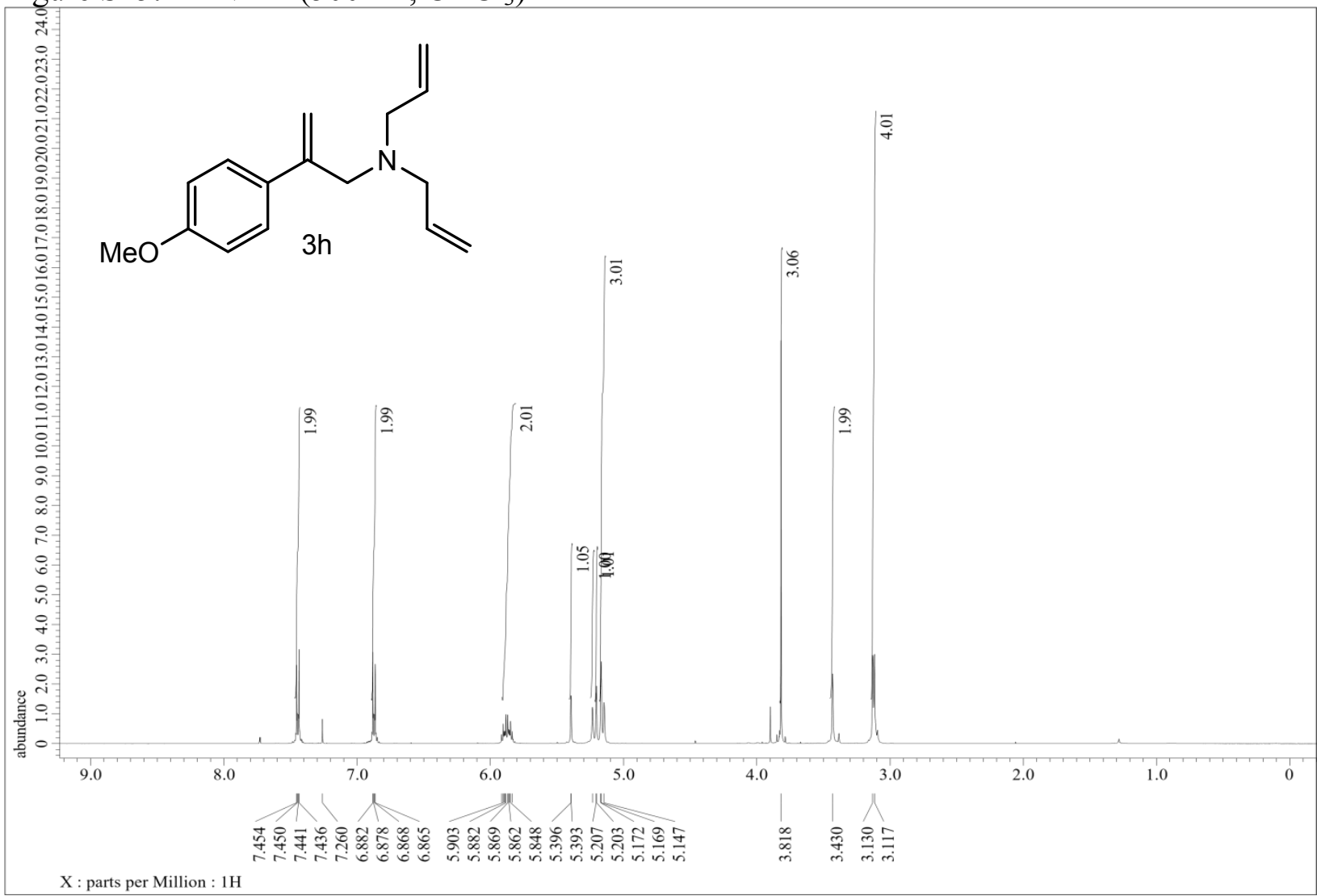

Figure S16: ${ }^{13} \mathrm{C}$ NMR $\left(75 \mathrm{MHz}, \mathrm{CDCl}_{3}\right)$

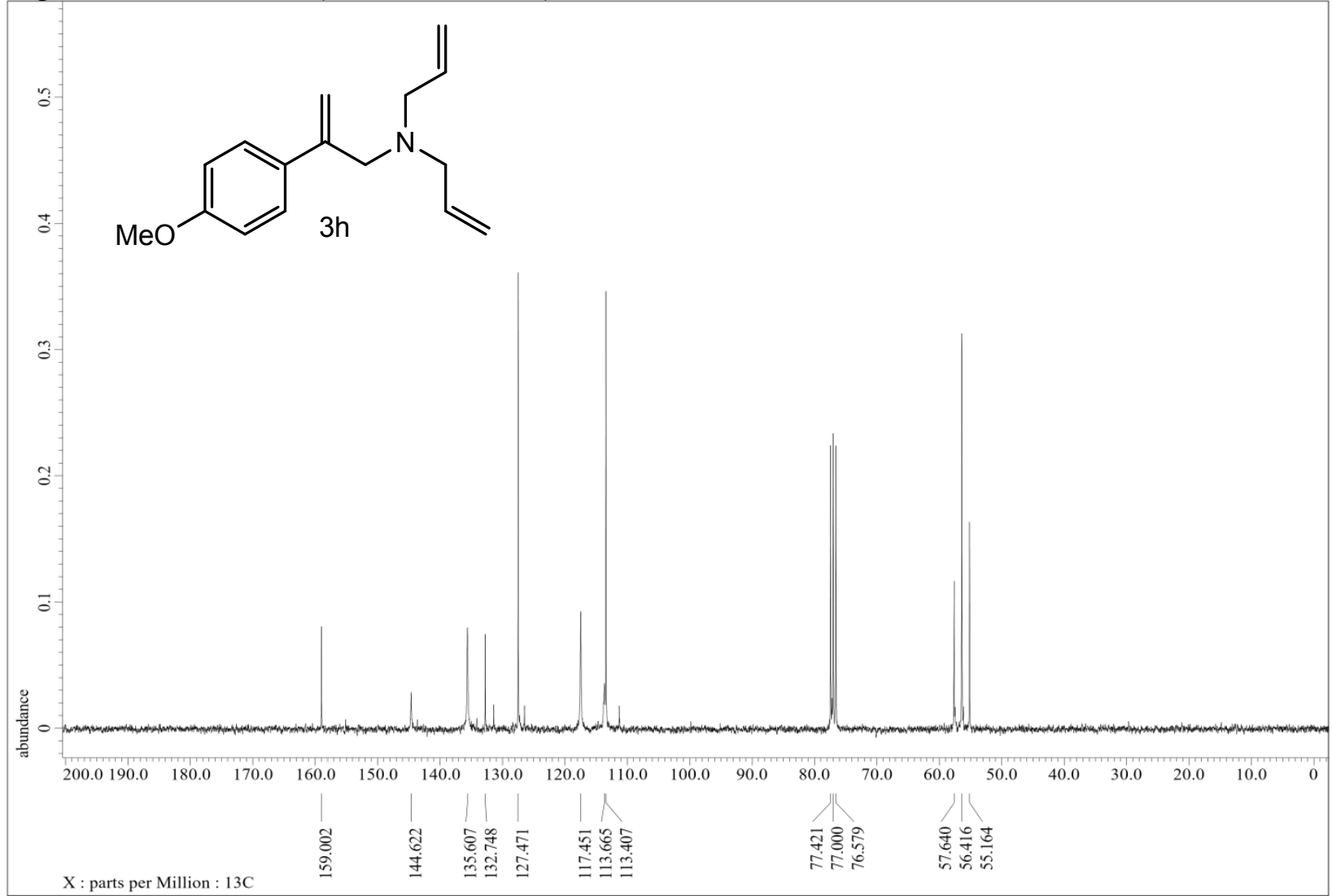


Figure S17: ${ }^{1} \mathrm{H}$ NMR $\left(500 \mathrm{MHz}, \mathrm{CDCl}_{3}\right)$

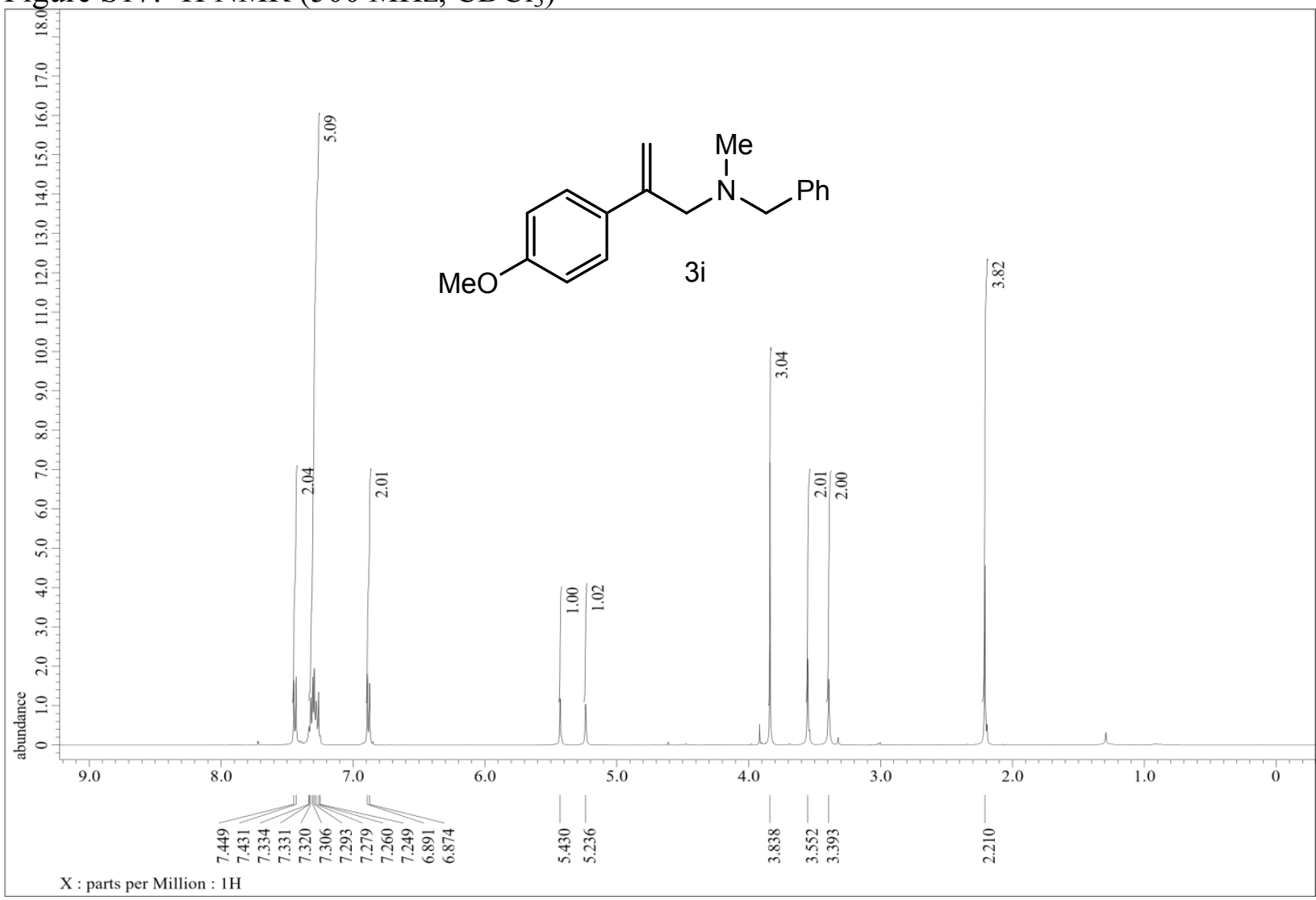

Figure S18: ${ }^{13} \mathrm{C}$ NMR $\left(125 \mathrm{MHz}, \mathrm{CDCl}_{3}\right)$

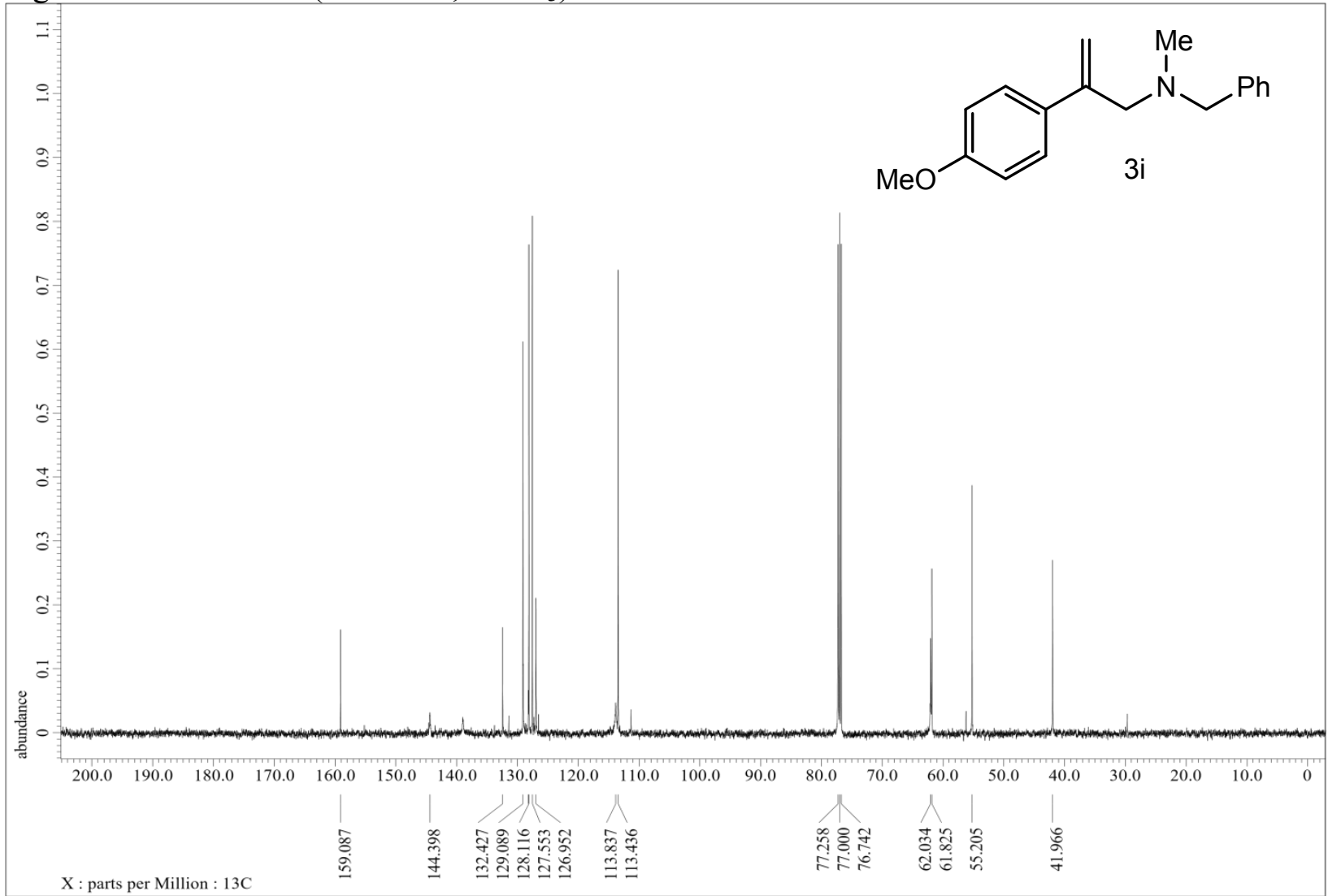


Figure S19: ${ }^{1} \mathrm{H}$ NMR $\left(500 \mathrm{MHz}, \mathrm{CDCl}_{3}\right)$

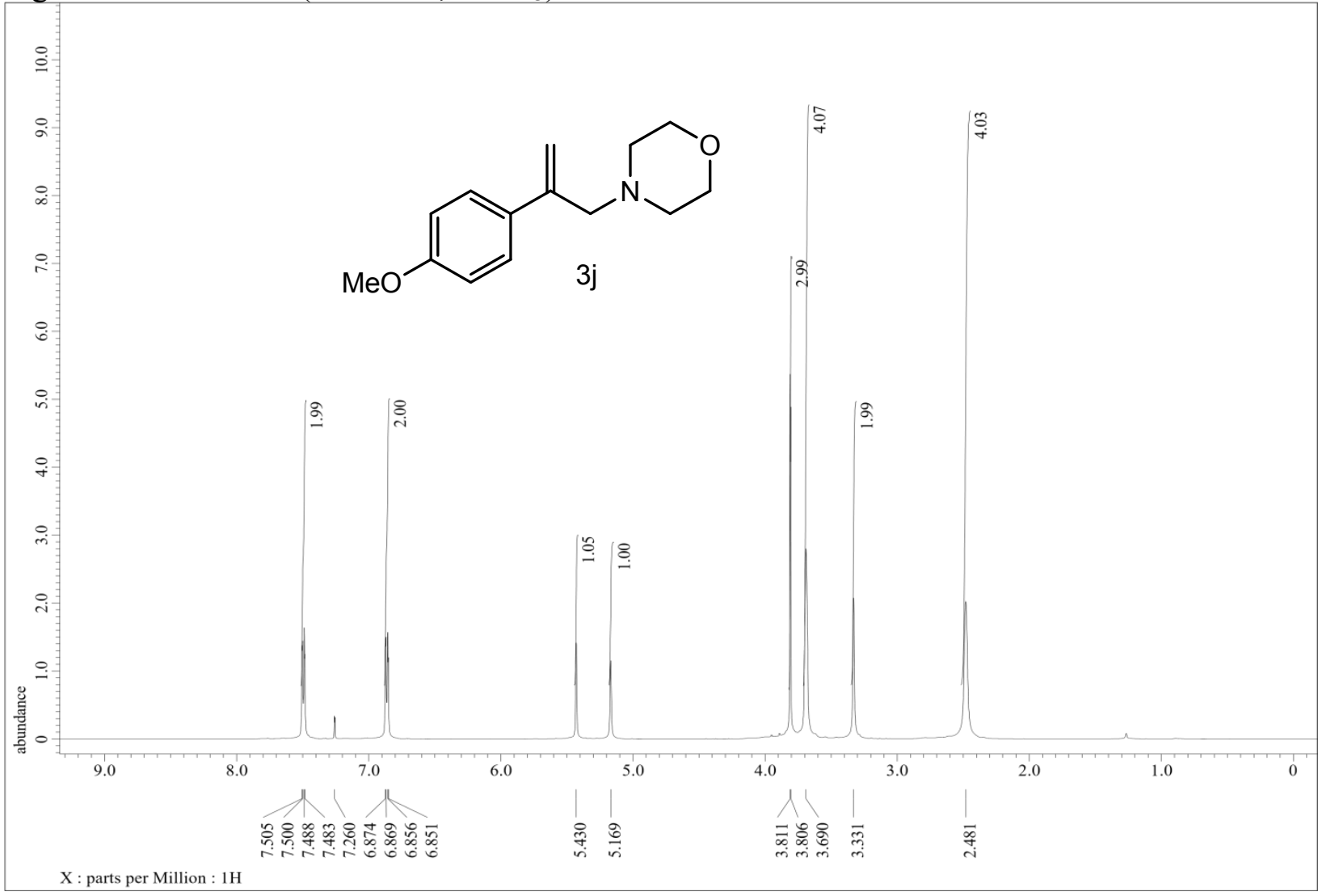

Figure S20: ${ }^{13} \mathrm{C}$ NMR $\left(125 \mathrm{MHz}, \mathrm{CDCl}_{3}\right)$

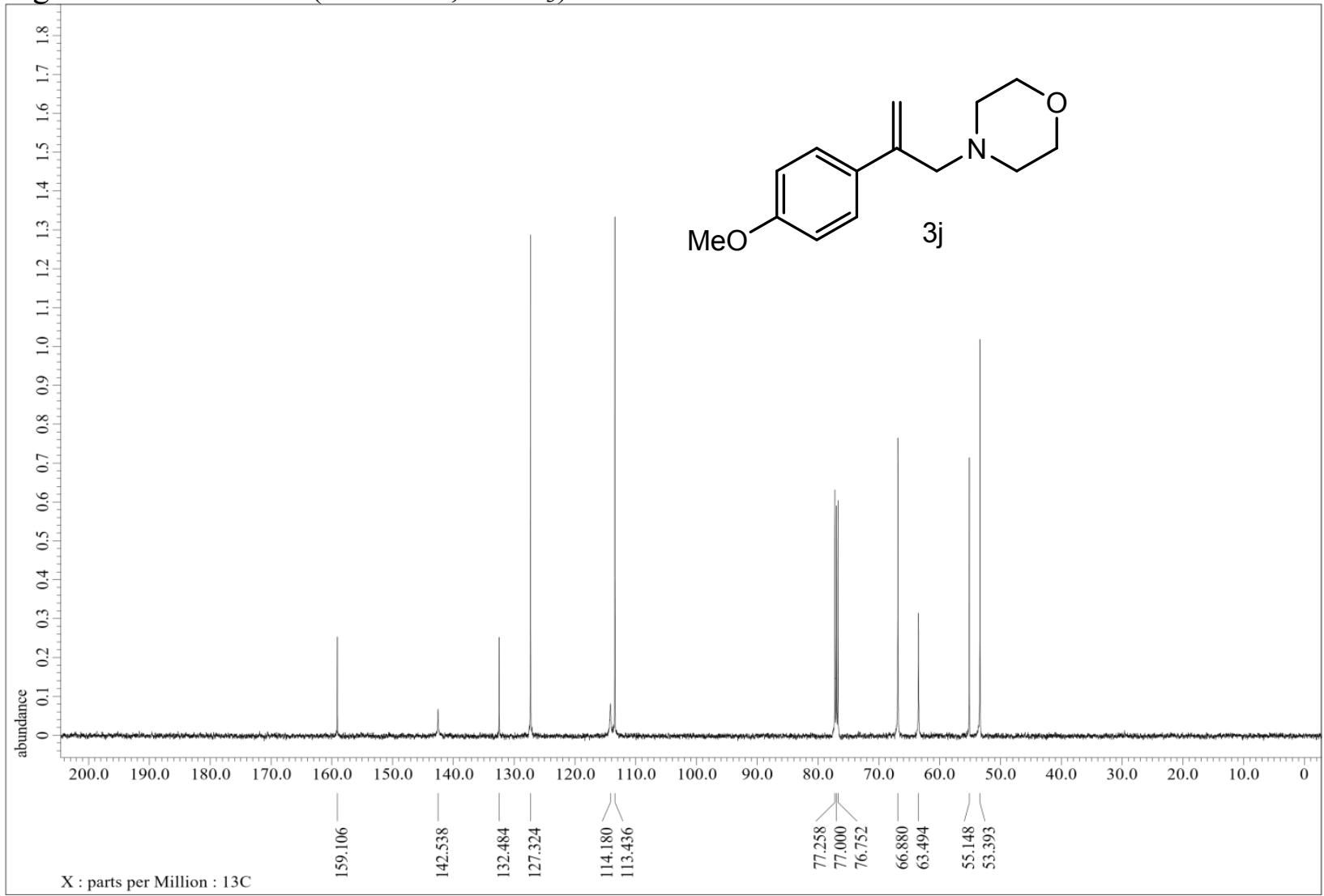


Figure S21: ${ }^{1} \mathrm{H}$ NMR $\left(500 \mathrm{MHz}, \mathrm{CDCl}_{3}\right)$

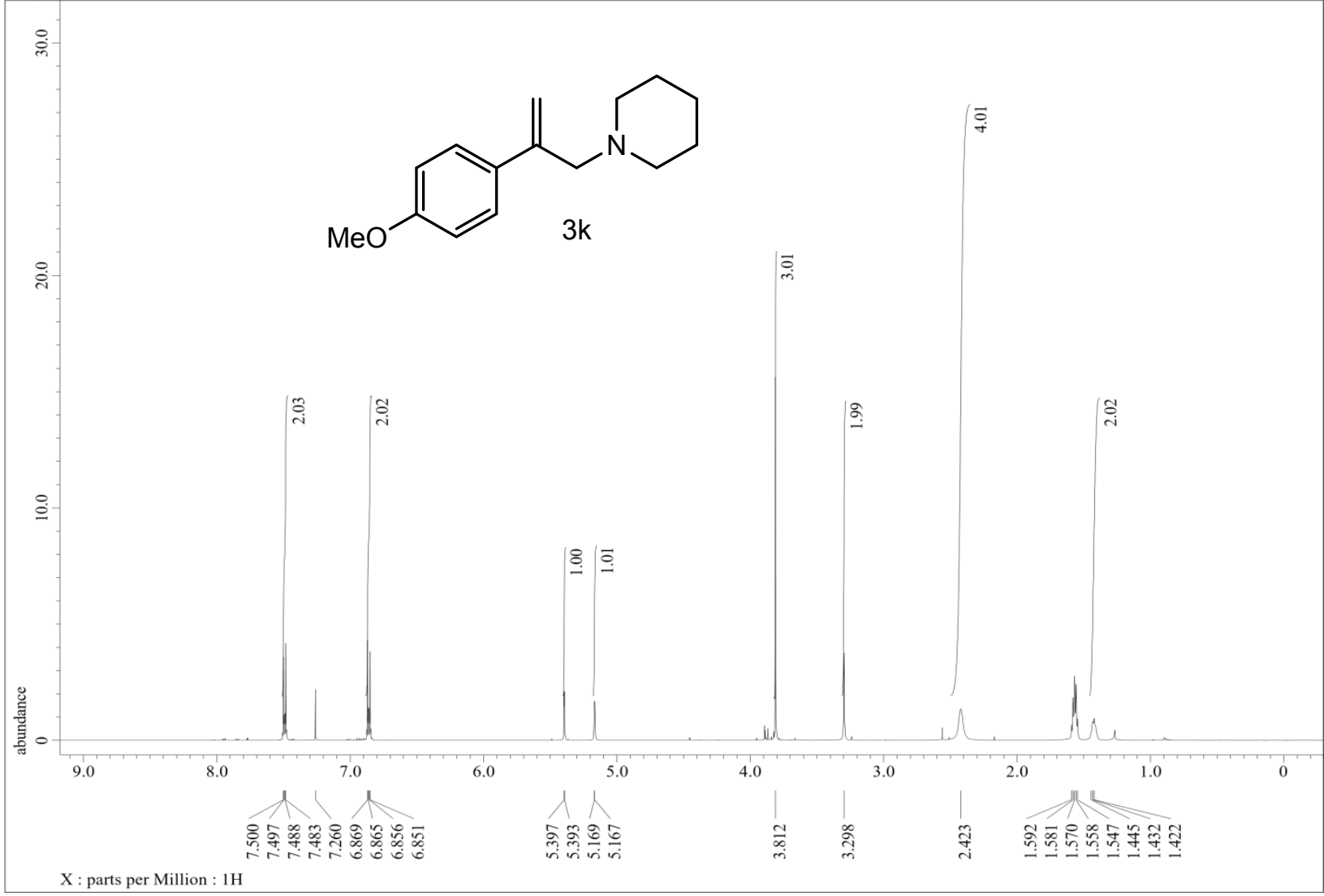

Figure S22: ${ }^{13} \mathrm{C}$ NMR $\left(125 \mathrm{MHz}, \mathrm{CDCl}_{3}\right)$

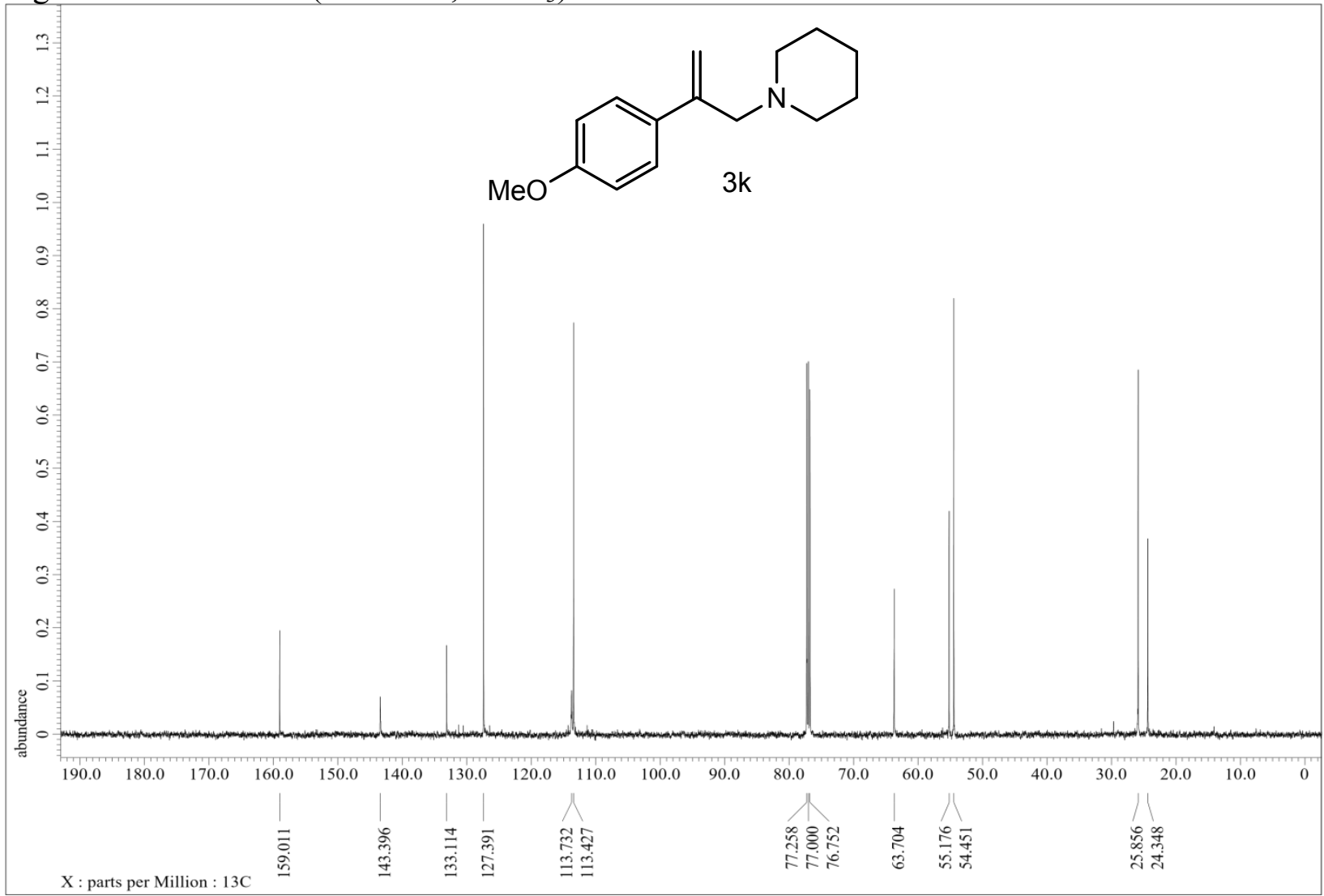


Figure S23: ${ }^{1} \mathrm{H}$ NMR $\left(500 \mathrm{MHz}, \mathrm{CDCl}_{3}\right)$

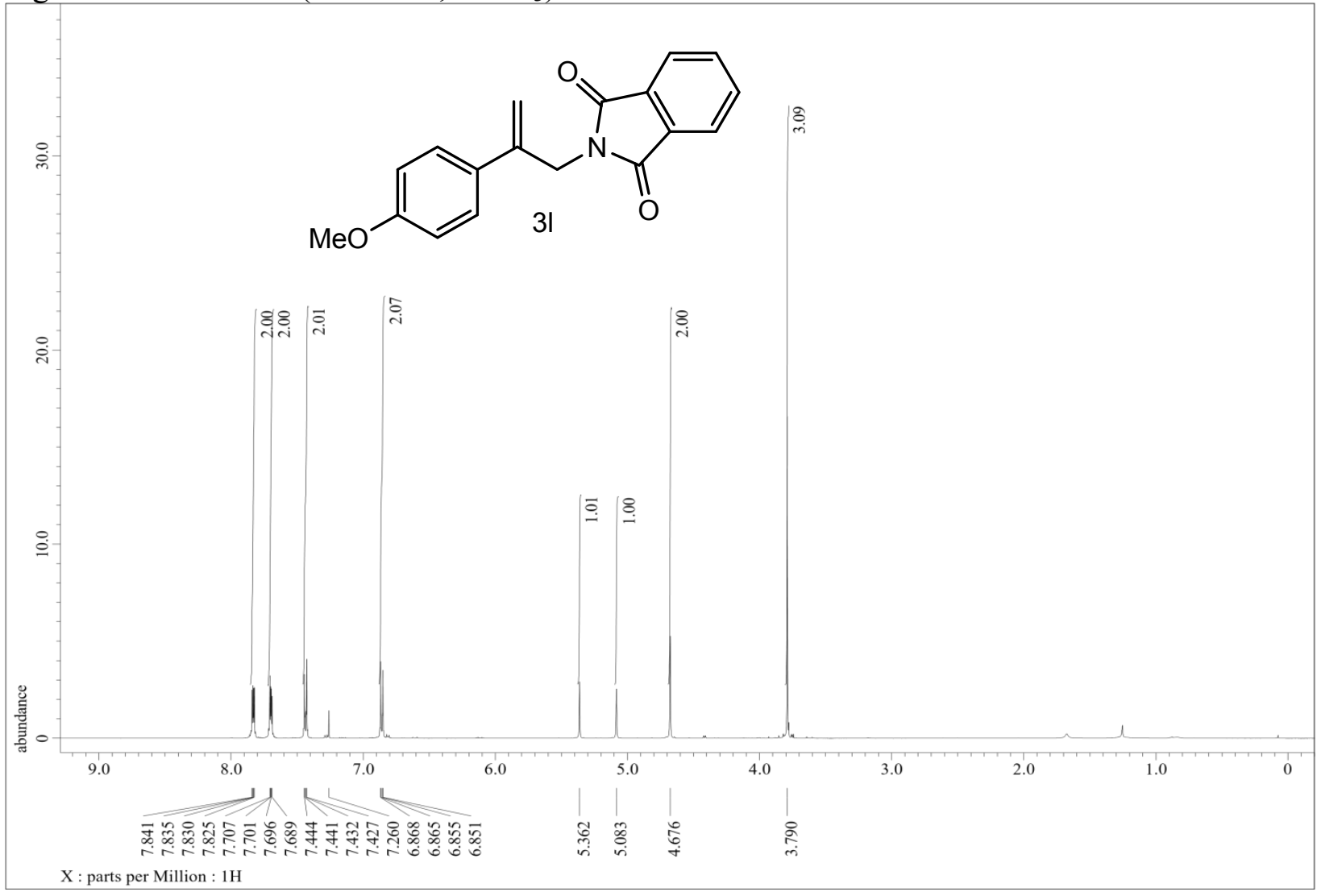

Figure S24: ${ }^{13} \mathrm{C}$ NMR $\left(125 \mathrm{MHz}, \mathrm{CDCl}_{3}\right)$

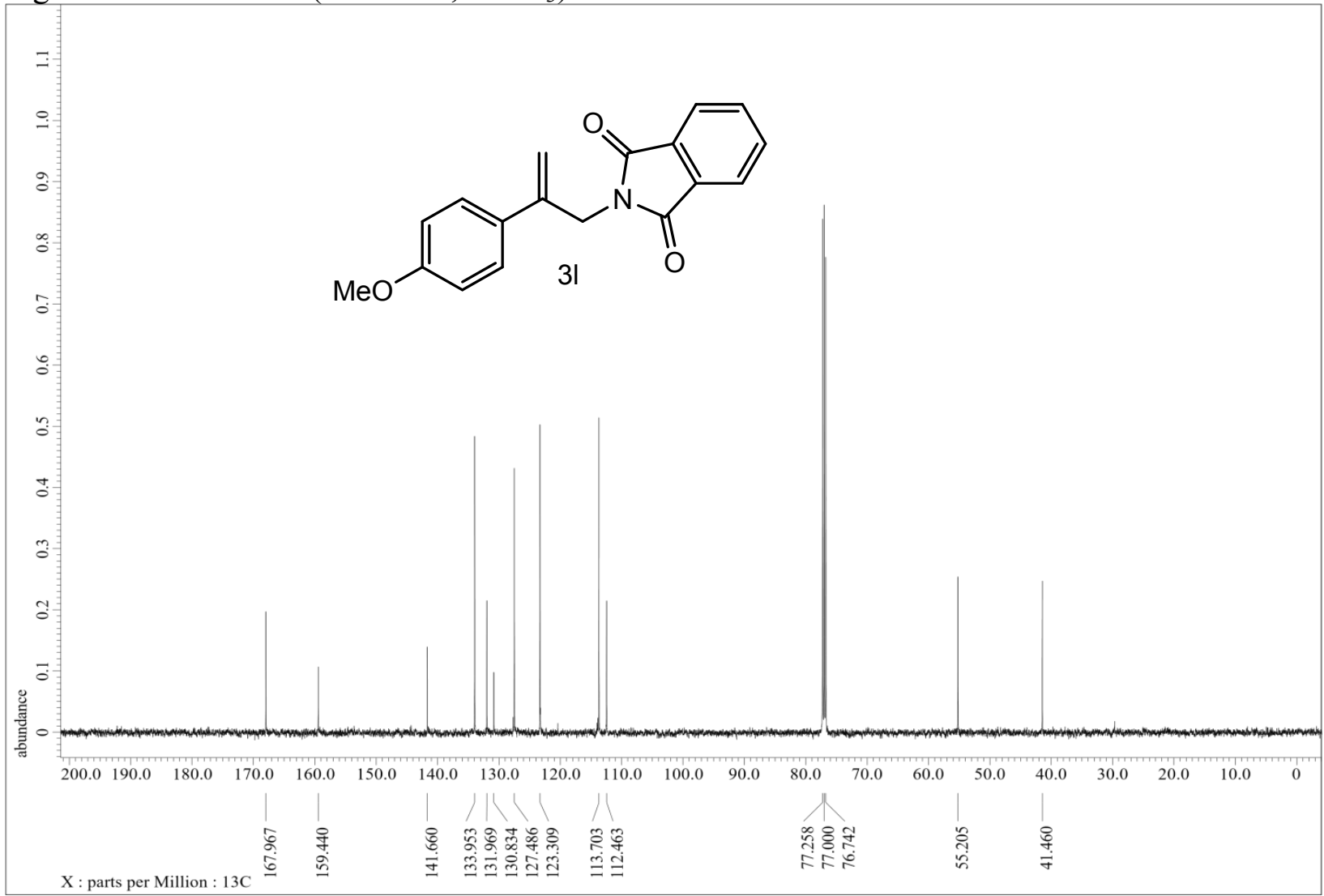


Figure S25: ${ }^{1} \mathrm{H}$ NMR $\left(500 \mathrm{MHz}, \mathrm{CDCl}_{3}\right)$

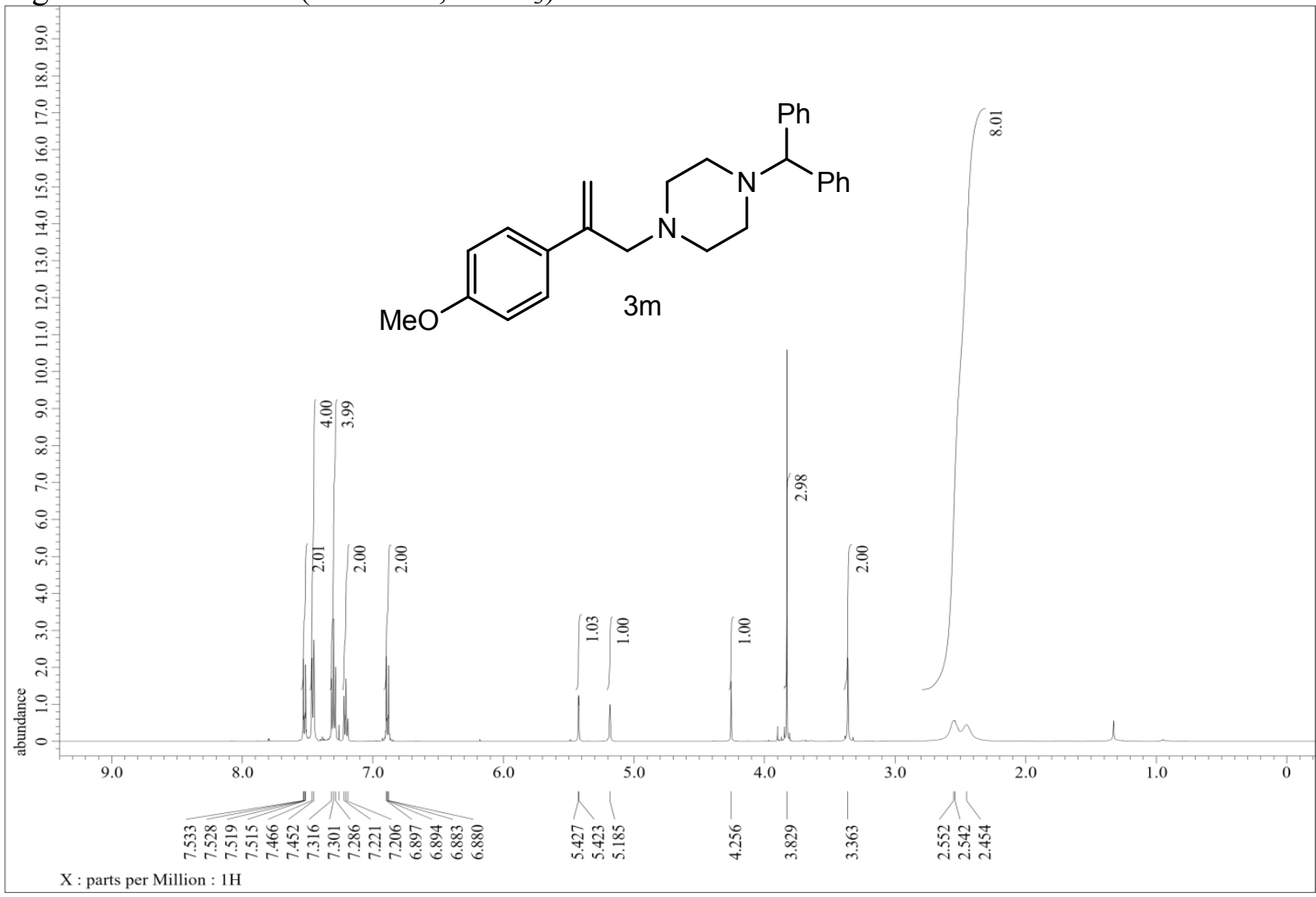

Figure S26: ${ }^{13} \mathrm{C}$ NMR $\left(125 \mathrm{MHz}, \mathrm{CDCl}_{3}\right)$

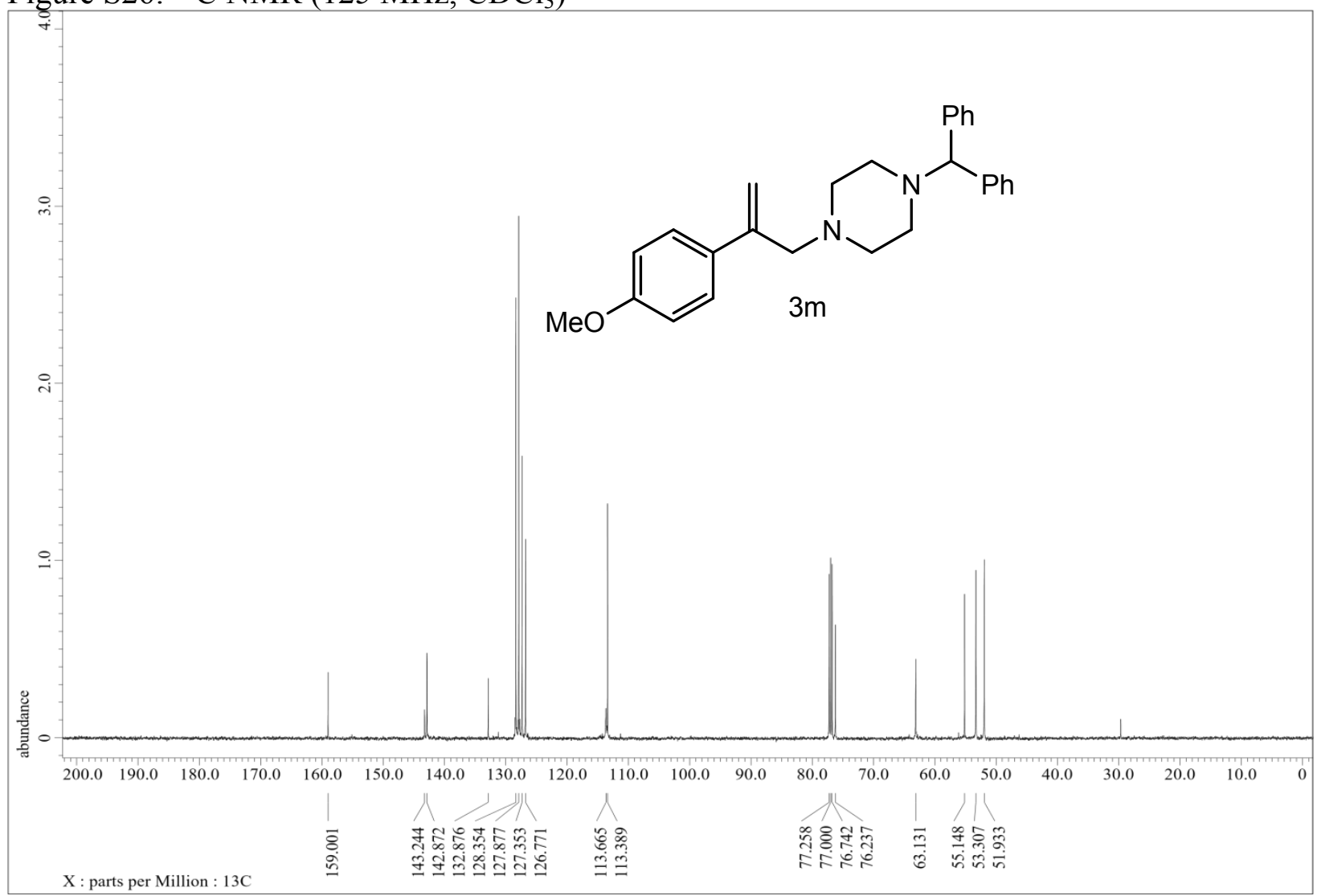


Supporting Information

S-19

Figure S27: ${ }^{1} \mathrm{H}$ NMR $\left(500 \mathrm{MHz}, \mathrm{CDCl}_{3}\right)$

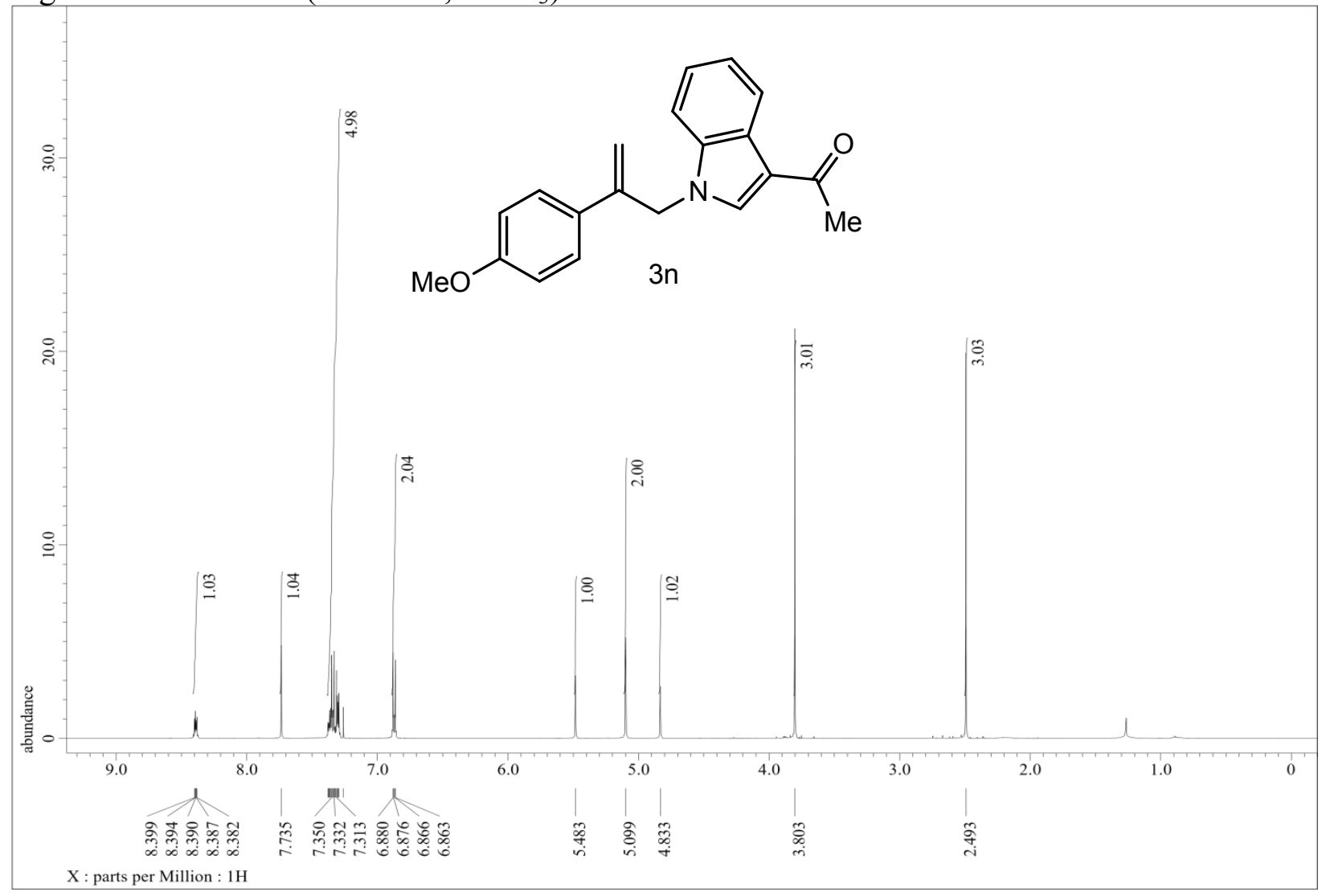

Figure S28: ${ }^{13} \mathrm{C} \mathrm{NMR}\left(125 \mathrm{MHz}, \mathrm{CDCl}_{3}\right)$

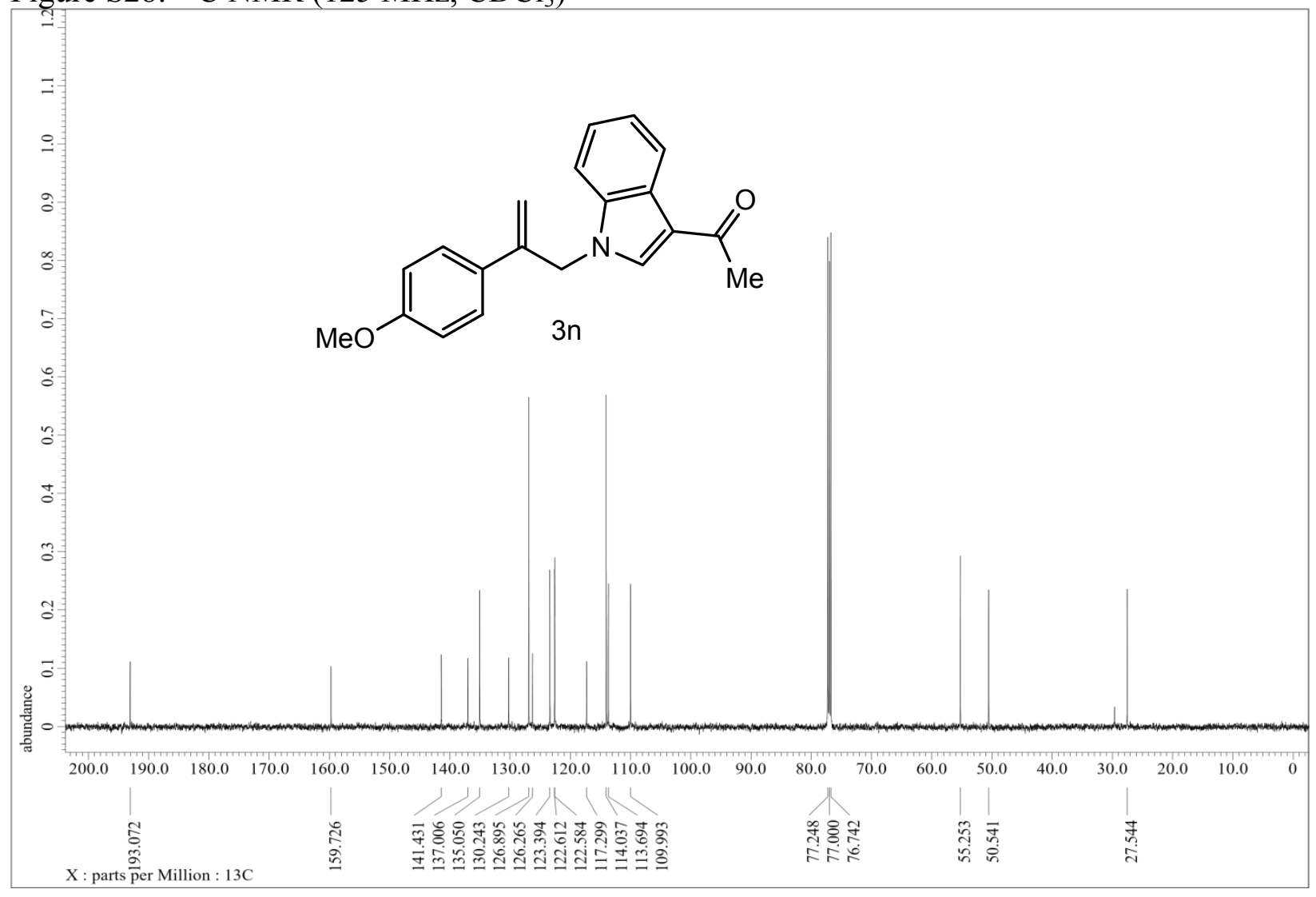


Figure S29: ${ }^{1} \mathrm{H}$ NMR $\left(300 \mathrm{MHz}, \mathrm{CDCl}_{3}\right)$

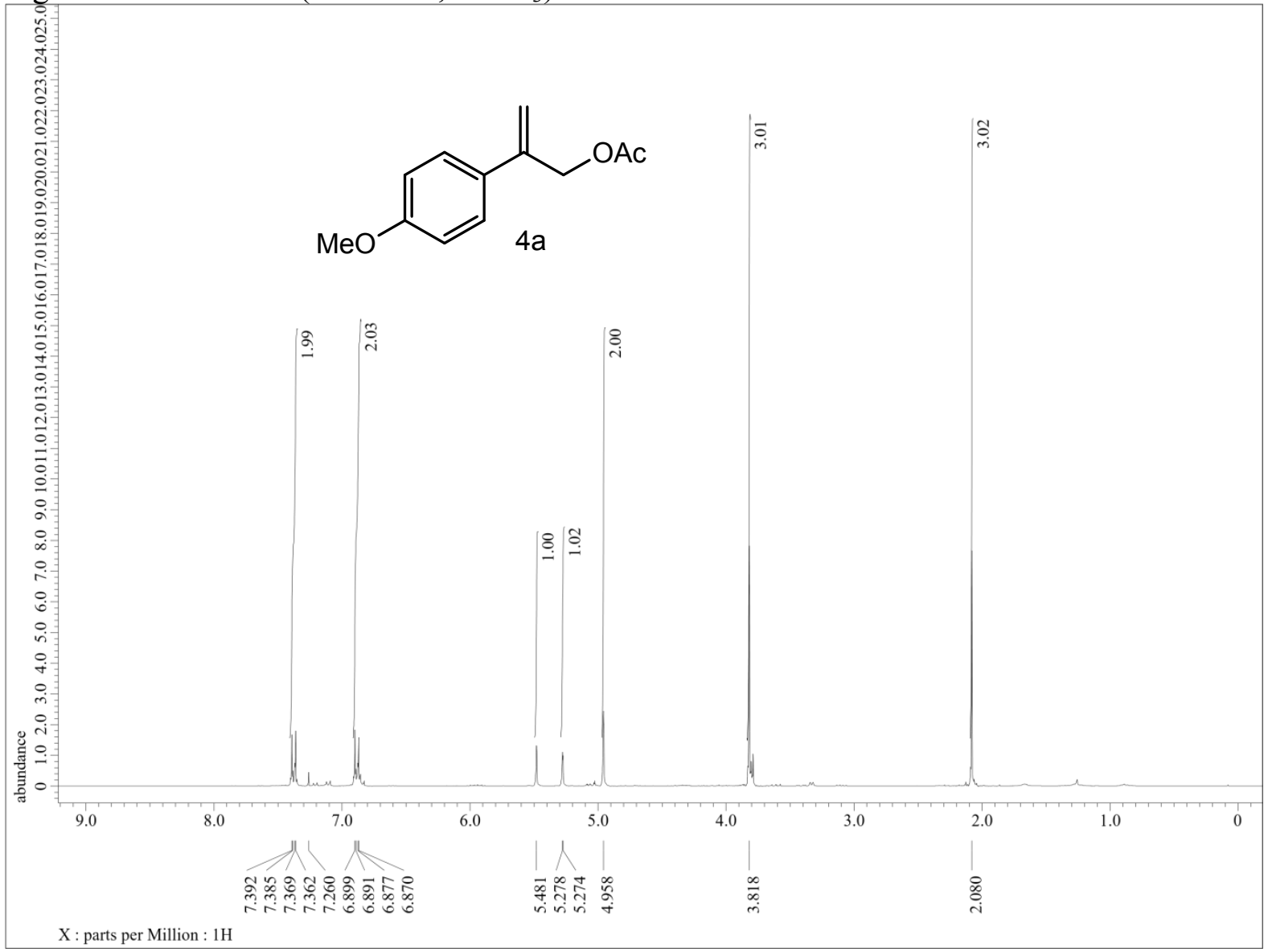

Figure S30: ${ }^{13} \mathrm{C}$ NMR $\left(75 \mathrm{MHz}, \mathrm{CDCl}_{3}\right)$

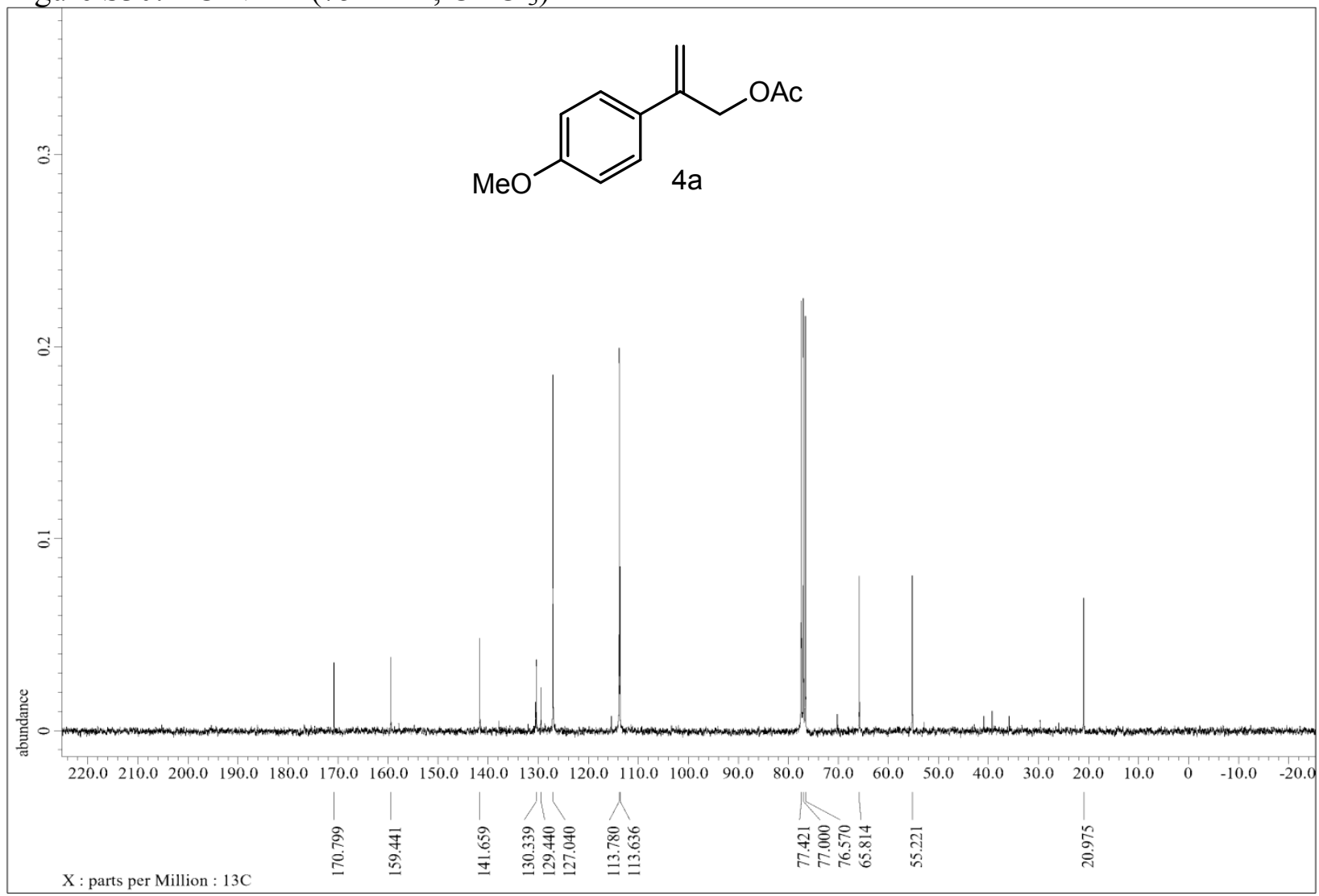


Figure S31: ${ }^{1} \mathrm{H} \mathrm{NMR}\left(500 \mathrm{MHz}, \mathrm{CDCl}_{3}\right)$

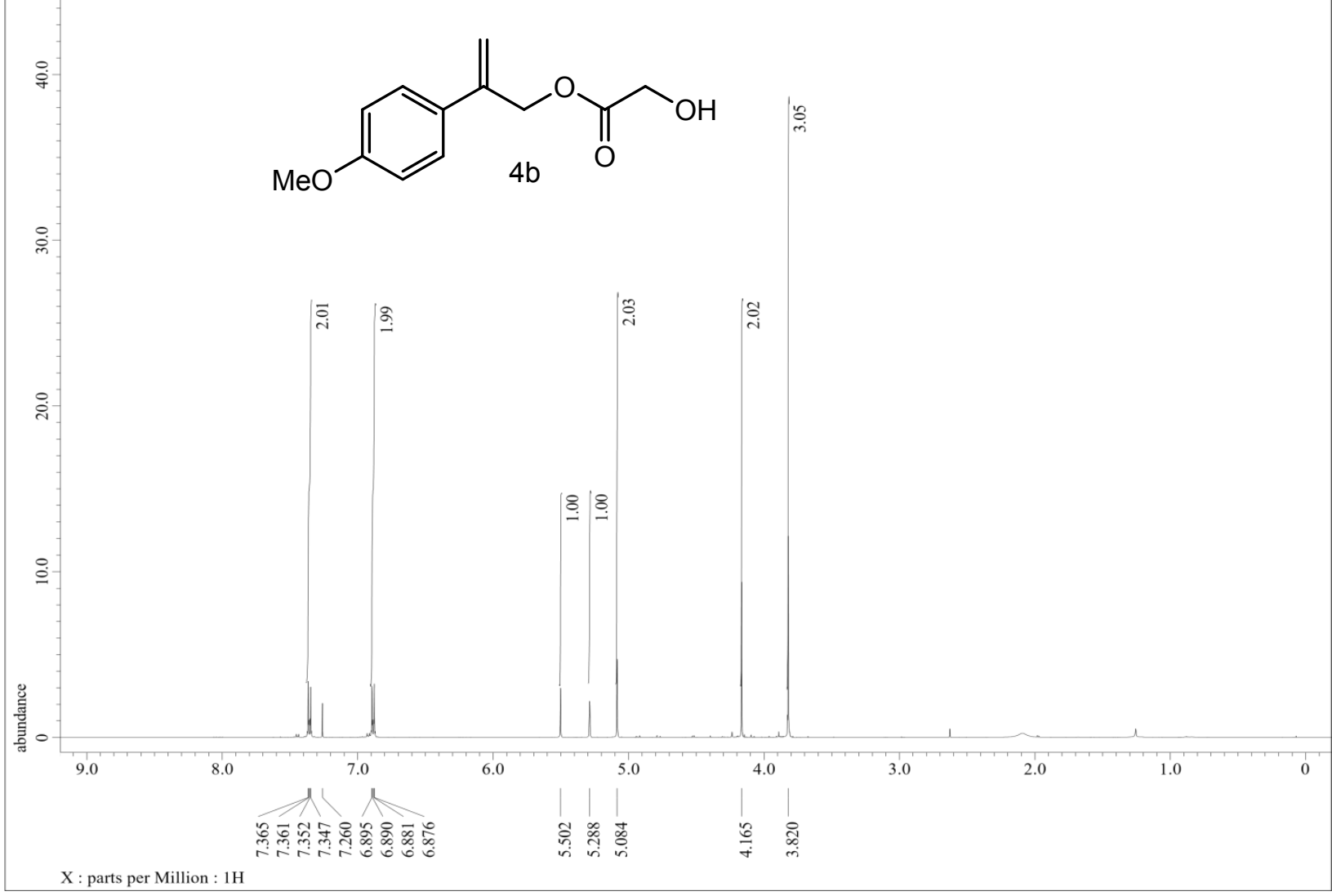

Figure S32: ${ }^{13} \mathrm{C}$ NMR $\left(125 \mathrm{MHz}, \mathrm{CDCl}_{3}\right)$

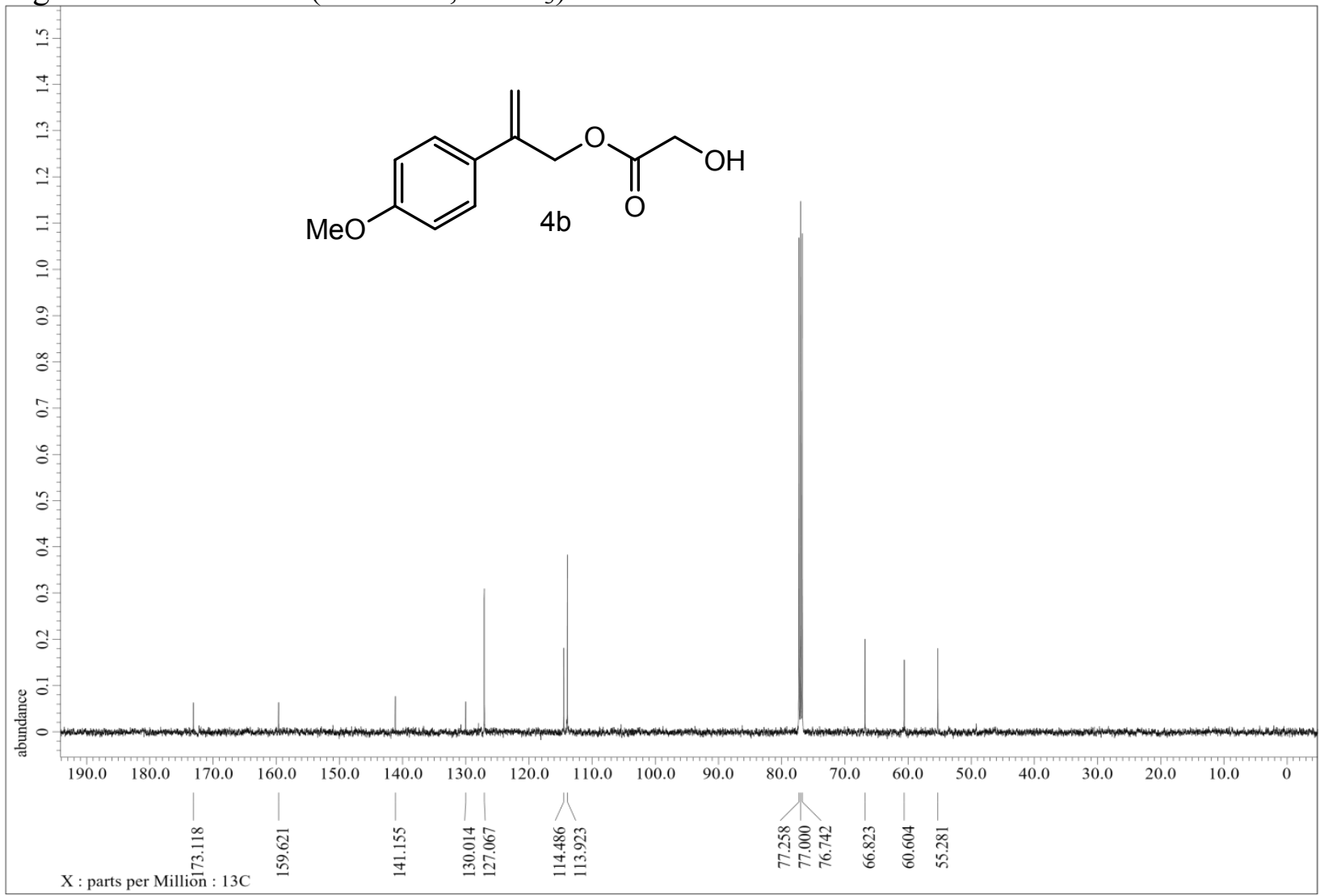


Figure S33: ${ }^{1} \mathrm{H}$ NMR $\left(500 \mathrm{MHz}, \mathrm{CDCl}_{3}\right)$

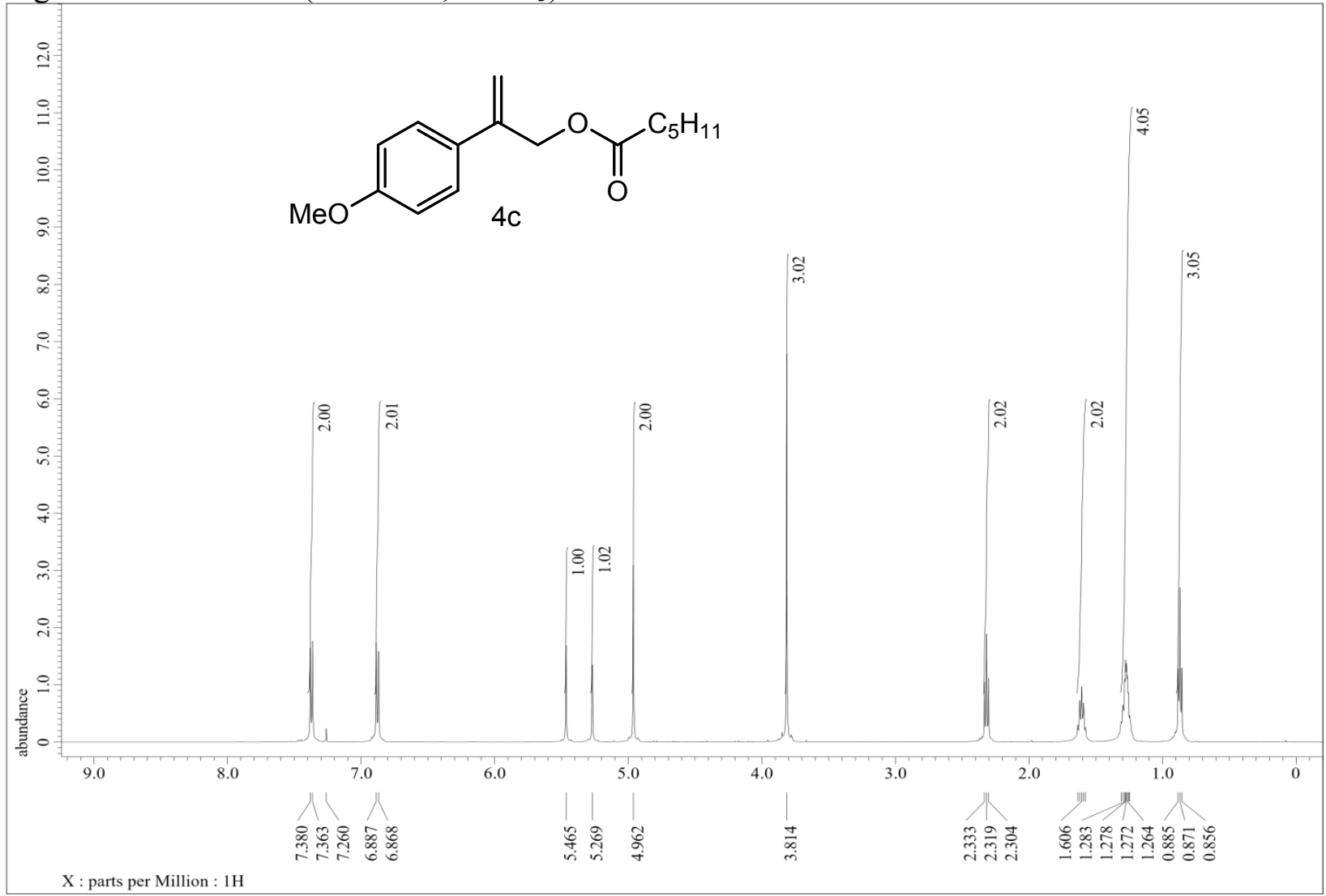

Figure S34: ${ }^{13} \mathrm{C}$ NMR (125 MHz, $\mathrm{CDCl}_{3}$ )

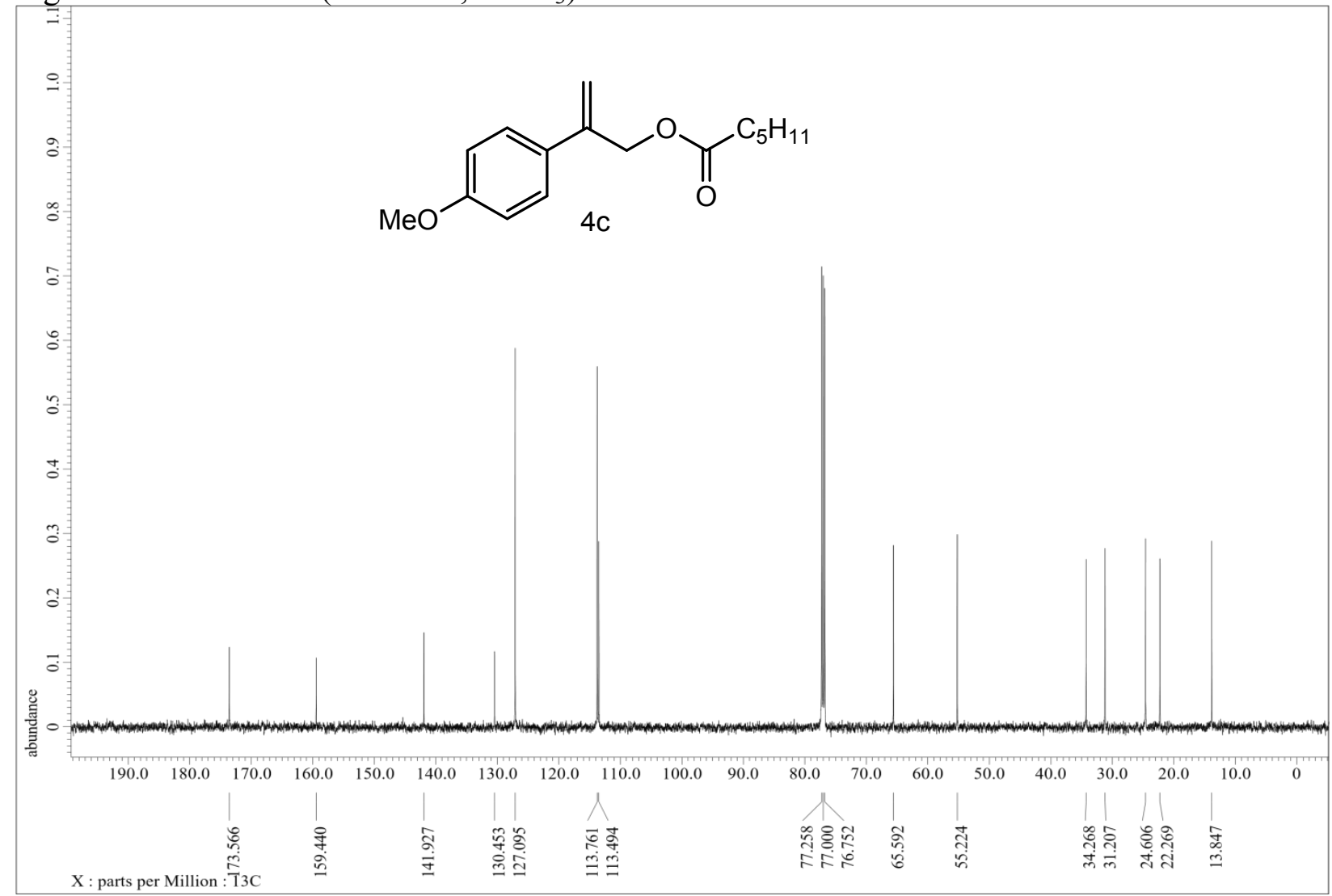


Figure S35: ${ }^{1} \mathrm{H}$ NMR $\left(300 \mathrm{MHz}, \mathrm{CDCl}_{3}\right)$

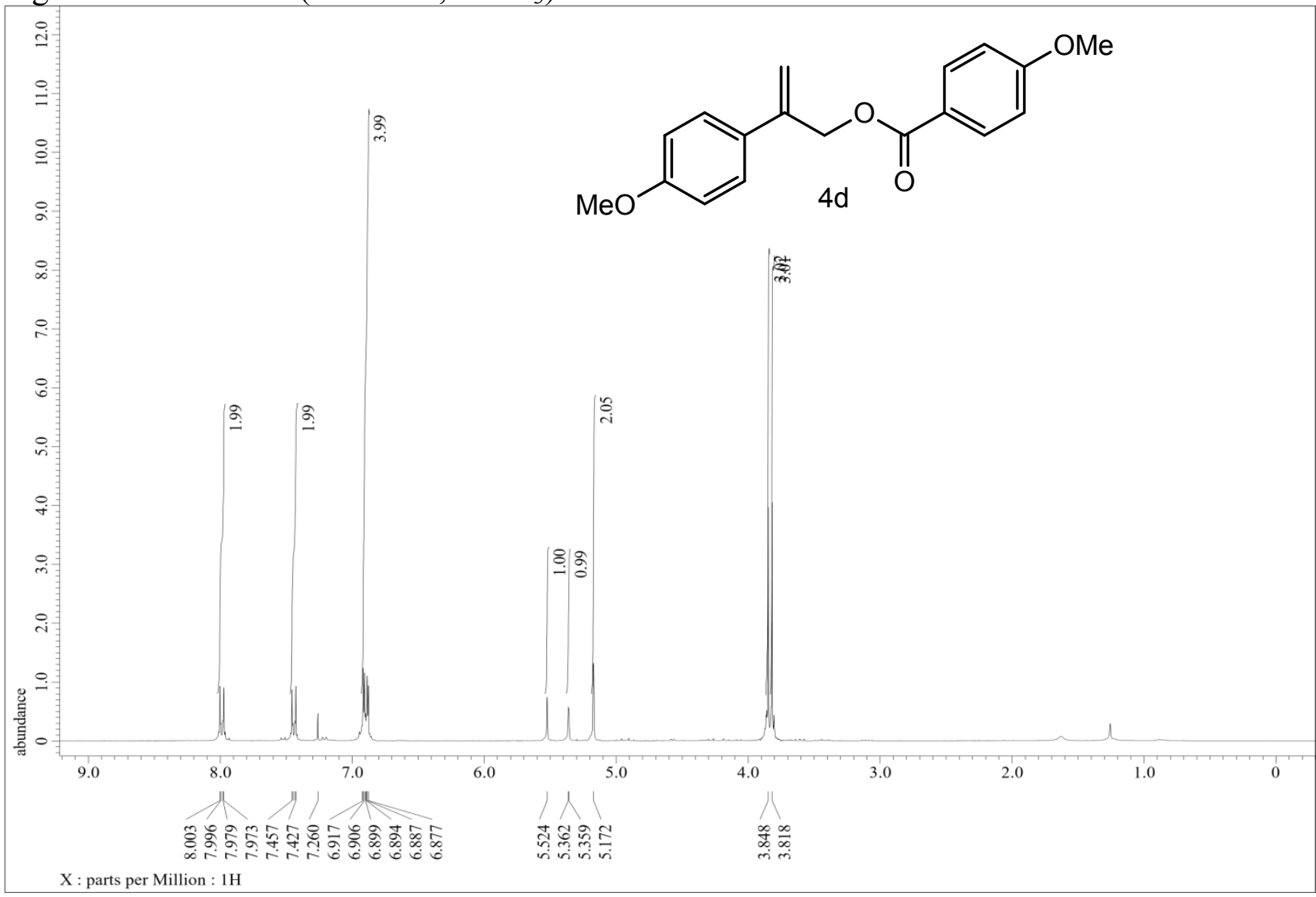

Figure S36: ${ }^{13} \mathrm{C}$ NMR $\left(75 \mathrm{MHz}, \mathrm{CDCl}_{3}\right)$

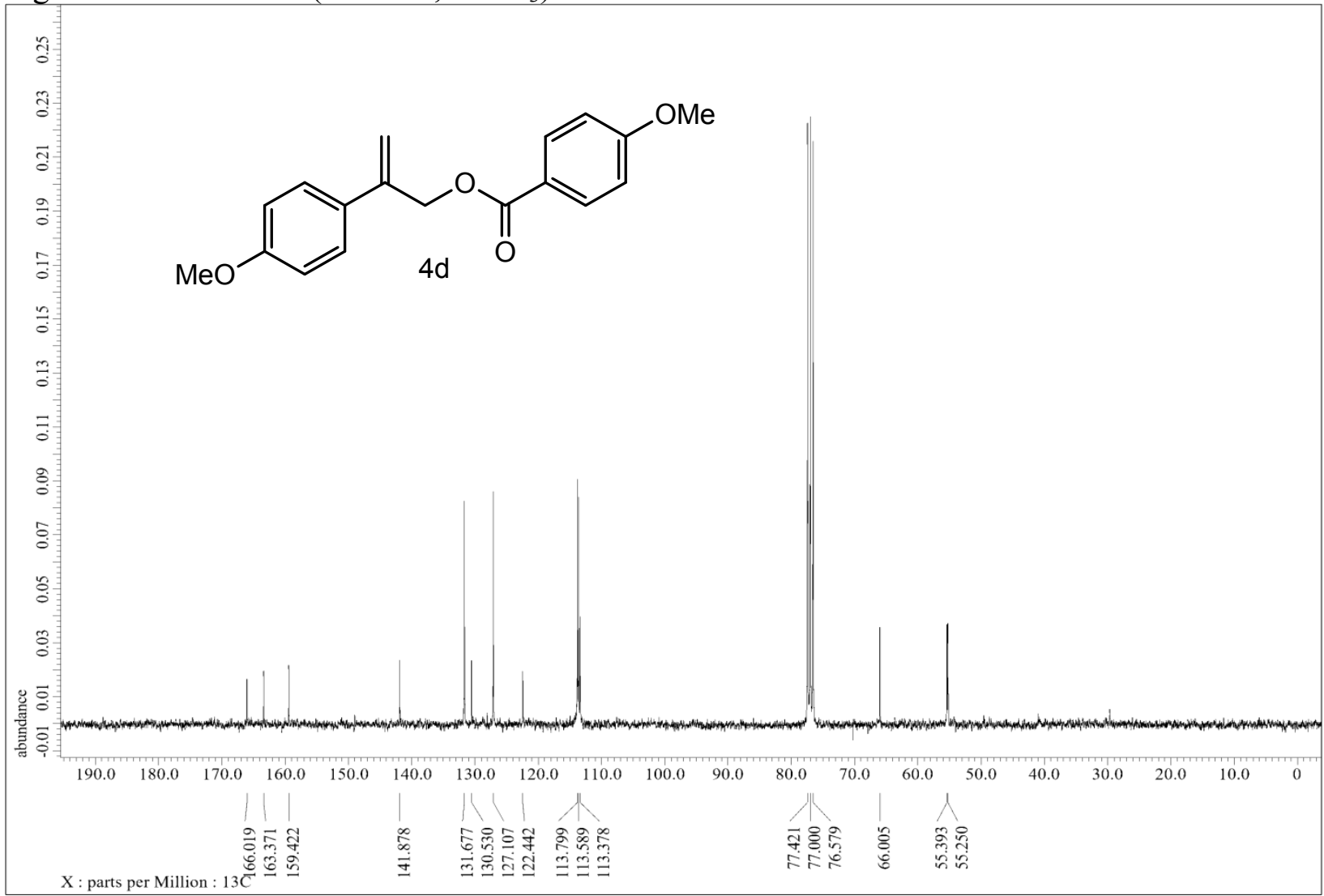


Figure S37: ${ }^{1} \mathrm{H} \mathrm{NMR}\left(500 \mathrm{MHz}, \mathrm{CDCl}_{3}\right)$

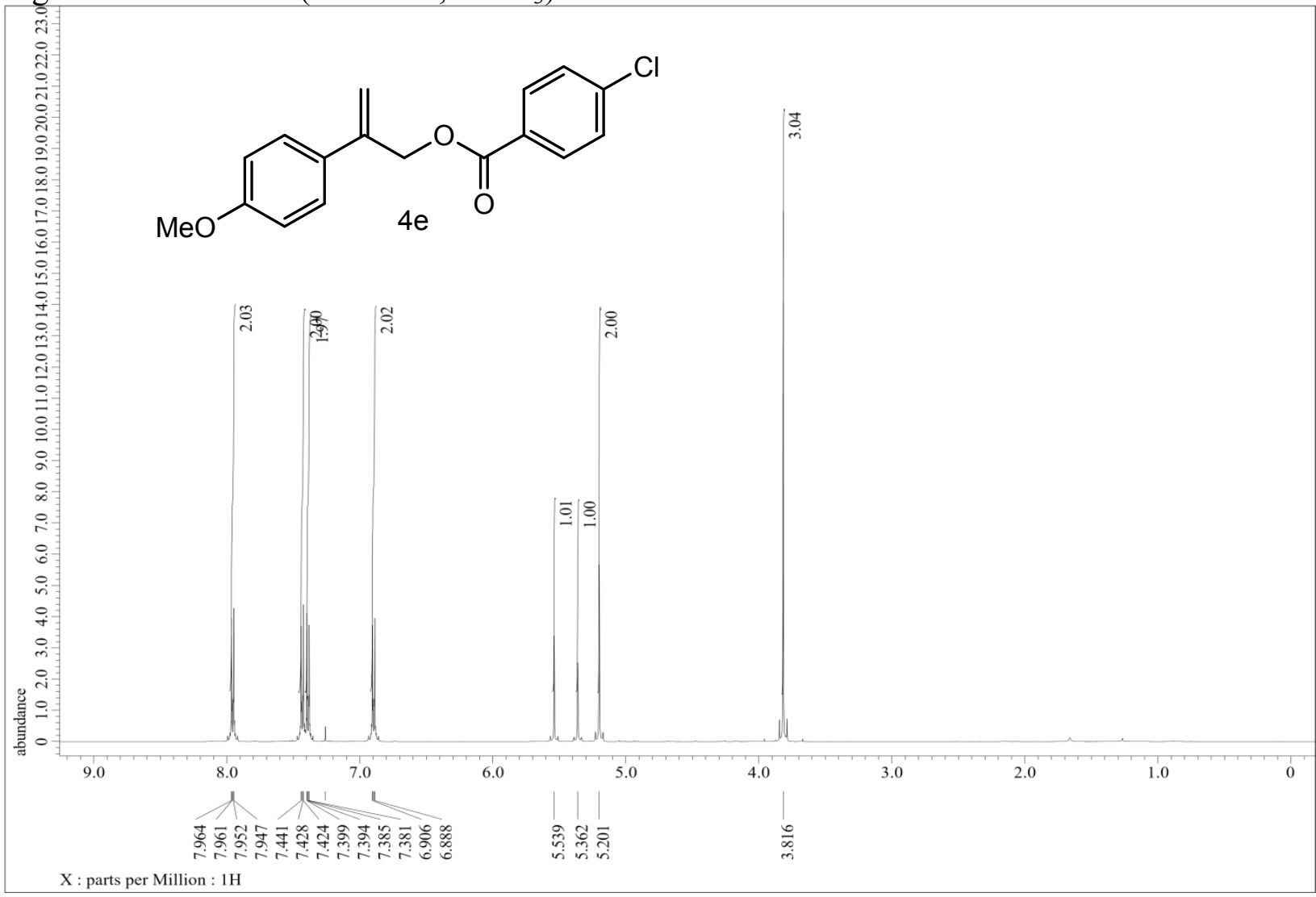

Figure S38: ${ }^{13} \mathrm{C}$ NMR $\left(125 \mathrm{MHz}, \mathrm{CDCl}_{3}\right)$

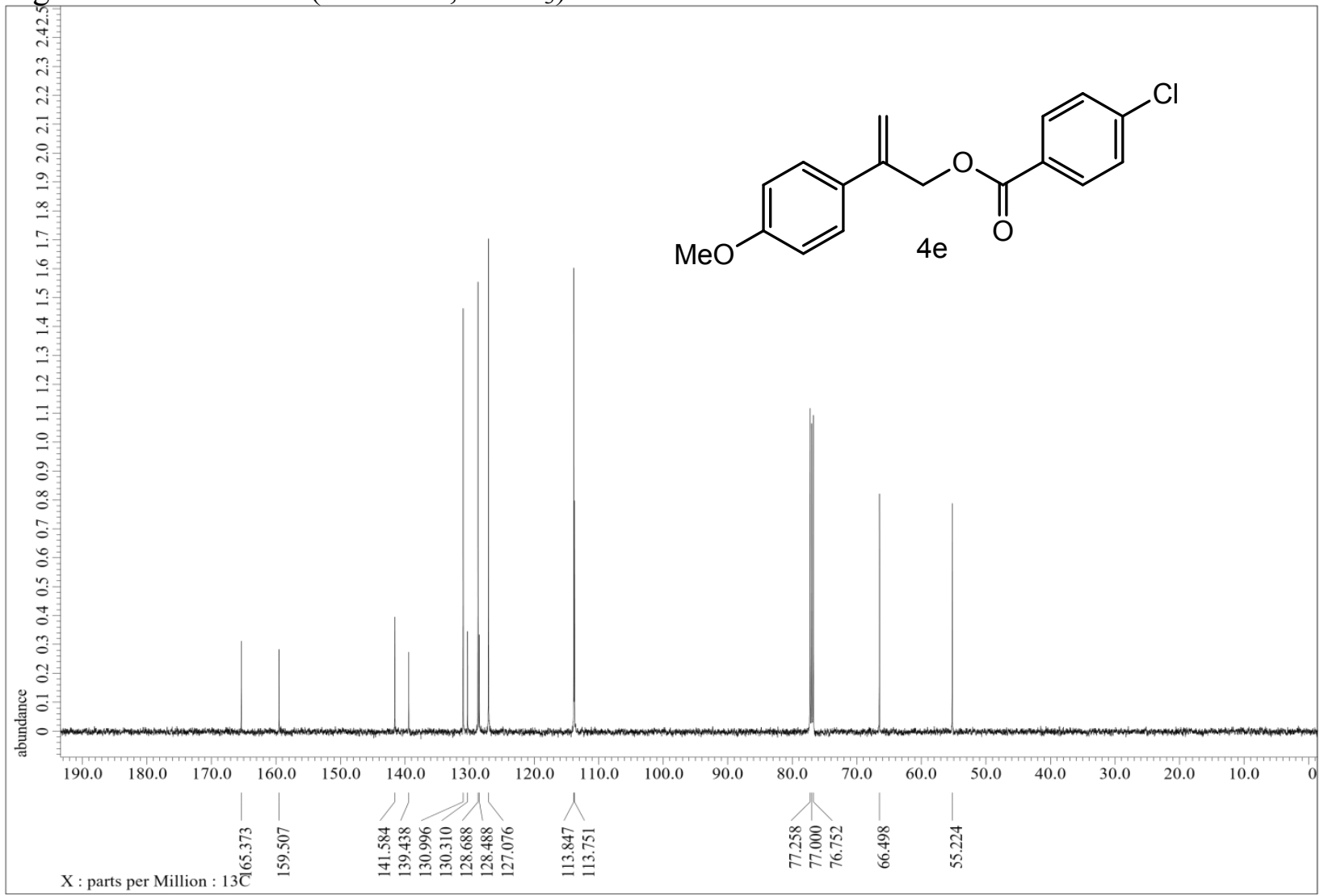


Figure S39: ${ }^{1} \mathrm{H} \mathrm{NMR}\left(300 \mathrm{MHz}, \mathrm{CDCl}_{3}\right)$

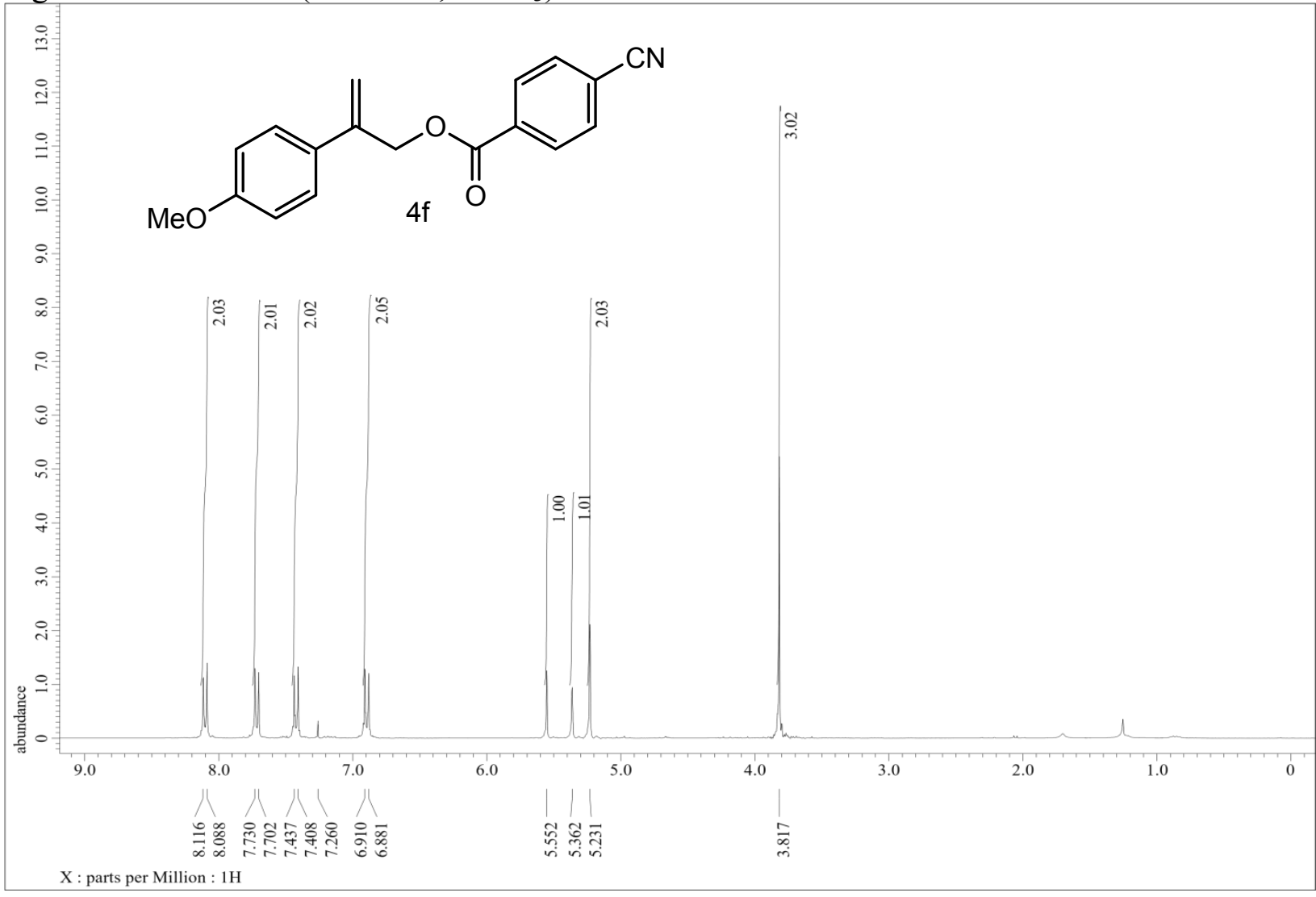

Figure S40: ${ }^{13} \mathrm{C}$ NMR $\left(75 \mathrm{MHz}, \mathrm{CDCl}_{3}\right)$

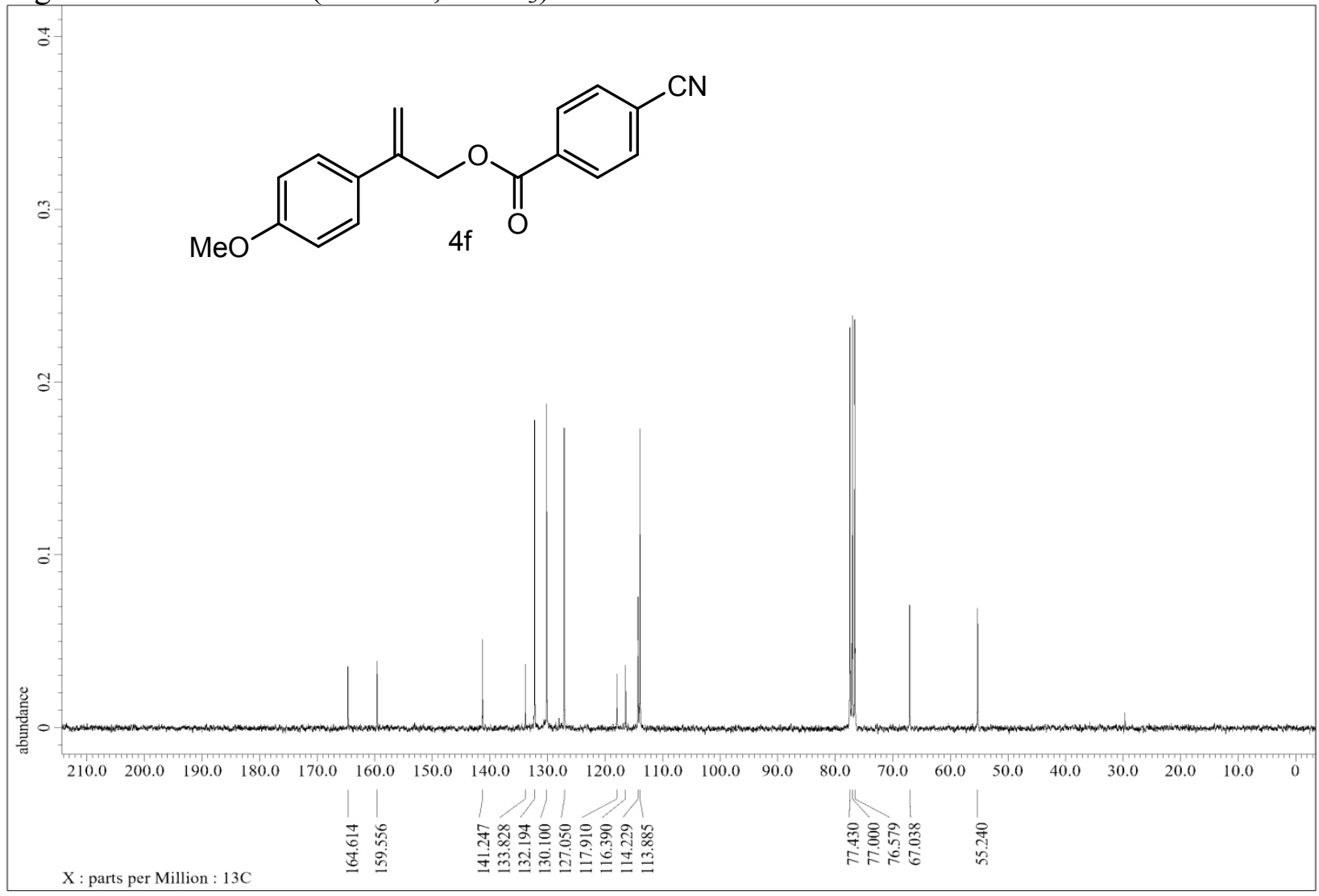


Figure S41: ${ }^{1} \mathrm{H} \mathrm{NMR}\left(500 \mathrm{MHz}, \mathrm{CDCl}_{3}\right)$

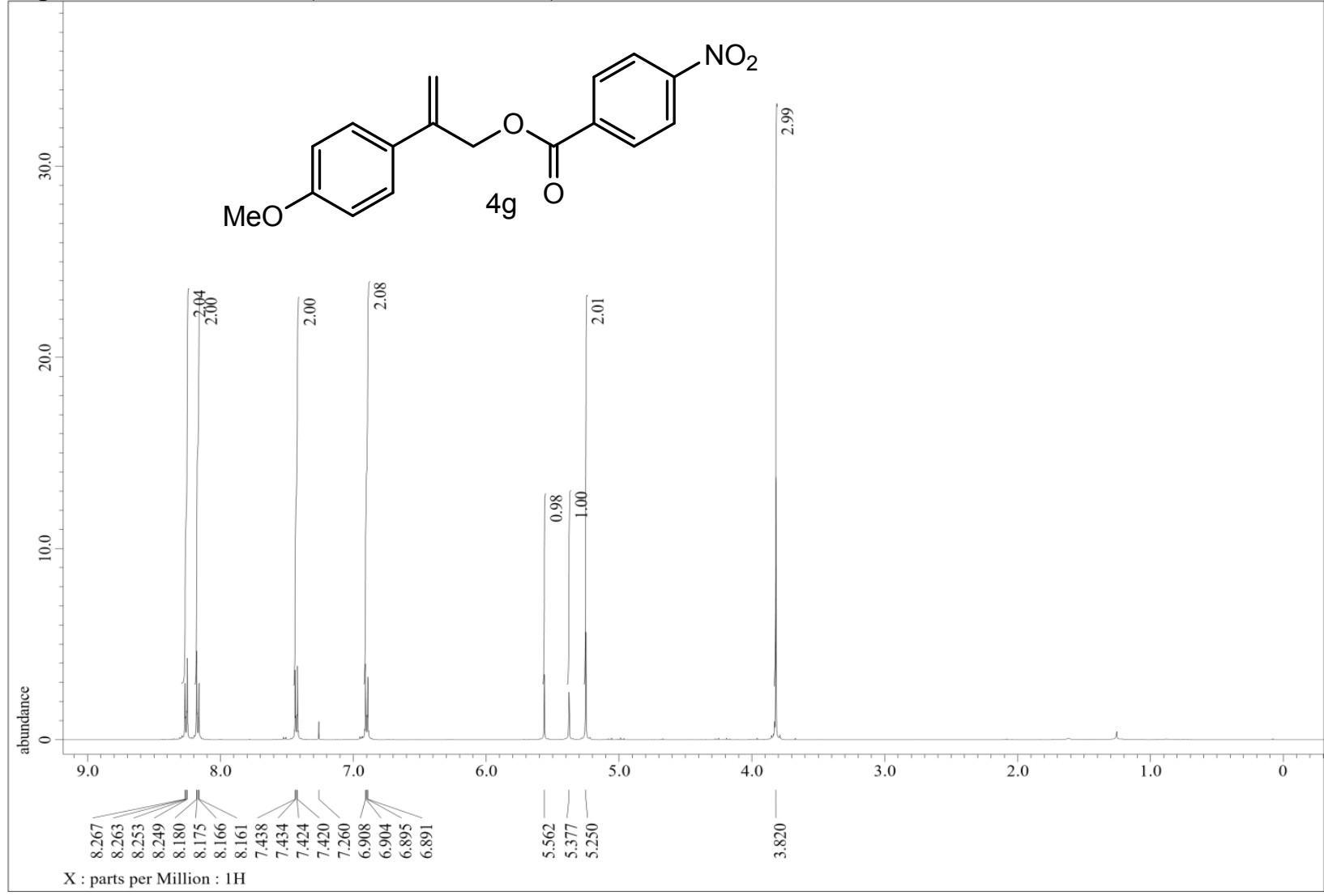

Figure S42: ${ }^{13} \mathrm{C}$ NMR $\left(125 \mathrm{MHz}, \mathrm{CDCl}_{3}\right)$

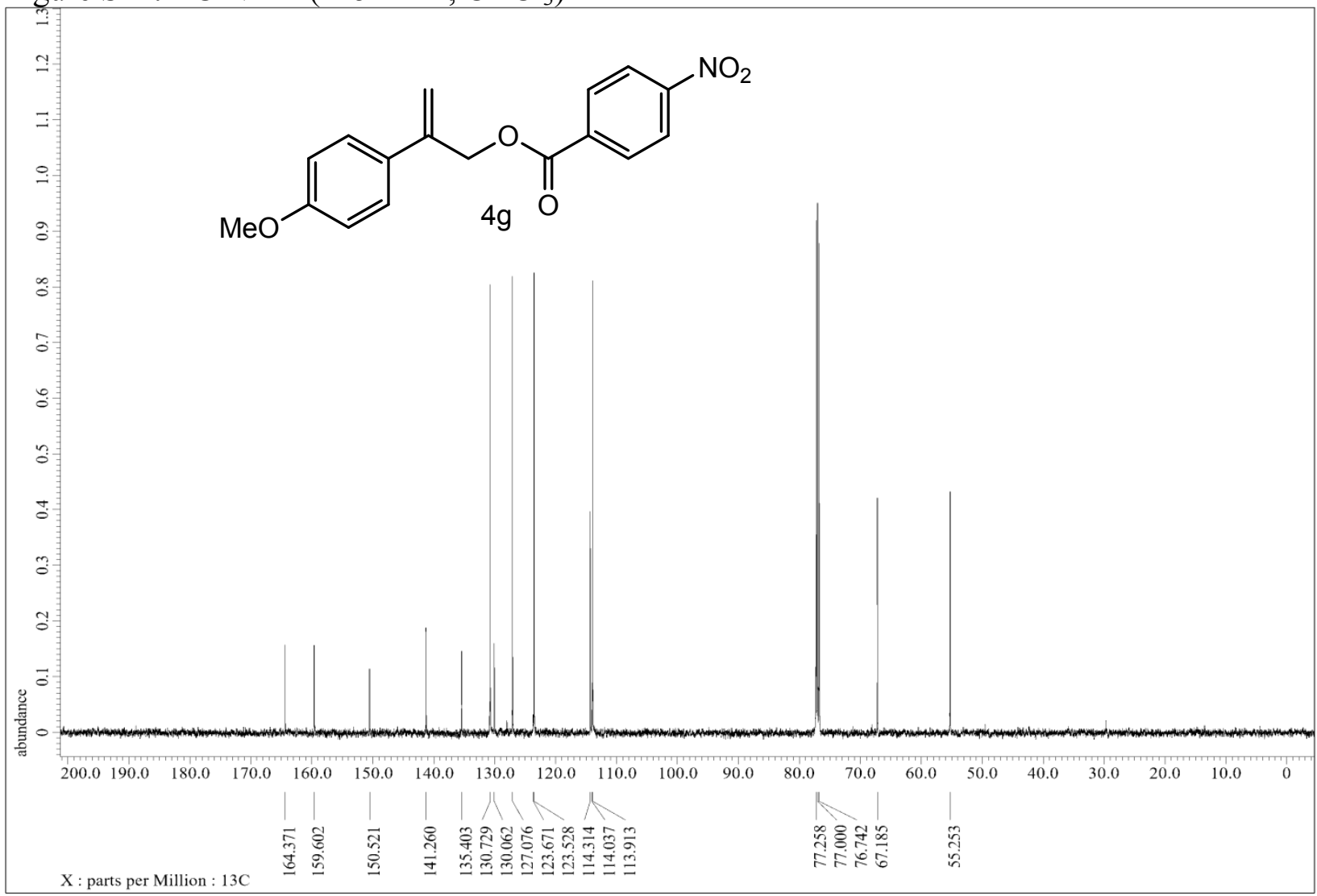


Figure S43: ${ }^{1} \mathrm{H}$ NMR $\left(500 \mathrm{MHz}, \mathrm{CDCl}_{3}\right)$

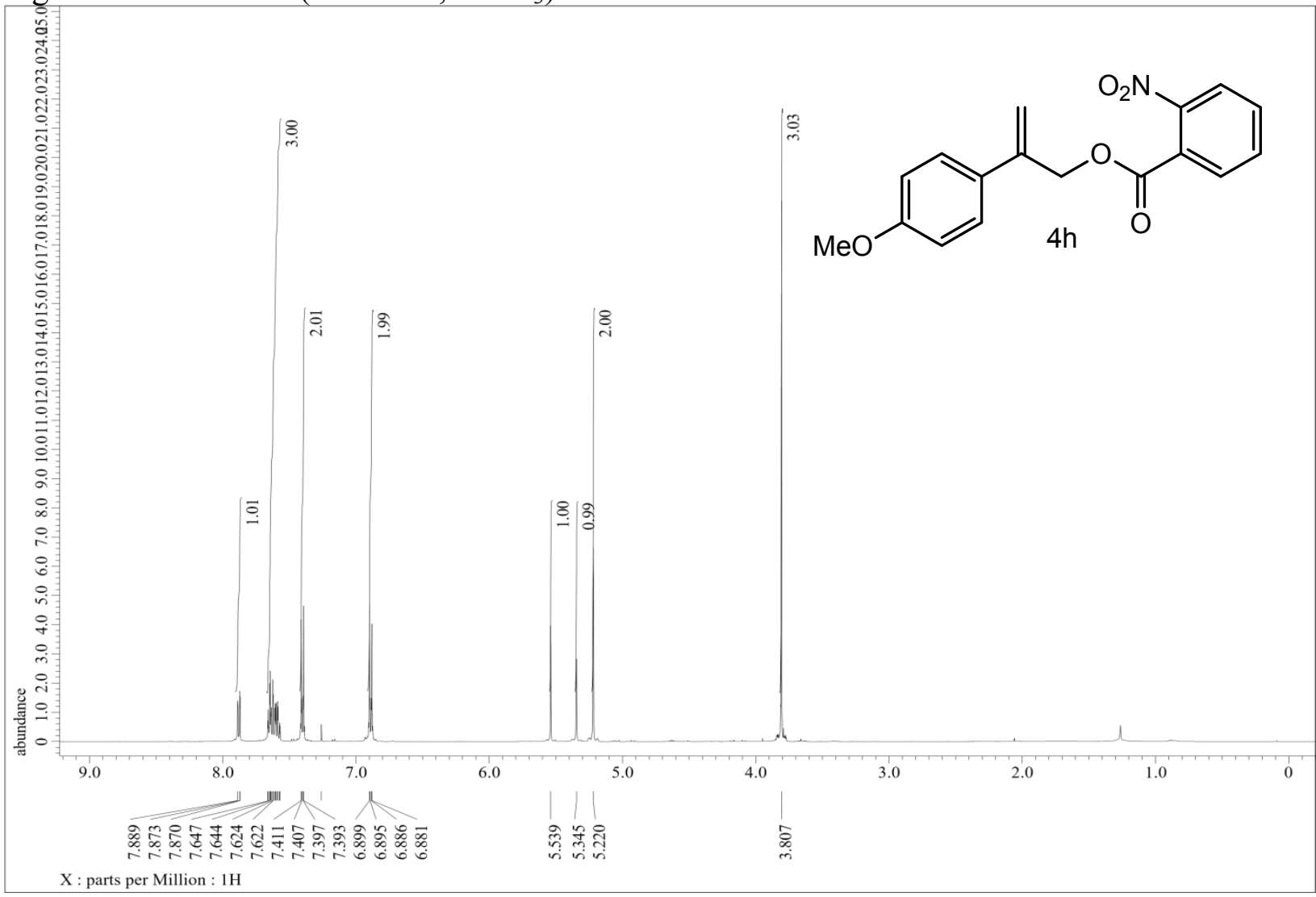

Figure S44: ${ }^{13} \mathrm{C}$ NMR $\left(125 \mathrm{MHz}, \mathrm{CDCl}_{3}\right)$

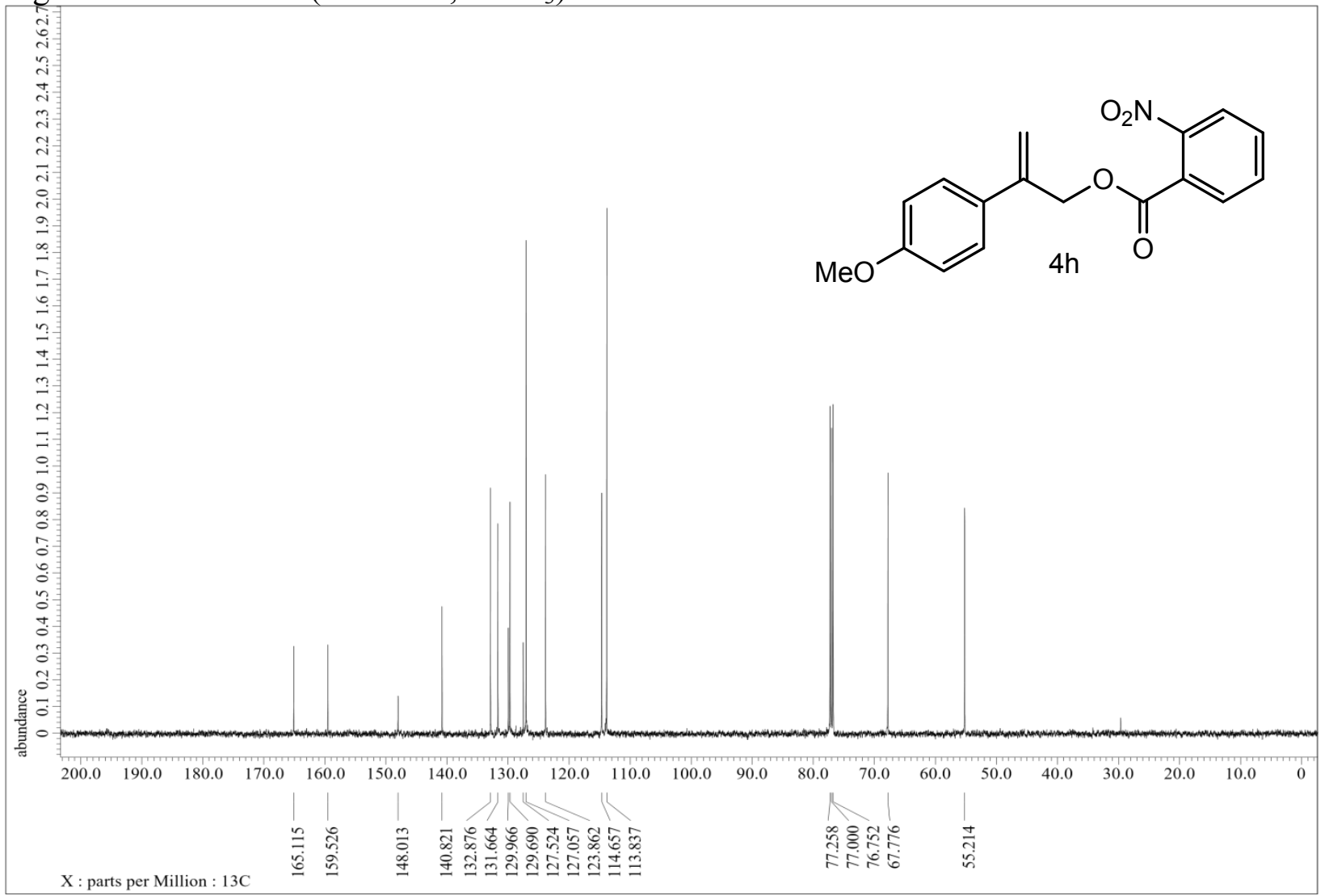


Figure S45: ${ }^{1} \mathrm{H}$ NMR $\left(500 \mathrm{MHz}, \mathrm{CDCl}_{3}\right)$

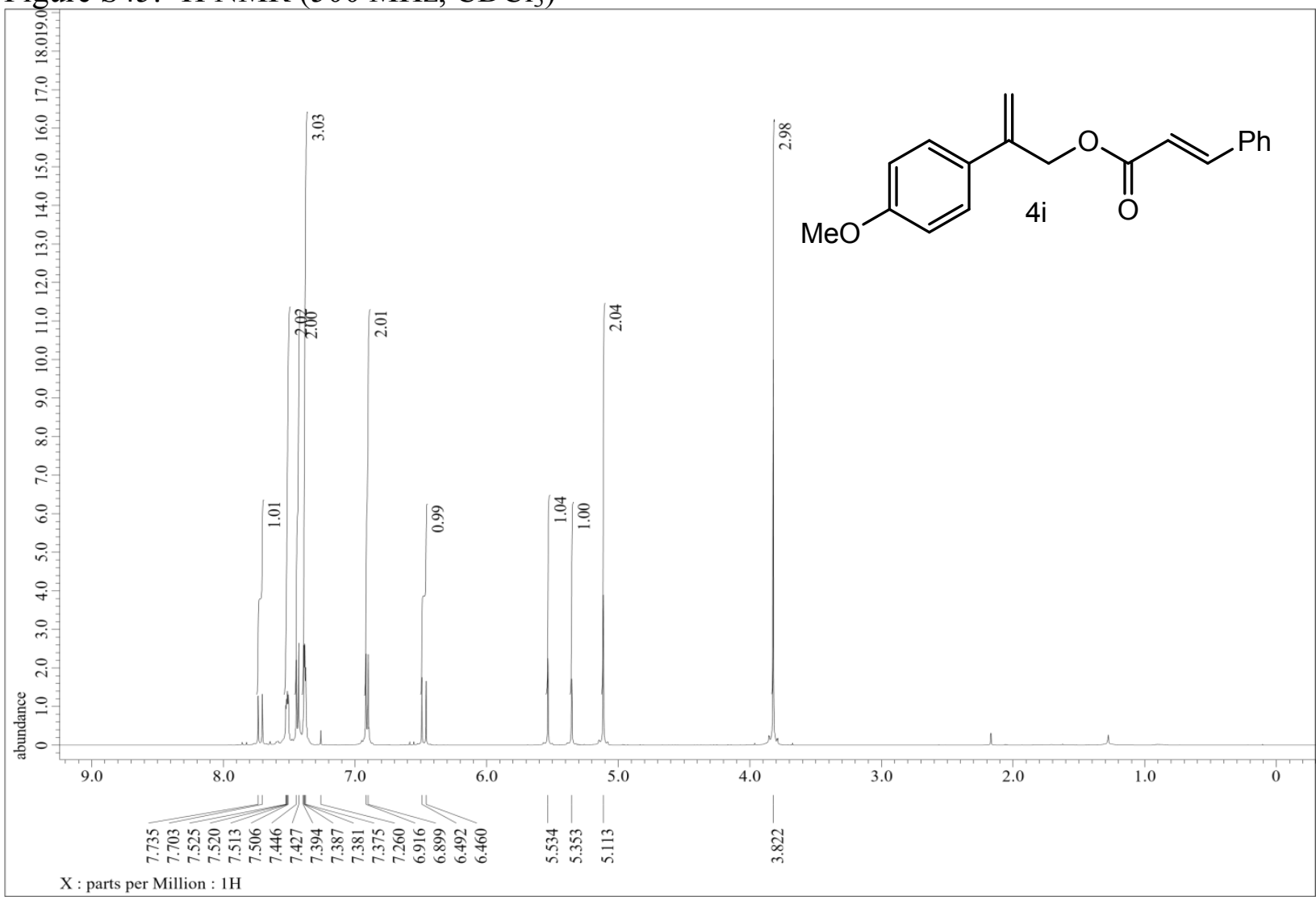

Figure S46: ${ }^{13} \mathrm{C}$ NMR $\left(125 \mathrm{MHz}, \mathrm{CDCl}_{3}\right)$

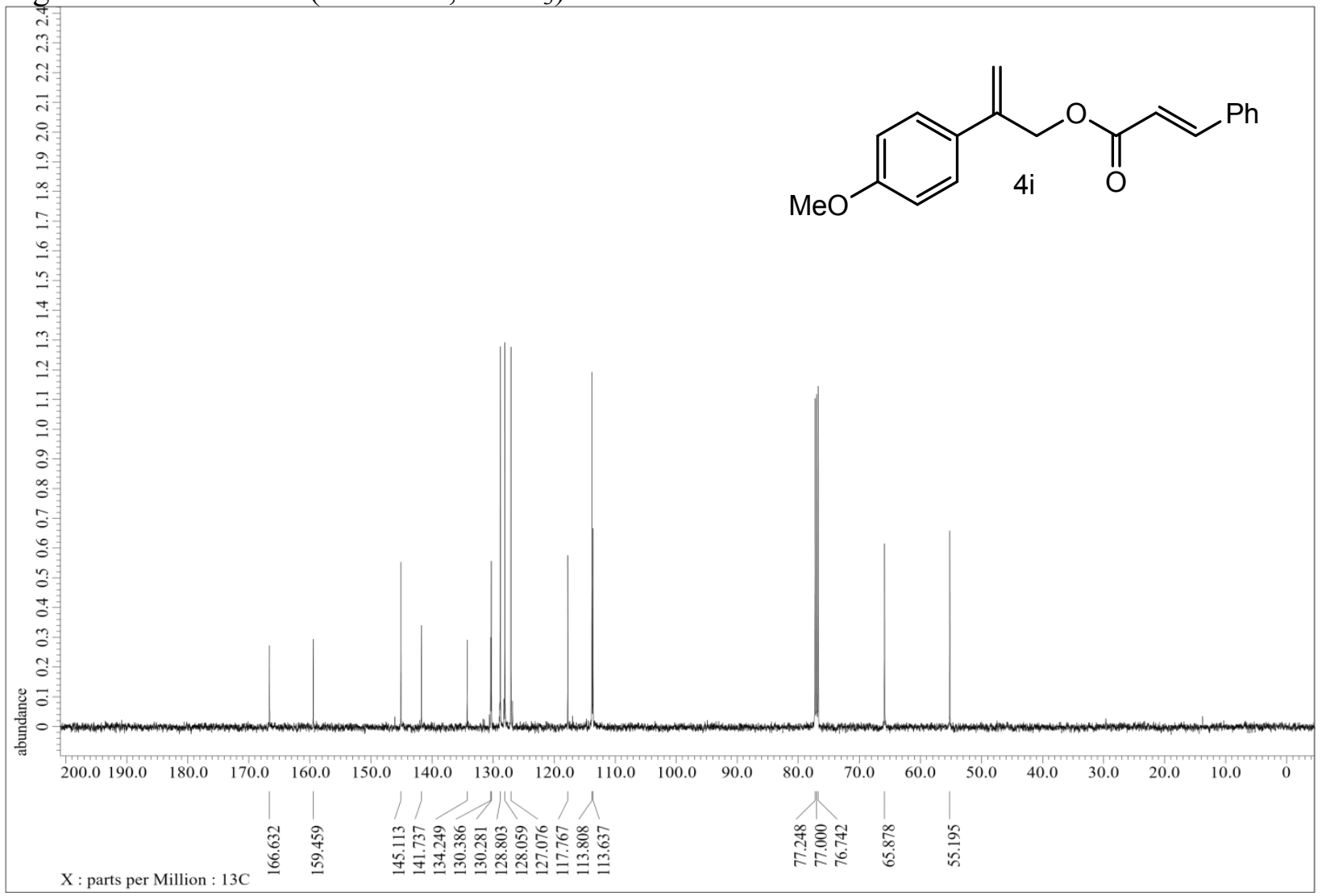


Figure S47: ${ }^{1} \mathrm{H} \mathrm{NMR}\left(500 \mathrm{MHz}, \mathrm{CDCl}_{3}\right)$

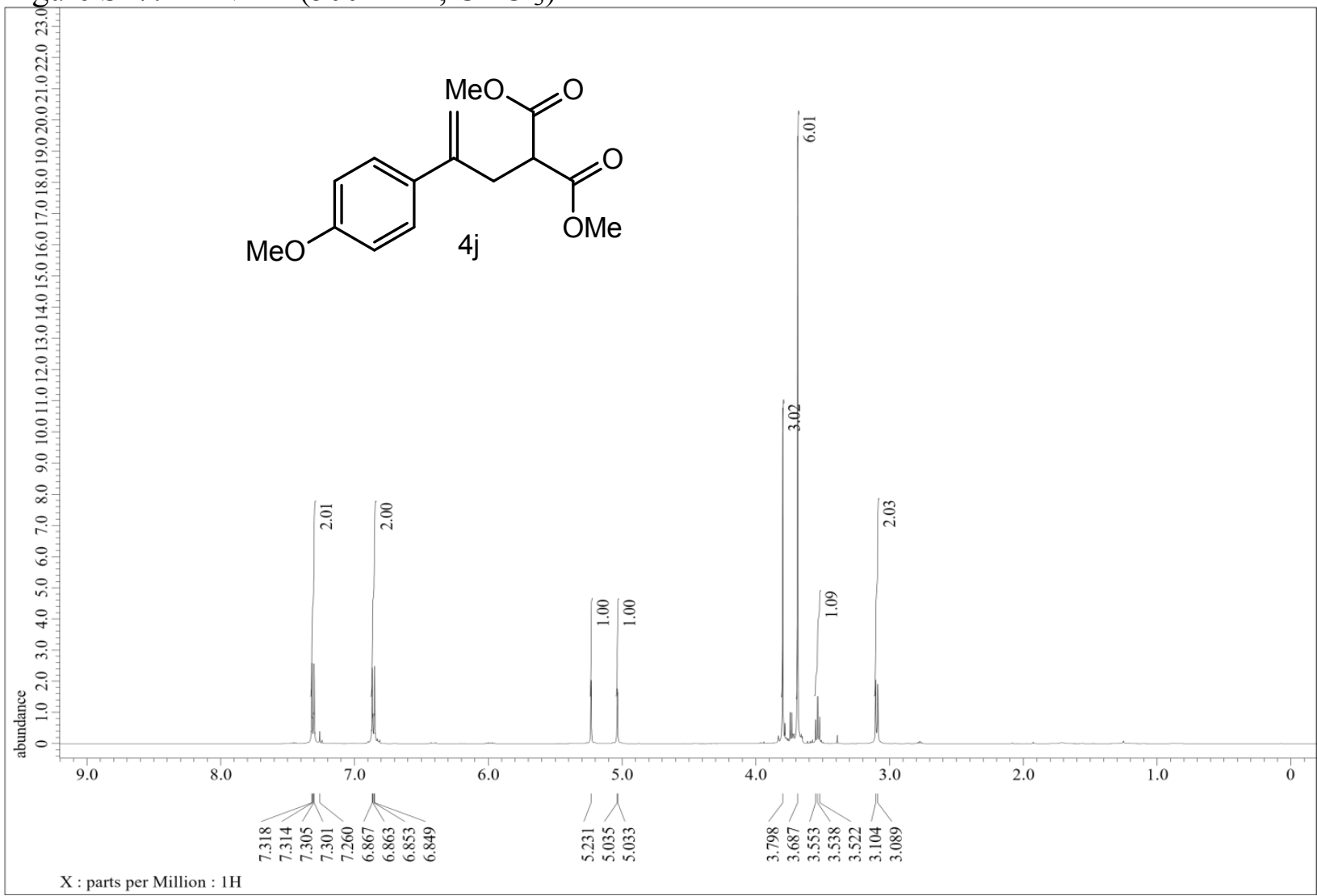

Figure S48: ${ }^{13} \mathrm{C}$ NMR $\left(125 \mathrm{MHz}, \mathrm{CDCl}_{3}\right)$

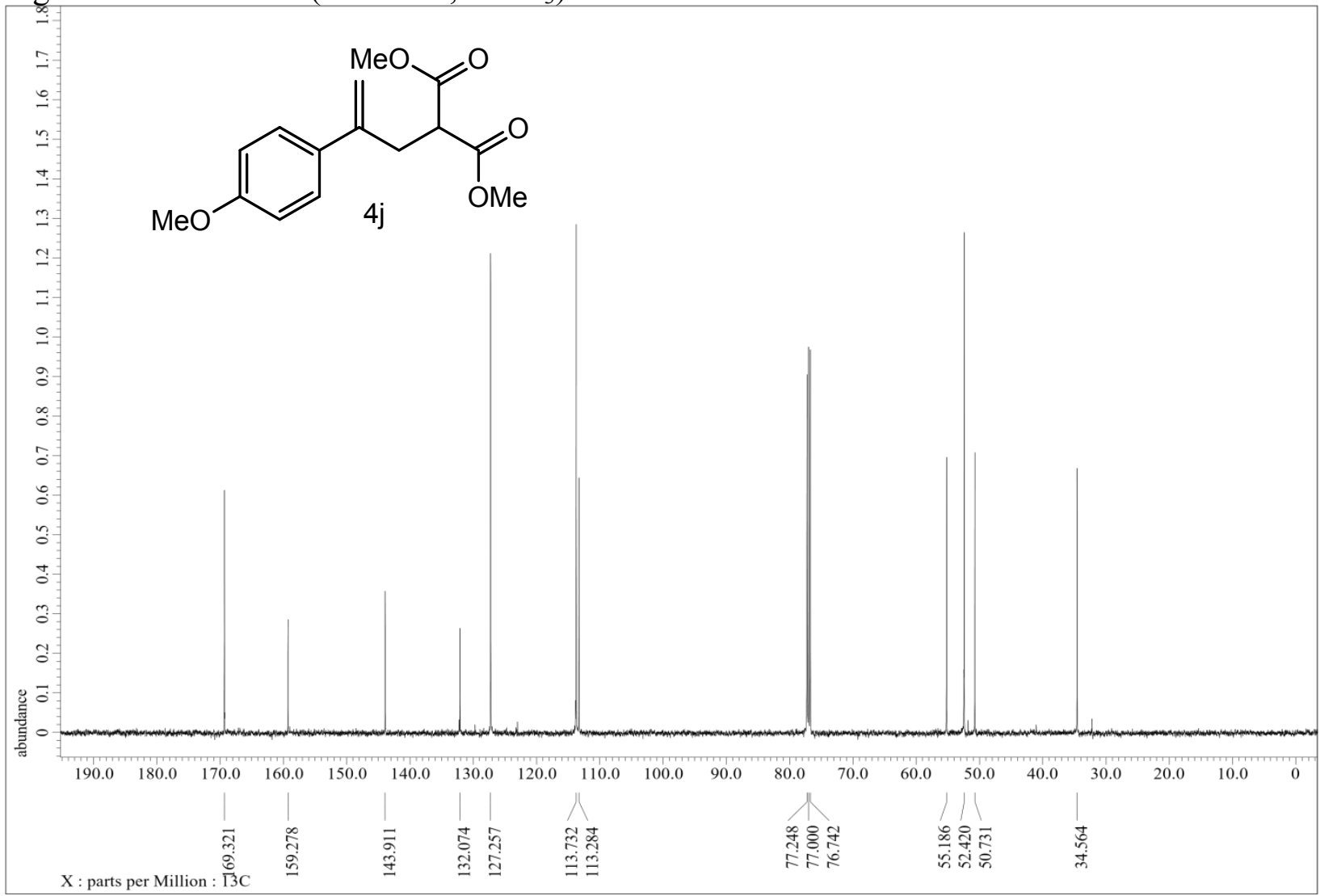


Figure S49: ${ }^{1} \mathrm{H}$ NMR $\left(500 \mathrm{MHz}, \mathrm{CDCl}_{3}\right)$

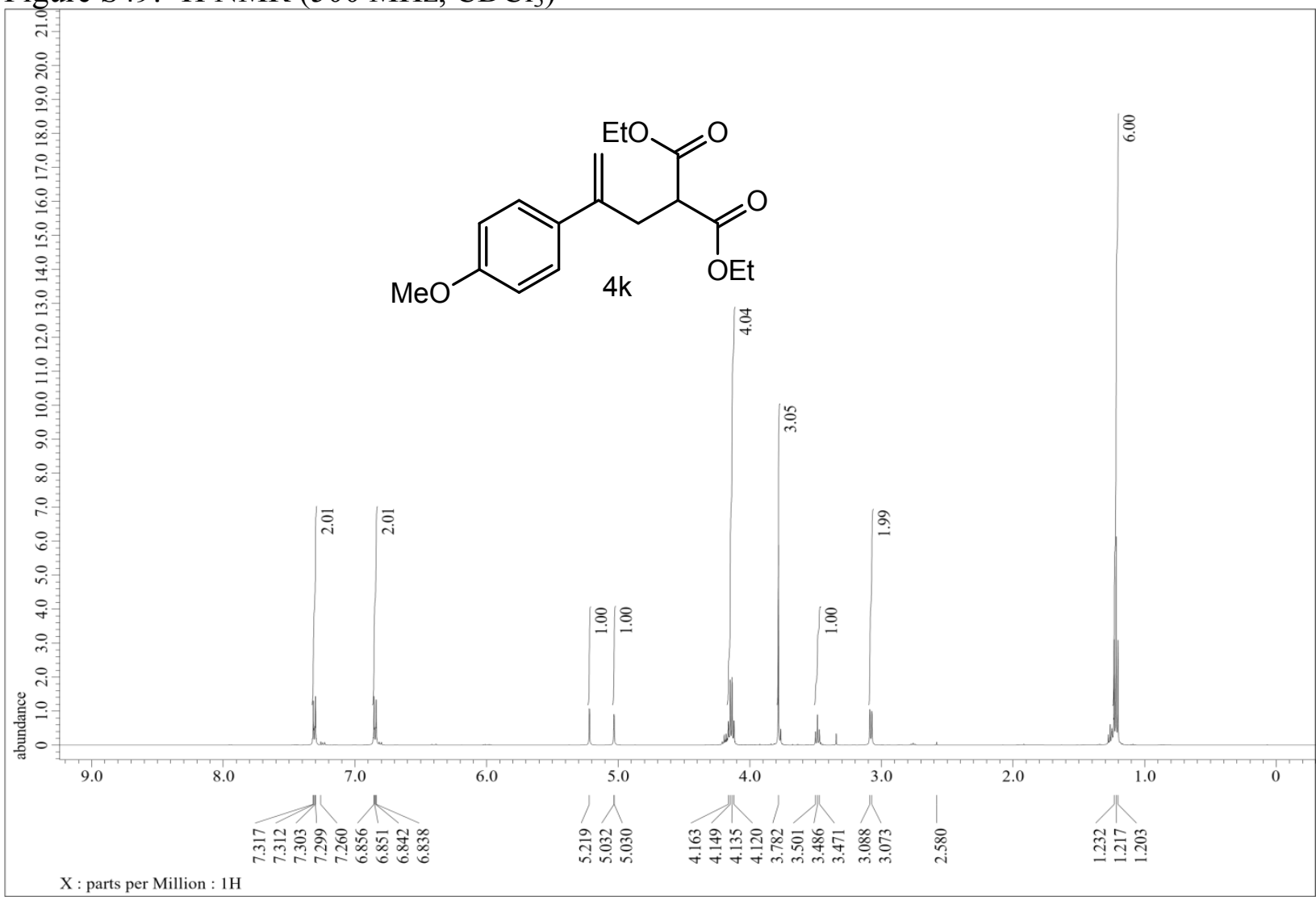

Figure S50: ${ }^{13} \mathrm{C}$ NMR $\left(125 \mathrm{MHz}, \mathrm{CDCl}_{3}\right)$

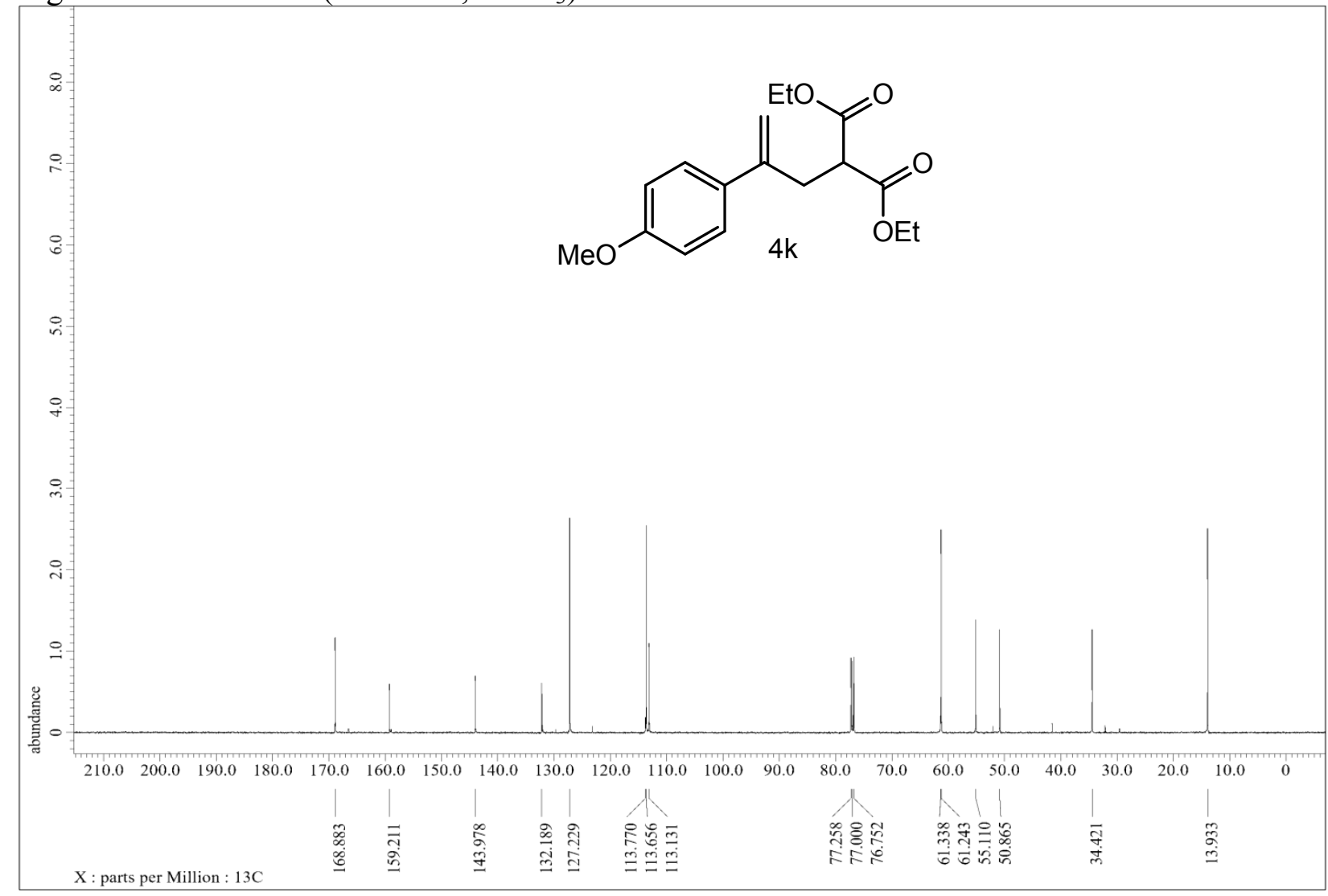


Figure S51: ${ }^{1} \mathrm{H}$ NMR $\left(500 \mathrm{MHz}, \mathrm{CDCl}_{3}\right)$

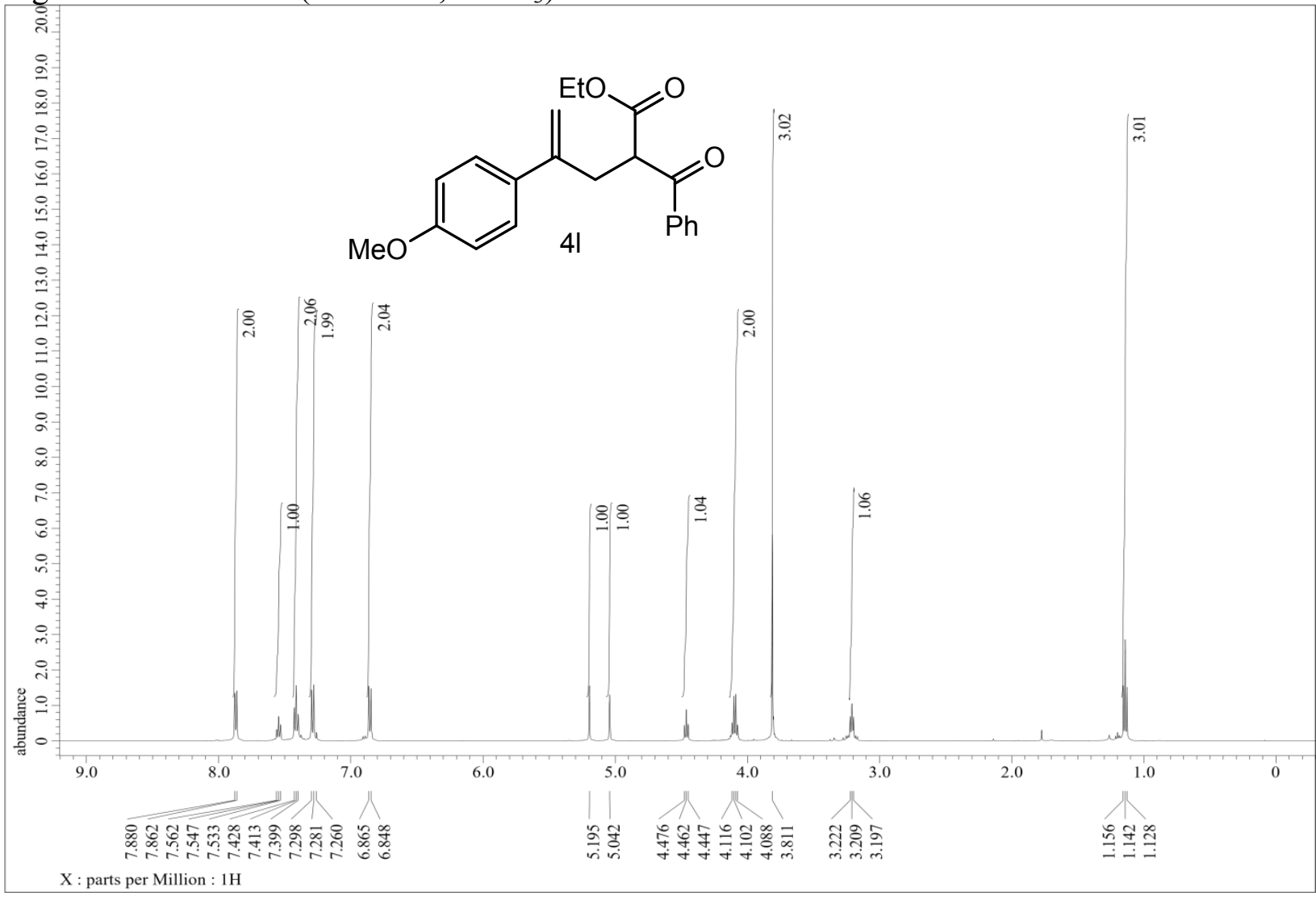

Figure S52: ${ }^{13} \mathrm{C}$ NMR $\left(125 \mathrm{MHz}, \mathrm{CDCl}_{3}\right.$ )

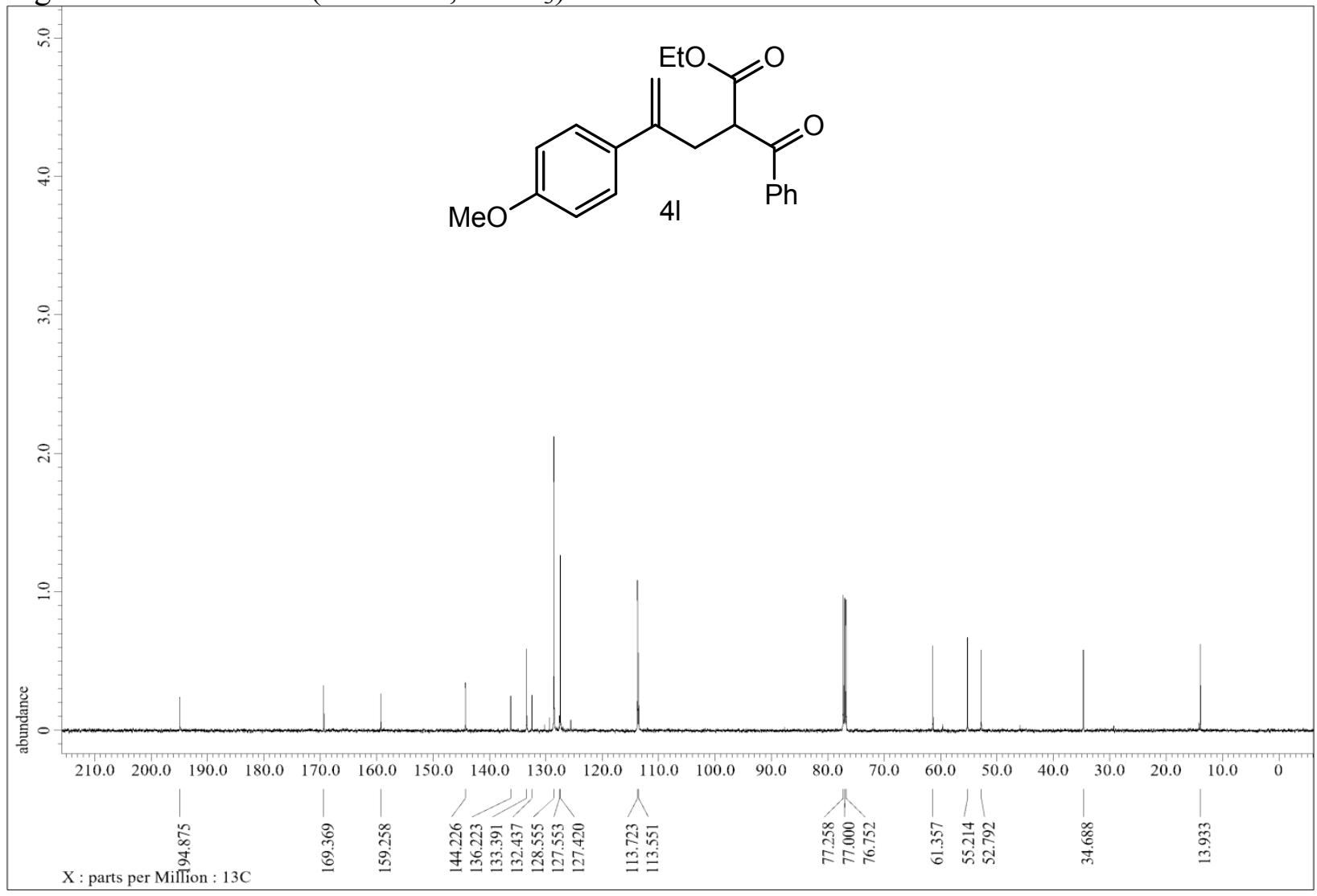


Figure S53: ${ }^{1} \mathrm{H} \mathrm{NMR}\left(500 \mathrm{MHz}, \mathrm{CDCl}_{3}\right)$

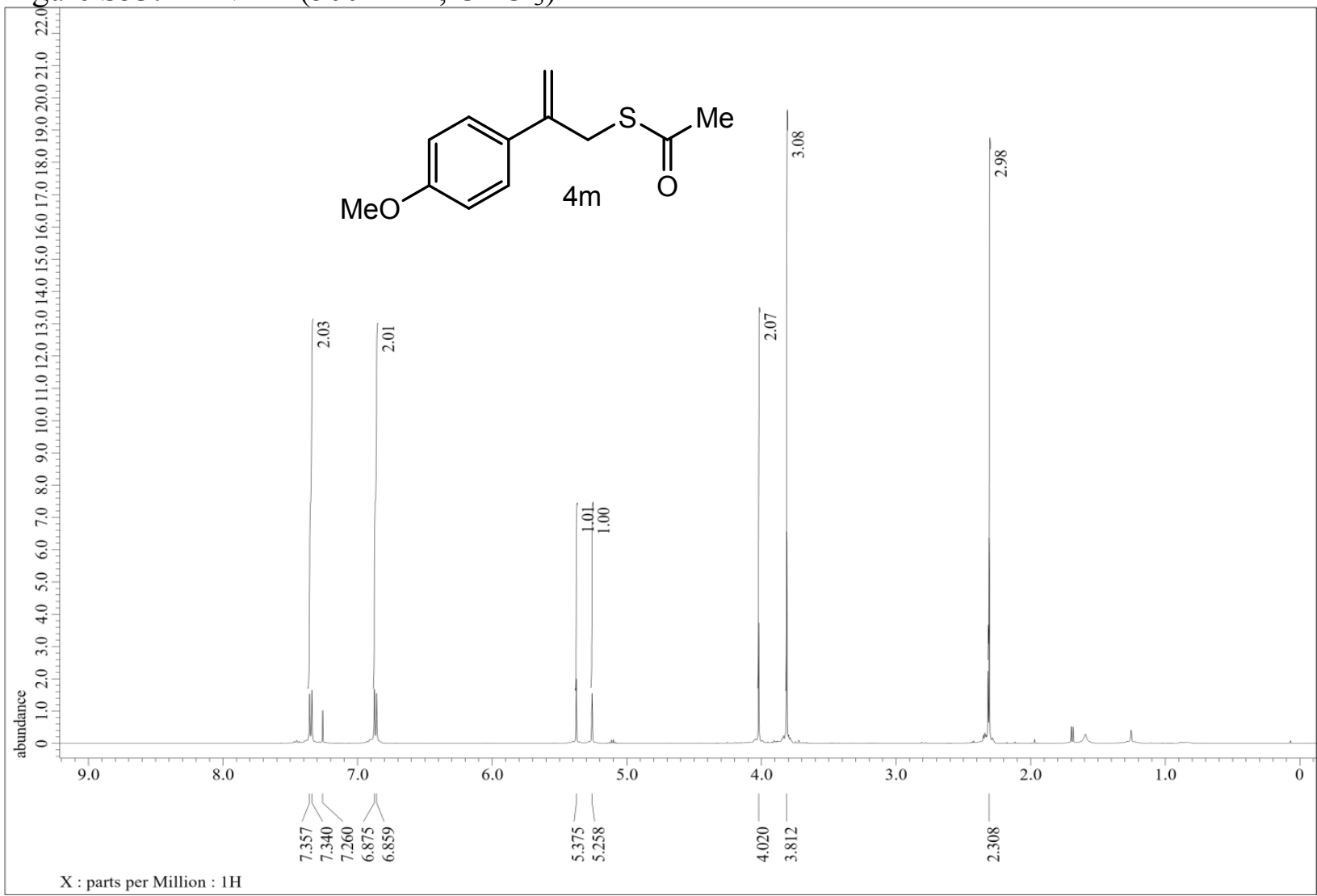

Figure S54: ${ }^{13} \mathrm{C}$ NMR $\left(125 \mathrm{MHz}, \mathrm{CDCl}_{3}\right)$

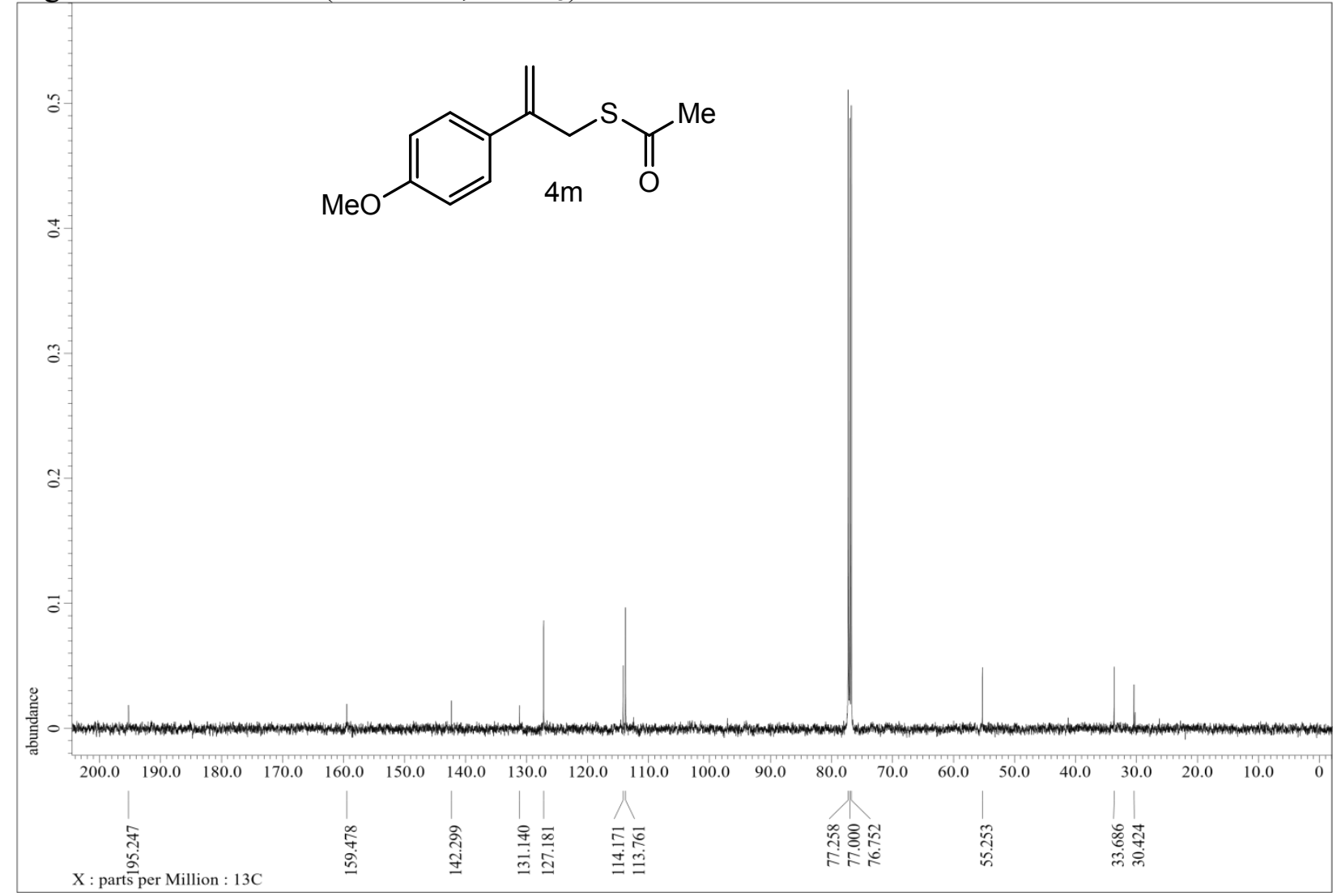


Figure S55: ${ }^{1} \mathrm{H} \mathrm{NMR}\left(500 \mathrm{MHz}, \mathrm{CDCl}_{3}\right)$

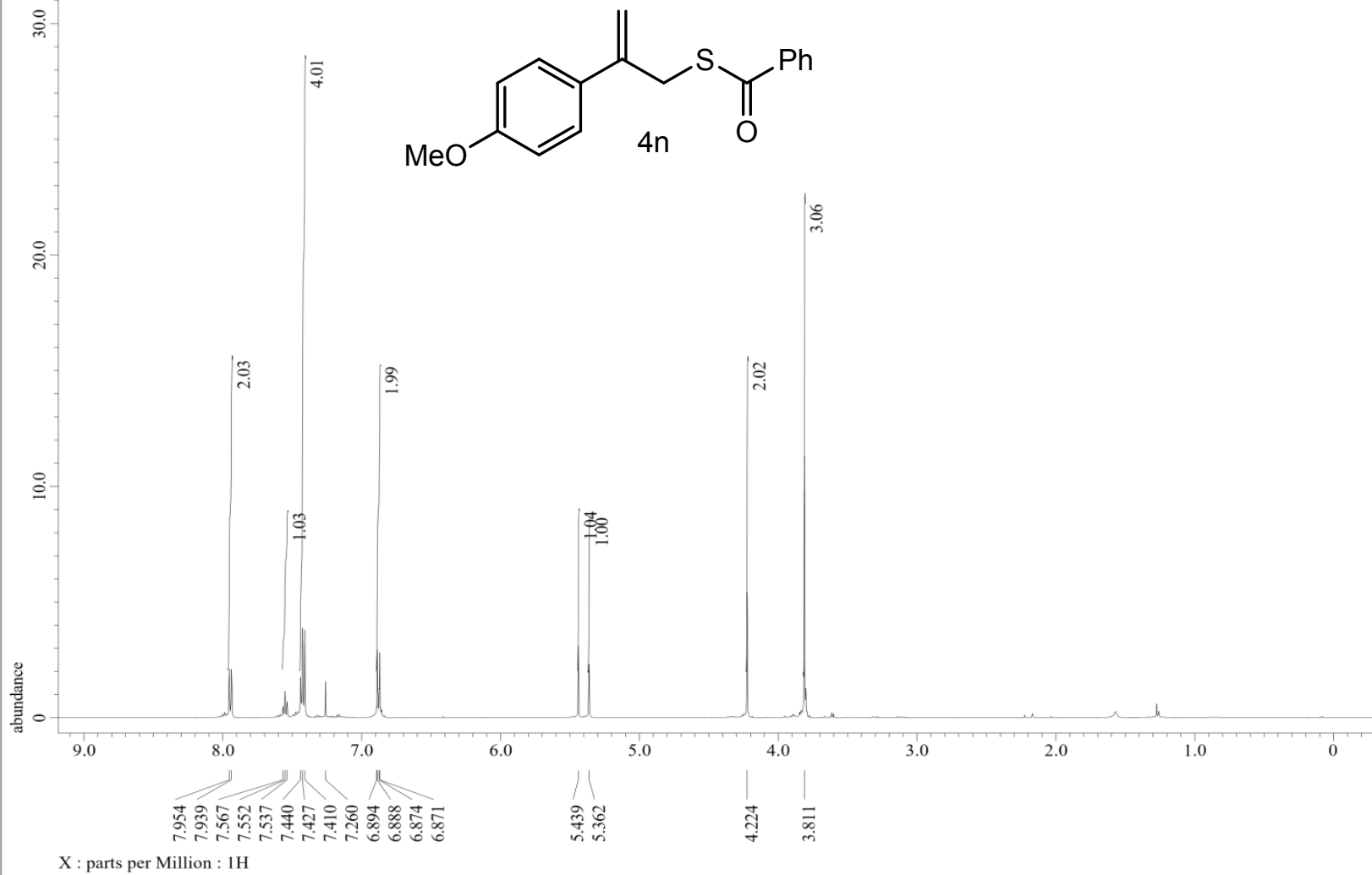

Figure S56: ${ }^{13} \mathrm{C}$ NMR $\left(125 \mathrm{MHz}, \mathrm{CDCl}_{3}\right)$

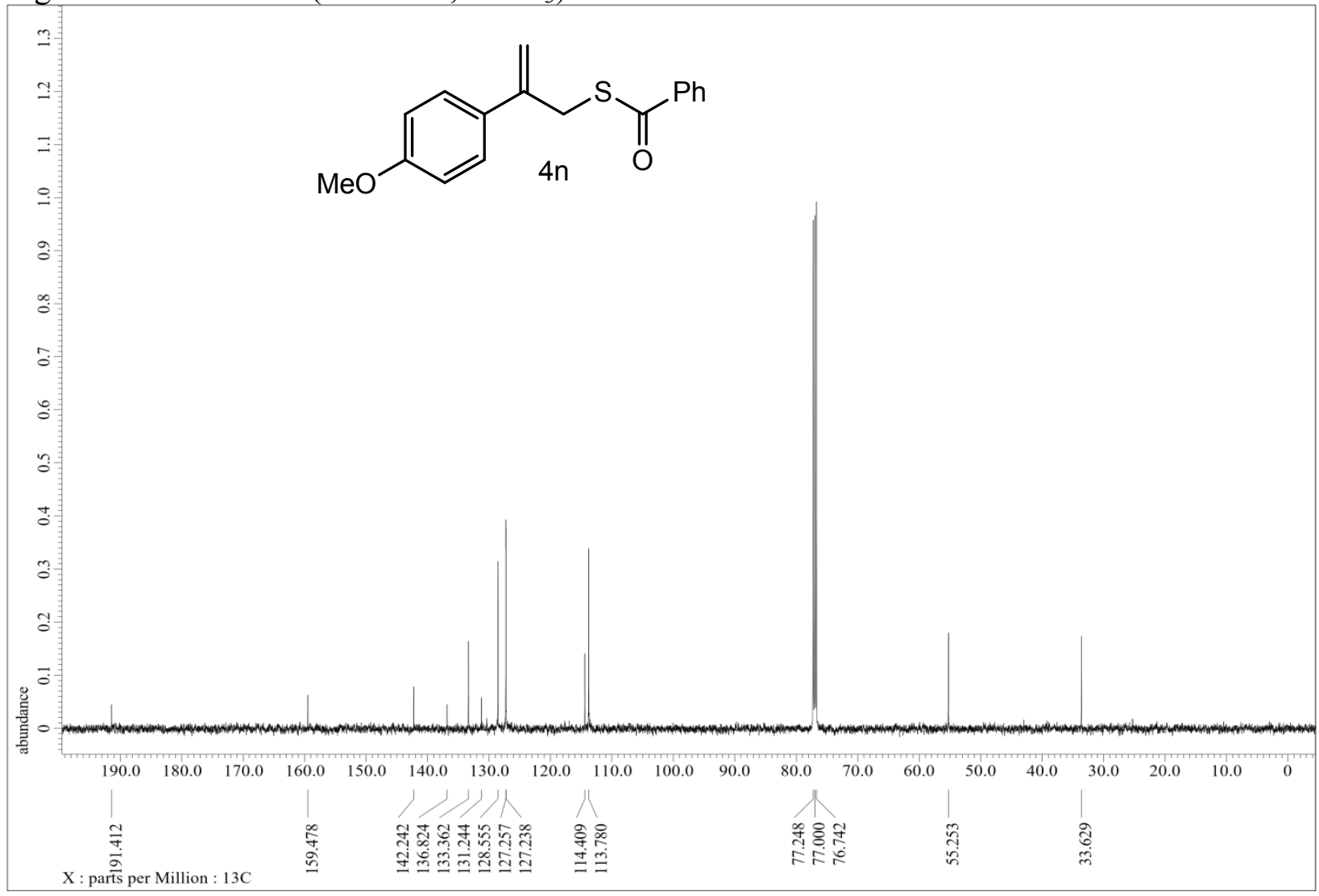


Figure S57: ${ }^{1} \mathrm{H} \mathrm{NMR}\left(500 \mathrm{MHz}, \mathrm{CDCl}_{3}\right)$

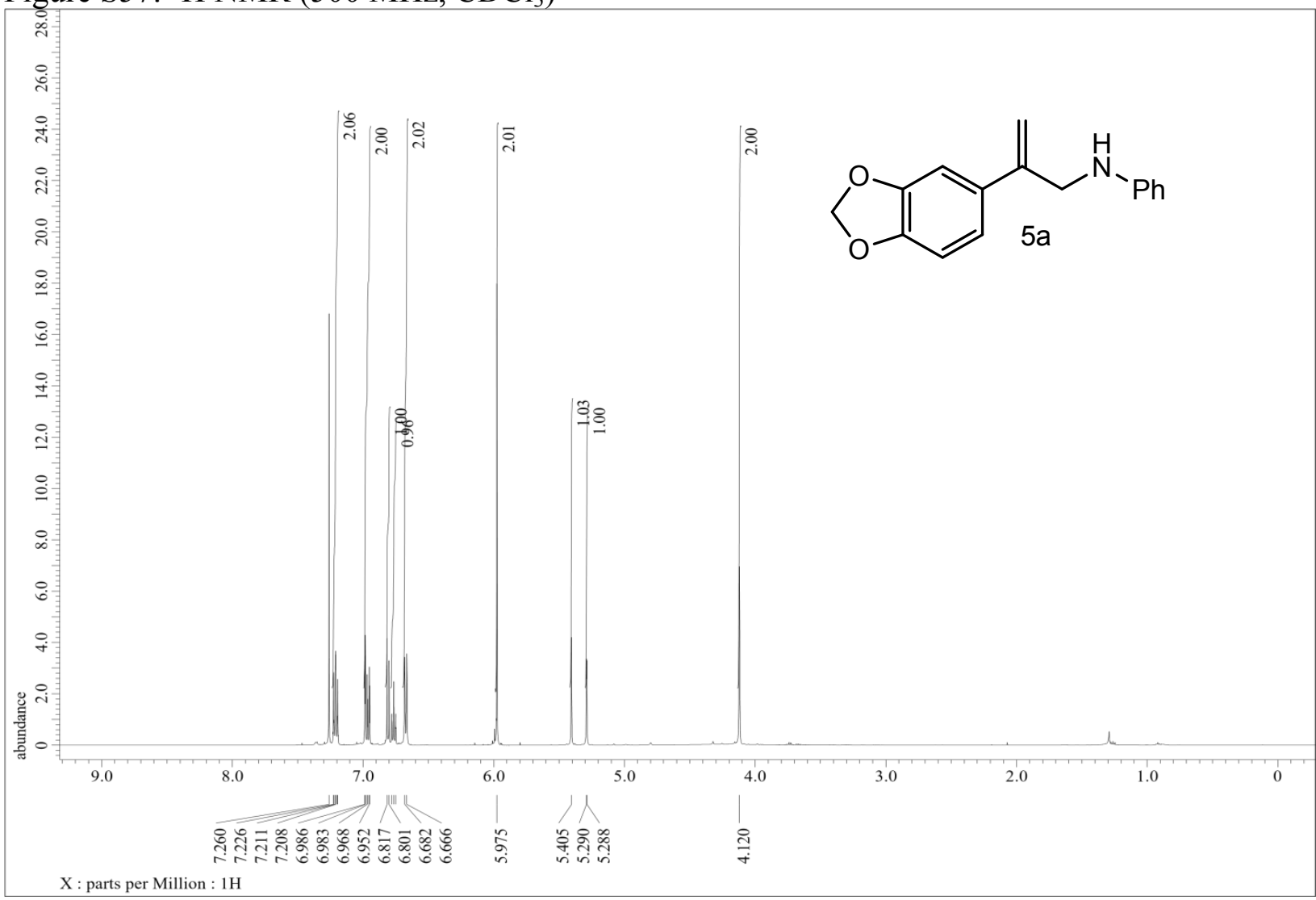

Figure S58: ${ }^{13} \mathrm{C}$ NMR $\left(125 \mathrm{MHz}, \mathrm{CDCl}_{3}\right.$ )

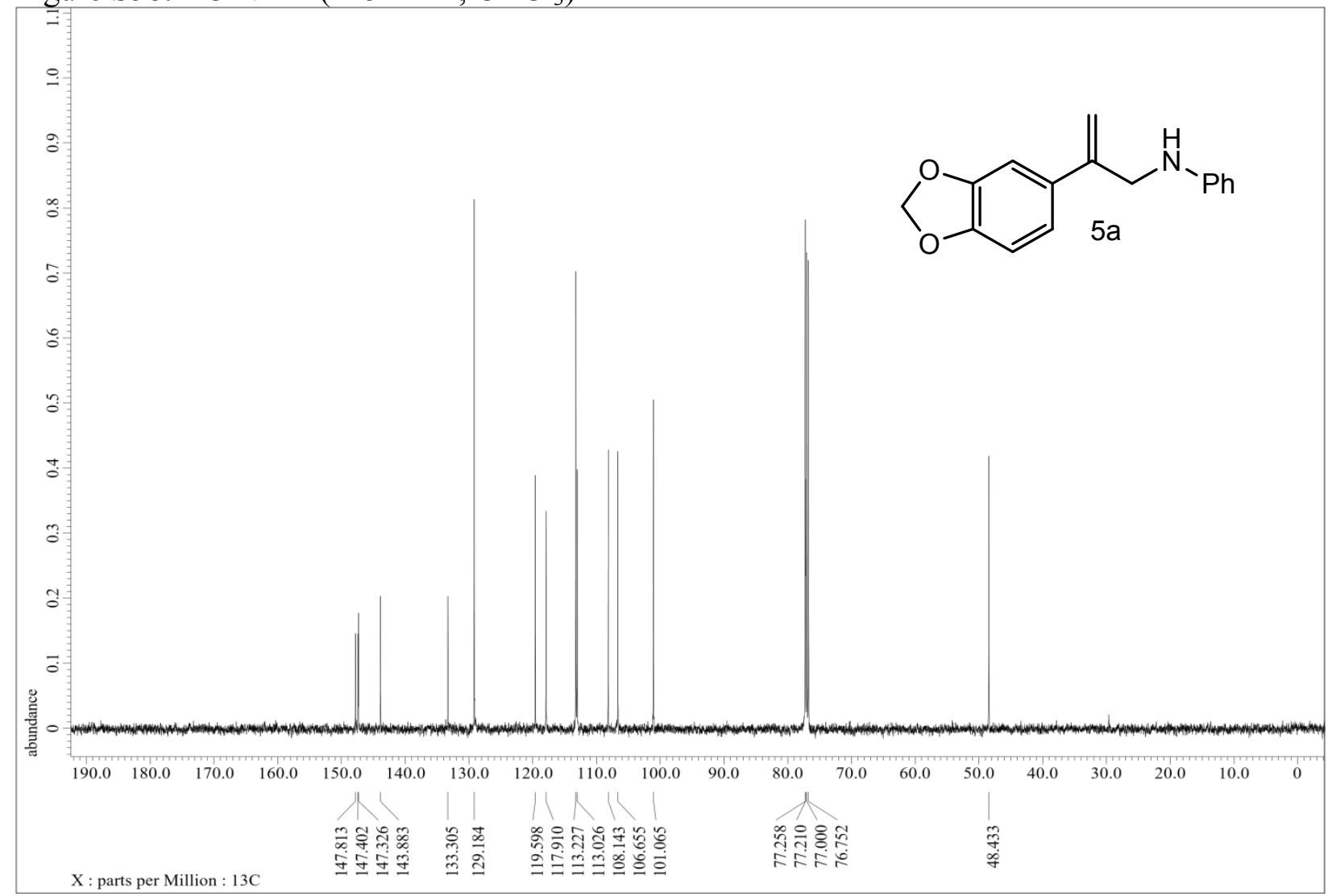


Figure S59: ${ }^{1} \mathrm{H}$ NMR $\left(500 \mathrm{MHz}, \mathrm{CDCl}_{3}\right)$

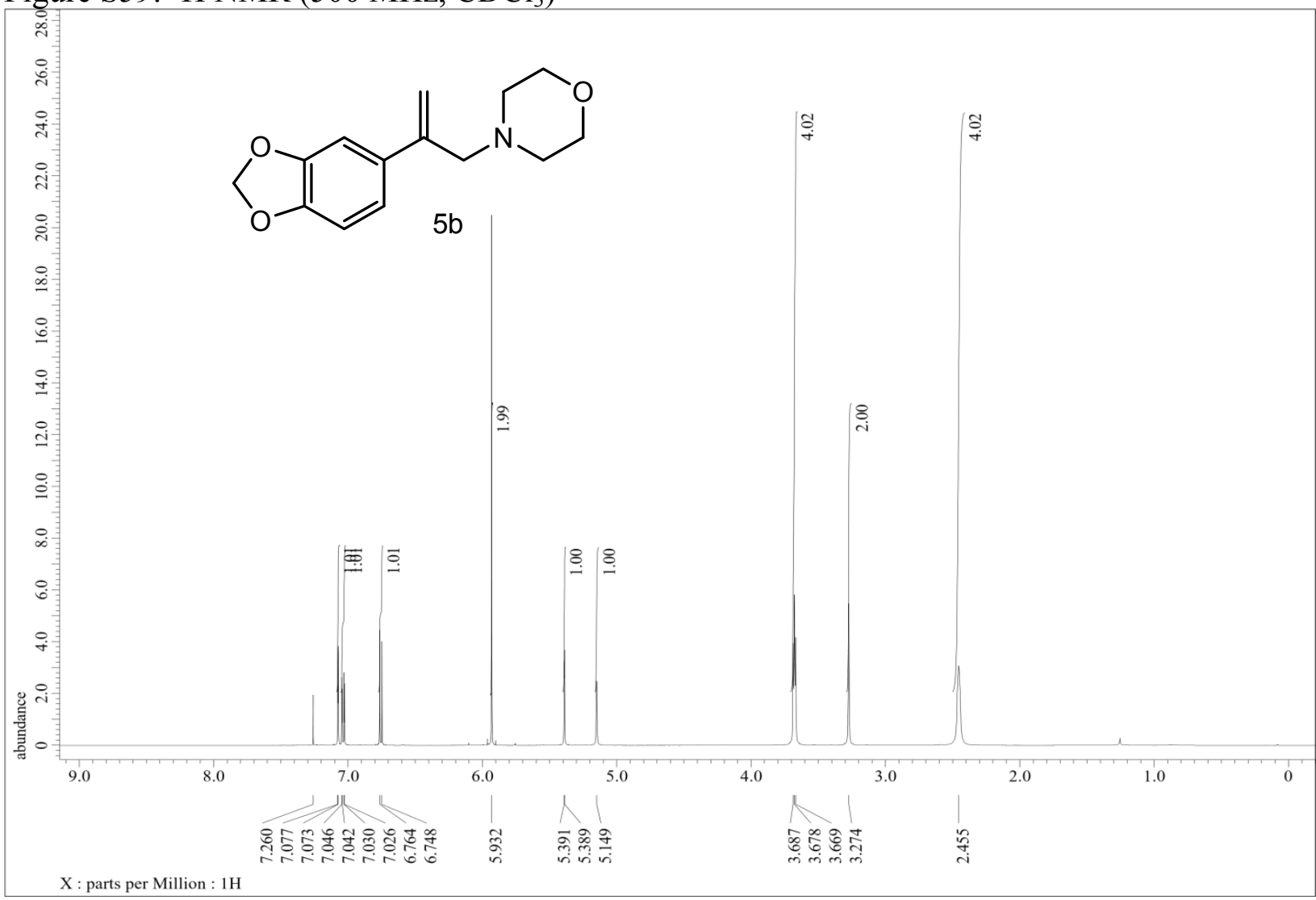

Figure S60: ${ }^{13} \mathrm{C}$ NMR (125 MHz, $\mathrm{CDCl}_{3}$ )

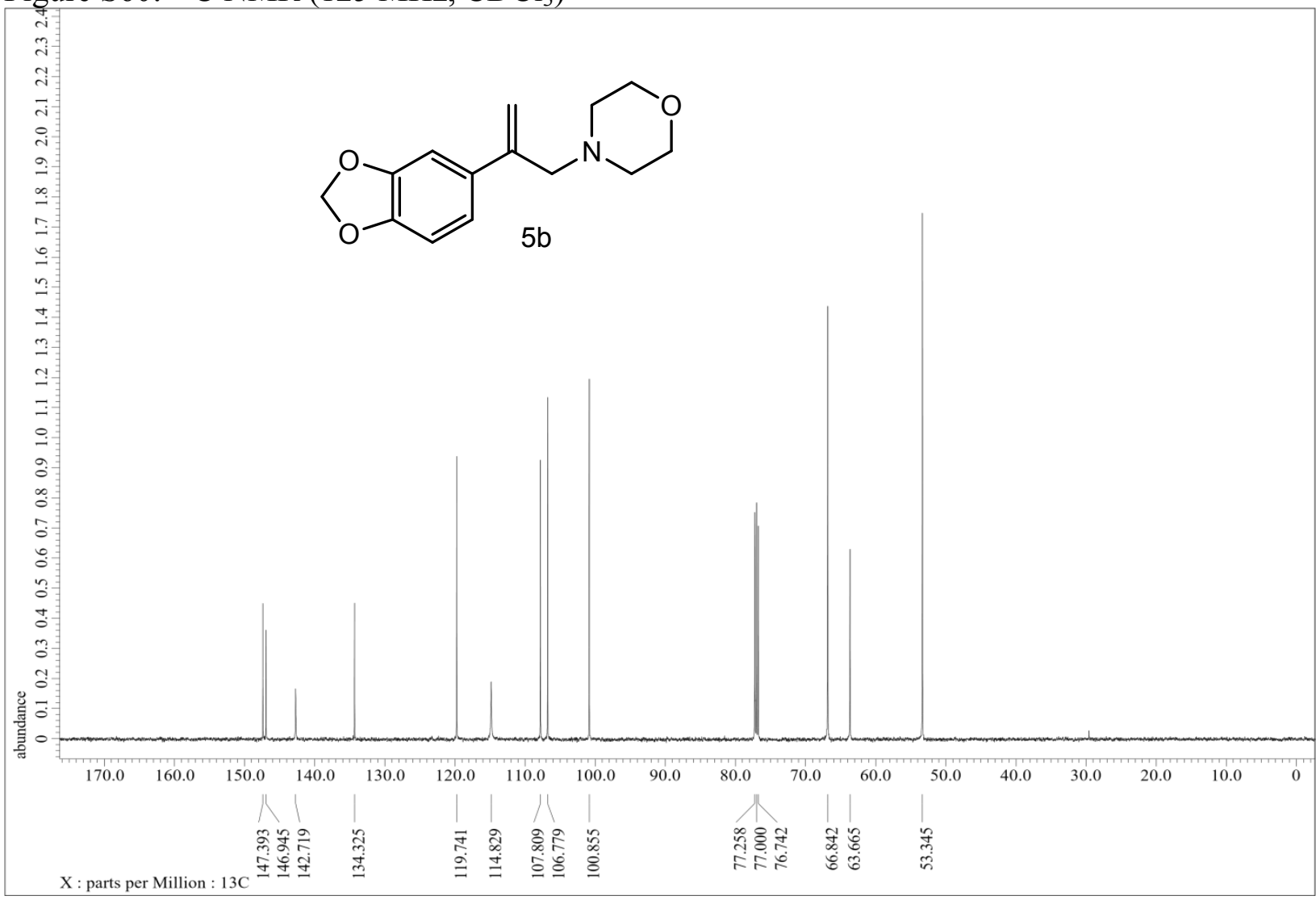


Figure S61: ${ }^{1} \mathrm{H}$ NMR $\left(500 \mathrm{MHz}, \mathrm{CDCl}_{3}\right)$

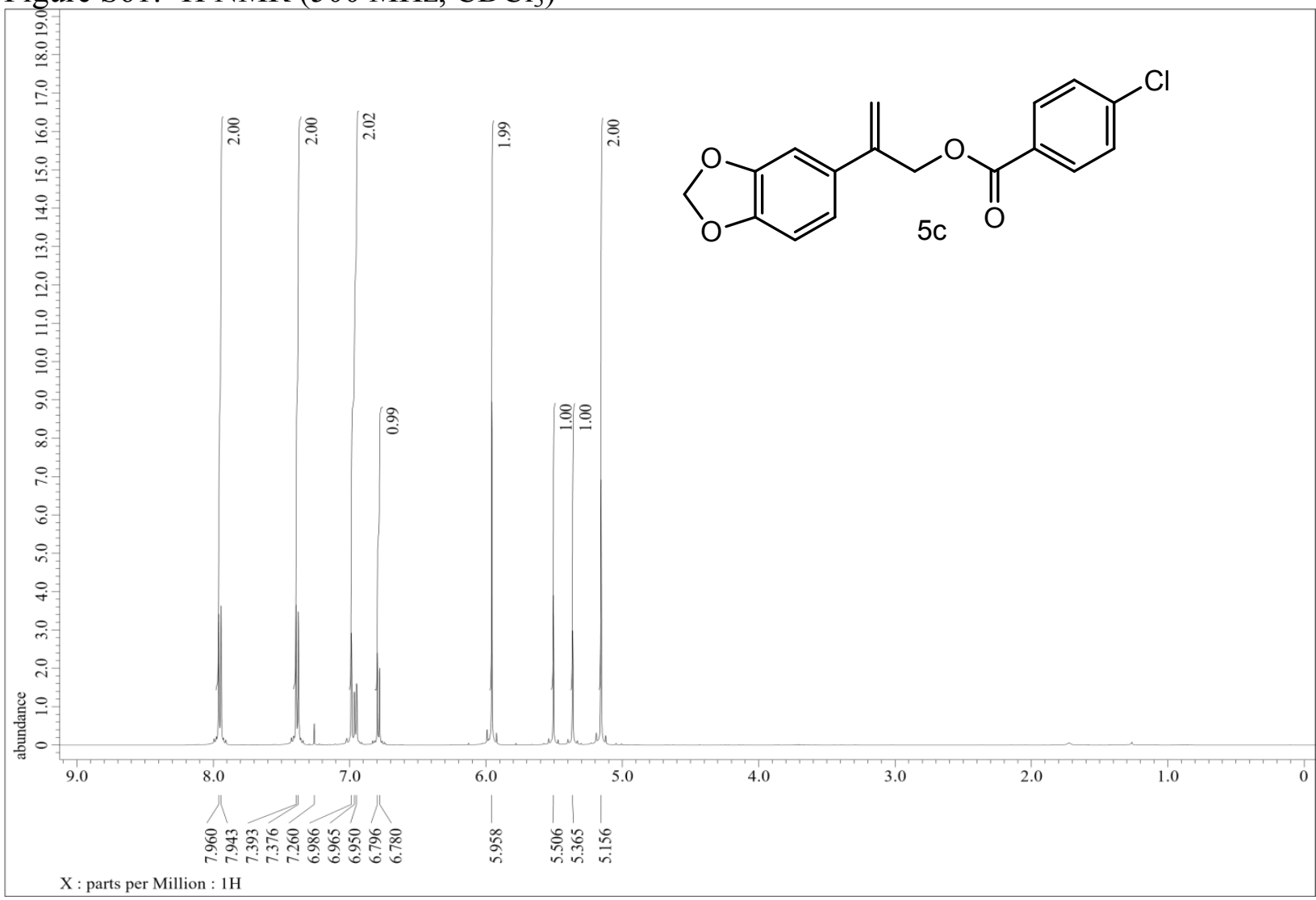

Figure S62: ${ }^{13} \mathrm{C}$ NMR $\left(125 \mathrm{MHz}, \mathrm{CDCl}_{3}\right)$

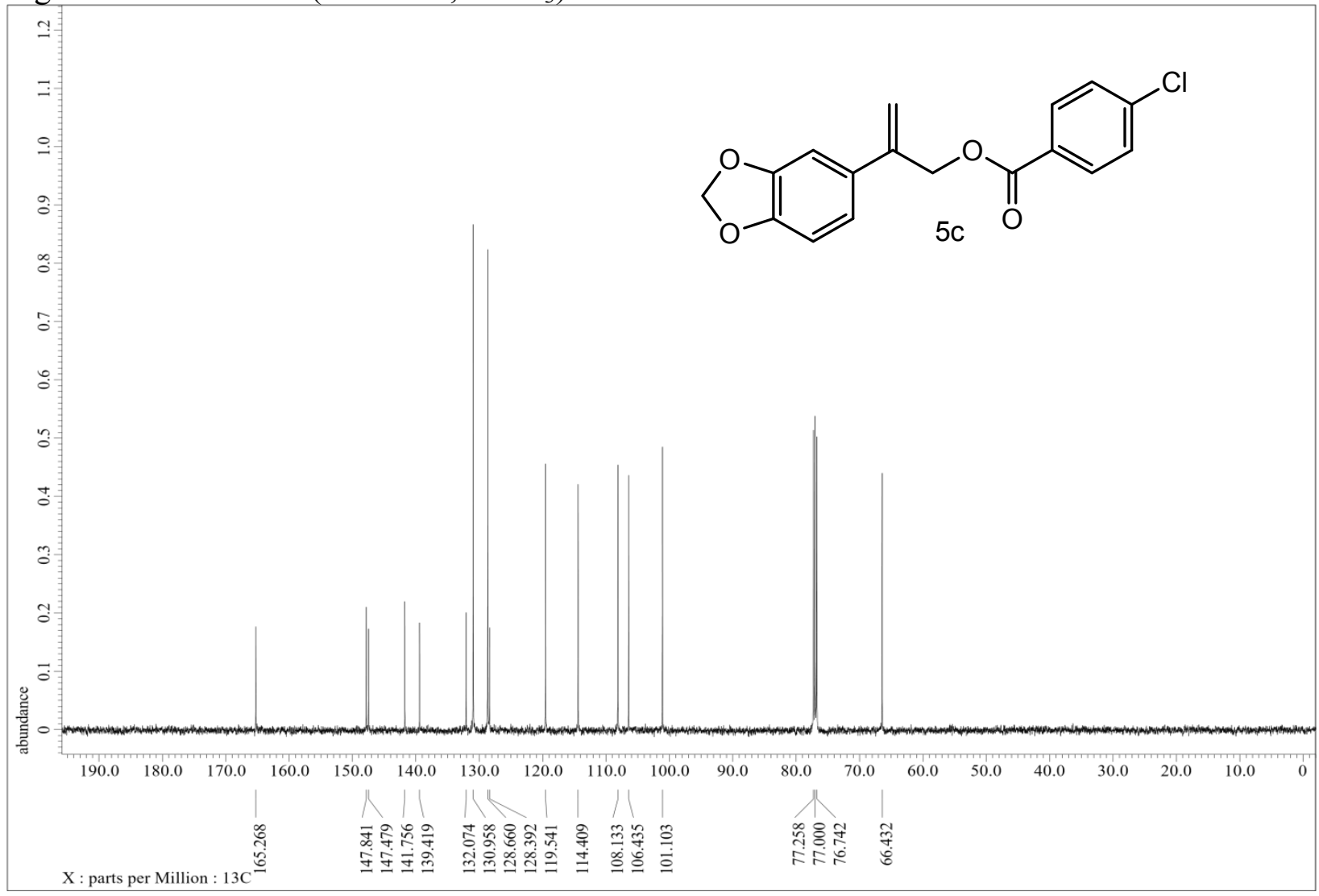


Figure S63: ${ }^{1} \mathrm{H}$ NMR $\left(500 \mathrm{MHz}, \mathrm{CDCl}_{3}\right)$

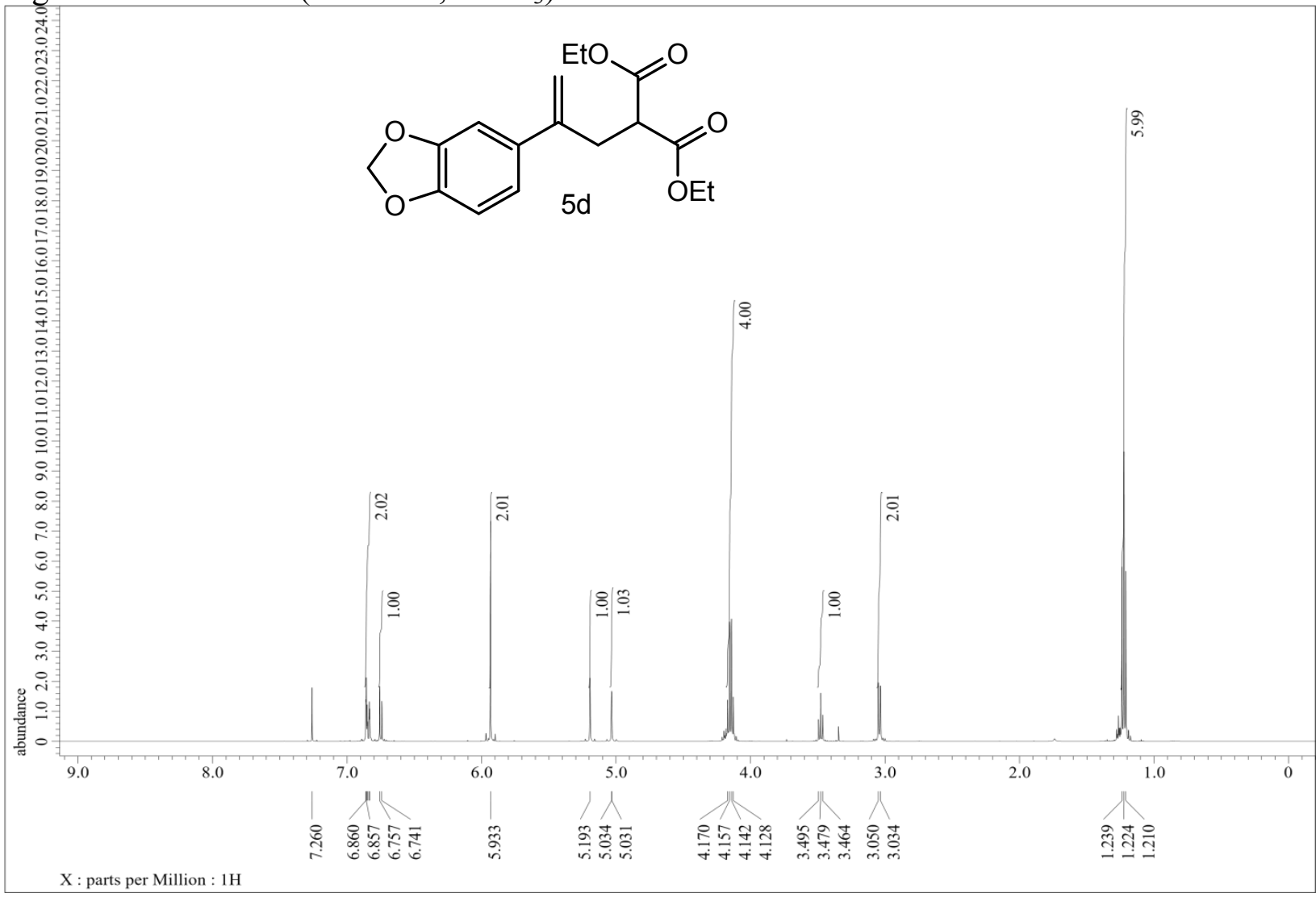

Figure S64: ${ }^{13} \mathrm{C}$ NMR $\left(125 \mathrm{MHz}, \mathrm{CDCl}_{3}\right)$

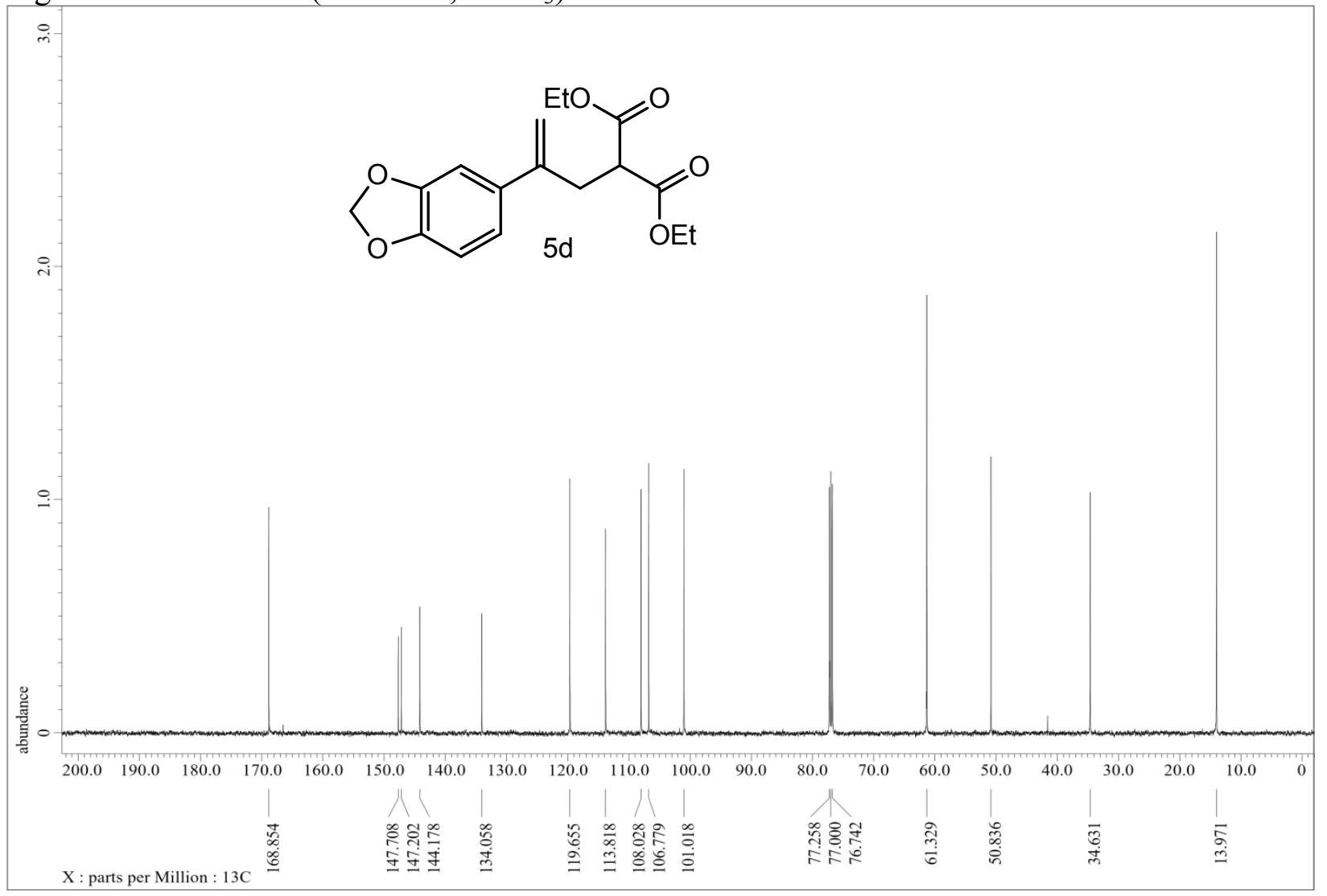

